As novas tecnologias no contexto escolar: uma abordagem sobre aplicações do GeoGebra em trigonometria

Jander Carlos Silva e Silva 


\title{
As novas tecnologias no contexto escolar: uma abordagem sobre aplicações do GeoGebra em trigonometria
}

\author{
Jander Carlos Silva e Silva
}

Orientadora: Profa. Dra. Vanessa Rolnik Artioli

Dissertação apresentada ao Instituto de Ciências Matemáticas e de Computação - ICMC-USP, como parte dos requisitos para obtenção do título de Mestre Programa de Mestrado Profissional em Matemática. VERSÃO REVISADA 
Ficha catalográfica elaborada pela Biblioteca Prof. Achille Bassi e Seção Técnica de Informática, ICMC/USP, com os dados fornecidos pelo(a) autor(a)

Carlos Silva e Silva, Jander
As novas tecnologias no contexto escolar: uma
abordagem sobre aplicaços do GeoGebra em
trigonometria / Jander Carlos Silva e Silva;
orientador Vanessa Rolnik Artioli. -- São Carlos,
2015.
$83 \mathrm{p}$.
Dissertação (Mestrado - Programa de Pós-Graduação
em Mestrado Profissional em Matemática em Rede
Nacional) -- Instituto de Ciências Matemáticas e de
Computação, Universidade de São Paulo, 2015.
1. GeoGebra. 2. Trigonometria. 3. Funções
trigonométricas. 4. Equaçoses trigonométricas. I.
Rolnik Artioli, Vanessa, orient. II. Título.


À minha esposa Valdirene e à minha filha Mariane, pela importância que representam na minha vida, e pela força que deram para a realização deste trabalho. 


\section{Agradecimentos}

Agradeço a minha orientadora pela dedicação e parceria.

Agradeço à USP pela abertura do PROFMAT.

Agradeço aos professores do PROFMAT pelo empenho no ensinar.

Agradeço aos meus colegas de turma pela união e colaboração.

Agradeço à CAPES pelo apoio financeiro.

E por fim, agradeço a todos que, de uma forma ou de outra, contribuiram para a concretização deste trabalho. 


\section{Resumo}

Este trabalho apresenta uma abordagem sobre as novas tecnologias no contexto escolar, com vistas para aplicação do GeoGebra em trigonometria. O objetivo é nortear professores da educação básica na preparação de aulas usando o GeoGebra, visando ao enriquecimento do tema trigonometria em sala de aula. As atividades propostas estão divididas em três grupos: trigonometria básica, funções trigonométricas e equações trigonométricas. Cada uma possui um alto nível de detalhamento, com o objetivo de incentivar o uso por professores com pouco ou nenhum conhecimento do software, bem como incentivar atividades que promovam a criação por parte dos alunos. A ideia é que os alunos construam as atividades, aprendendo a utilizar o software, interagindo por meio da movimentação dos objetos, e tirando suas conclusões pertinentes às atividades. De maneira geral, pretende-se contribuir para o desenvolvimento do raciocínio lógico do aluno por meio do ensino de Matemática agregando a utilização de tecnologia, de forma que o aluno não seja somente um expectador, mas sim, participante da construção da própria atividade.

Título: As novas tecnologias no contexto escolar: uma abordagem sobre aplicações do GeoGebra em trigonometria

Palavras-chave: Geometria dinâmica, GeoGebra, Trigonometria, funções trigonométricas, Equações trigonométricas 


\section{Abstract}

This work presents na approach to new Technologies in the educational context, with a view to applications of the GeoGebra in trigonometry. The goal is to guide teachers of the basic education in preparing lessons using GeoGebra, aiming to enrich trigonometry the in the classroom. The proposed activities are divided into three groups : basic trigonometry, trigonometry functions and trigonometry equations. Each one has a high level of details, in order to encourage the use by teachers with little or no knowledge of the software, and also encourage activities that promote the creation by the students. The idea is that students build the activities, learning how to use the software, interacting by moving objects, and taking their conclusions about the activities. In general, one intends to contribute to the development of logical thinking of students through the teaching of Mathematics adding the use of technology, so that the student is not only a spectator, but, participant of the construction of their own activity.

Title: The new technologies in the educational context : an approach about applications of GeoGebra in trigonometry

Keywords: Dynamic geometry, GeoGebra, Trigonometry, Trigonometry functions, Trigonometry equations. 


\section{Sumário}

1 Introdução 11

2 Revisão Bibliográfica $\quad 14$

2.1 Trigonometria e GeoGebra . . . . . . . . . . . . . . . . . . . . . . 14

2.2 Noções de trigonometria . . . . . . . . . . . . . . . . . . . . . . . . . . 18

2.2.1 Arcos de circunferência . . . . . . . . . . . . . . . . 18

2.2.2 Medidas de arcos - graus . . . . . . . . . . . . . . . . . 19

2.2.3 Medidas de arcos - radianos . . . . . . . . . . . . . . . . . 19

2.2.4 Ciclo trigonométrico . . . . . . . . . . . . . . . . . . . 19

2.2 .5 Seno . . . . . . . . . . . . . . . . . 20

2.2 .6 Cosseno . . . . . . . . . . . . . . . . . . . . 21

2.2.7 Tangente . . . . . . . . . . . . . . . . . . . . 21

2.2.8 Equações trigonométricas . . . . . . . . . . . . . . . . . 22

2.2 .9 Funções trigonométricas . . . . . . . . . . . . . . . . . . . 23

2.2.10 Gráficos de funções trigonométricas . . . . . . . . . . . . . . . . 24

3 As Tecnologias de Informação e Comunicação no ambiente escolar 25

3.1 Tecnologias e a missão da escola . . . . . . . . . . . . . . . . . 25

3.2 O atual uso das TICs no ambiente escolar . . . . . . . . . . . . . . . 29

3.3 Aprendizado para uso das TICs . . . . . . . . . . . . . . . . . . . . . . 30

3.4 Os alunos das escolas brasileiras . . . . . . . . . . . . . . . . . . . . 32

4 Geometria dinâmica e o GeoGebra 34

4.1 Geometria Dinâmica . . . . . . . . . . . . . . . . . 34

4.2 Softwares de geometria dinâmica . . . . . . . . . . . . . . . 36

4.2 .1 Régua e compasso . . . . . . . . . . . . . . . . . . 37

4.2 .2 Tabulae . . . . . . . . . . . . . . . . . 37

4.2 .3 Cabri-Géomètre . . . . . . . . . . . . . . . . 38

4.2 .4 Cinderella . . . . . . . . . . . . . . . . . 38

4.2 .5 GeoGebra ...................... . . 40 
4.3 Explorando o GeoGebra . . . . . . . . . . . . . . . . . . . . . 40

5 Trigonometria básica com o auxílio do GeoGebra $\quad 47$

5.1 Atividade 1 - Construindo uma circunferência - Medidas de arcos . . . 47

5.1.1 Passo a passo da construção - $1^{\text {a }}$ Parte - Graus . . . . . . . . . . 48

5.1.2 Passo a passo da construção - $2^{\text {a }}$ Parte - Radianos . . . . . . . . 49

5.2 Atividade 2 - Construindo a circunferência trigonométrica . . . . . . . 51

5.2 .1 Passo a passo da construção . . . . . . . . . . . . . 52

5.3 Atividade 3 - Definindo a tangente na circunferência trigonométrica . . 54

5.3.1 Passo a passo da construção . . . . . . . . . . . . . 55

6 Funções trigonométricas com o auxílio do GeoGebra 58

6.1 Atividade 1 - Construindo os gráficos das funções seno e cosseno . . . . 59

6.1 .1 Passo a passo da construção . . . . . . . . . . . . . . 59

6.2 Atividade 2: Explorando a função $f(x)=a \cdot \operatorname{sen}(b \cdot x+c)+d$, através dos parâmetros $a, b, c$ e $d \ldots \ldots \ldots 62$

6.2.1 Passo a passo da construção . . . . . . . . . . . . . . . 62

6.3 Atividade 3: Comparando as funções $f(x)=\operatorname{sen}(x)$ e $g(x)=\cos (x+\pi / 2) 68$

6.3.1 Passo a passo da construção - $1^{\text {a }}$ Parte . . . . . . . . . . . 68

6.3.2 Passo a passo da construção - $2^{\text {a }}$ Parte . . . . . . . . . . . . . . 69

7 Equações trigonométricas com o auxílio do GeoGebra 71

7.1 Atividade 1 - Verificando a relação fundamental da trigonometria: $\operatorname{sen}^{2}(x)+$

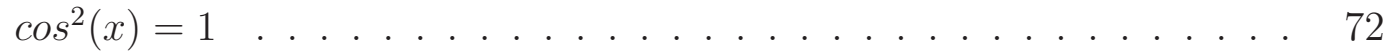

7.1.1 Passo a passo da construção - $1^{\circ}$ Modo . . . . . . . . . . . . . . 72

7.1.2 Passo a passo da construção - 20 Modo . . . . . . . . . . . . . 73

7.2 Atividade 2 - Resolvendo a equação $\operatorname{sen}(x)=a$, para todo $a$ real . . . . 74 7.2.1 Passo a passo da construção . . . . . . . . . . . . . . . 75

7.3 Atividade 3 - Descobrindo a simetria das raízes da equação $\operatorname{sen}^{2}(x)-$ $\cos (x)=0$ no intervalo $[2 \pi, 2 \pi] \ldots \ldots \ldots \ldots$

7.3 .1 Passo a passo da construção . . . . . . . . . . . . . . 76

8 Considerações finais $\quad 80$ 


\section{Lista de Figuras}

2.1 Arco de circunferência - Fonte: Iezzi (1993) . . . . . . . . . . . . . . 18

2.2 Medida de arcos - graus - Fonte: Iezzi (1993) . . . . . . . . . . . . . . . 19

2.3 Medida de arcos - radianos - Fonte: Iezzi (1993) . . . . . . . . . . . . . 19

2.4 Ciclo trigonométrico - Fonte: Iezzi (1993) . . . . . . . . . . . . . . . 20

2.5 Seno - Fonte: Iezzi $(1993)$. . . . . . . . . . . . . . . . . . . 20

2.6 Cosseno - Fonte: Iezzi (1993) . . . . . . . . . . . . . . . . . . . . . 21

2.7 Tangente - Fonte: Iezzi (1993) . . . . . . . . . . . . . . . 22

2.8 Resolução da equação sen $\alpha=\operatorname{sen} \beta=O P_{1}$ - Fonte: Iezzi (1993) . . . 23

2.9 Gráfico da função $f(x)=\operatorname{sen} x$ - Fonte: Iezzi (1993) . . . . . . . . . . 24

3.1 Proporção de professores de escolas públicas, por uso do computador e internet nas atividades realizadas com aluno - Percentual sobre o total de professores de escolas públicas que costumam realizar a atividade Parte 1 - Fonte: Brasil (2013) . . . . . . . . . . . . . .

3.2 Proporção de professores de escolas públicas, por uso do computador e internet nas atividades realizadas com alunos - Percentual sobre o total de professores de escolas públicas que costumam realizar a atividade Parte 2 - Fonte: Brasil (2013) . . . . . . . . . . . . . . .

3.3 Proporção de alunos de escolas públicas que possuem computador em seu domicílio. Percentual sobre o total de alunos de escolas públicas -

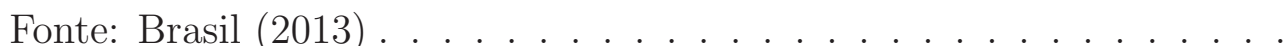

4.1 Quadrado construído no GeoGebra utilizando-se circunferência e retas perpendiculares . . . . . . . . . . . . . . . . . . 36

4.2 Tela inicial do Régua e Compasso com exemplos de construções geométricas 37

4.3 Tela inicial do Tabulae com exemplos de construções geométricas . . . 38

4.4 Tela inicial do Cabri-Géomètre com exemplos de construções geométricas 39

4.5 Tela inicial do Cinderella com exemplos de construções geométricas . . 39

4.6 Tela inicial do GeoGebra mostrando uma verificação do Teorema de Pitágoras - Fonte: www.tube.geogebra.org/material/show/id/5611 . . . 41

4.7 Barra de menus . . . . . . . . . . . . . . . . . . . . . . . . . . 42 
4.8 Barra de ferramentas de acesso rápido f . . . . . . . . . . . . . . . . . 42

4.9 (esquerda) Grupo Mover, (centro) Grupo Ponto e (direita) Grupo Reta 42

4.10 (esquerda) Grupo Reta Perpendicular, (centro) Grupo Polígono e (direita) Grupo Círculo Dados Centro e Um de Seus Pontos . . . . . . . .

4.11 (esquerda) Grupo Elipse, (centro) Grupo Ângulo e (direita) Grupo Reflexão em Relação a Uma Reta . . . . . . . . . . . . . . . . . . . . . . .

4.12 (esquerda) Grupo Texto, (centro) Grupo Controle Deslizante e (direita) Grupo Mover Janela de Visualização . . . . . . . . . . . . . . . . . . . 44

4.13 Janela de álgebra . . . . . . . . . . . . . . . . . . . . . . . . . . . . . . 44

4.14 Janela de visualização . . . . . . . . . . . . . . . . . . . . . . 45

4.15 Caixa de entrada . . . . . . . . . . . . . . . . . . 45

4.16 Opções e propriedades do botão direito, referentes ao ponto A . . . . . 45

4.17 Rastro de segmento habilitado . . . . . . . . . . . . . . . . . 46

5.1 Arco de uma circunferência obtido através da execução dos passos 1-6 da Atividade 1 - $1^{\text {a }}$ Parte . . . . . . . . . . . . . . . . . . . .

5.2 Circunferência dividida em 6 partes iguais obtida executando-se os passos 1-13 da Atividade $1-2^{\text {a }}$ Parte . . . . . . . . . . . . . . . . .

5.3 Circunferência dividida em 6 partes iguais obtida executando-se os passos 1-13 da Atividade 1 - 2 $2^{\text {a }}$ Parte - Com alteração do passo 1 . . . . . 52

5.4 Construção resultante da execução dos passos 1-16 da Atividade 2 . . . 55

5.5 Construção resultante da execução dos passos 1-15 da Atividade $3 \mathrm{em}$ dois momentos do ponto A . . . . . . . . . . . . . . . . 57

6.1 Gráfico da função $\cos (\mathrm{x})$ no intervalo $[0,2 \pi]$ resultado da construção dos passos de 1 a 8 da Atividade 1 . . . . . . . . . . . . . . . . 61

6.2 Gráfico da função sen(x) no intervalo de $[0,2 \pi]$ resultado da construção

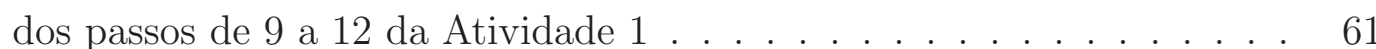

6.3 Gráfico das funções $\operatorname{sen}(\mathrm{x})$ e $\cos (\mathrm{x})$ no intervalo de $[0,2 \pi]$ na mesma janela de visualização . . . . . . . . . . . . . . . . . . . . . . .

6.4 Gráfico da função $f(x)=a \cdot \operatorname{sen}(b \cdot x+c)+d$ para $a=1, b=1, c=0$ e $d=0$, resultante da execução dos passos 1-5 da Atividade $1 . . .$.

6.5 Gráfico da função $f(x)=a \cdot \operatorname{sen}(b \cdot x+c)+d$ para $a=5, b=1, c=0$ e $d=0 \ldots \ldots \ldots \ldots \ldots \ldots \ldots$

6.6 Gráfico da função $f(x)=a \cdot \operatorname{sen}(b \cdot x+c)+d$ para $a=-4, b=1, c=0$ e

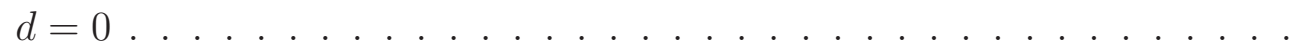

6.7 Gráfico da função $f(x)=a \cdot \operatorname{sen}(b \cdot x+c)+d$ para $a=1, b=-5, c=0$ e $d=0$. 
6.8 Gráfico da função $f(x)=a \cdot \operatorname{sen}(b \cdot x+c)+d$ para $a=1, b=0,2, c=0$ e $d=0 \ldots \ldots \ldots \ldots \ldots \ldots \ldots$

6.9 Gráfico da função $f(x)=a \cdot \operatorname{sen}(b \cdot x+c)+d$ para $a=1, b=5, c=0$ e $d=0$

6.10 Gráfico da função $f(x)=a \cdot \operatorname{sen}(b \cdot x+c)+d$ para $a=1, b=1, c=2 \mathrm{e}$ $d=0 \ldots \ldots \ldots \ldots \ldots \ldots \ldots \ldots$

6.11 Gráfico da função $f(x)=a \cdot \operatorname{sen}(b \cdot x+c)+d$ para $a=1, b=1, c=0$ e $d=4$.

6.12 Gráfico das funções $f(x)=\operatorname{sen}(\mathrm{x}), g(x)=\cos (x+\pi / 2)$ e $h(x)=\operatorname{sen}(x)+$ $\cos (x+\pi / 2)$ da $1^{\mathrm{a}}$ Parte da Atividade $3 \ldots \ldots$. . . . . . . . .

6.13 Gráfico das funções $p(x)=\operatorname{sen}(x+\pi), g(x)=\cos (x+\pi / 2)$ e $d(x)=$ $\operatorname{sen}(x+\pi)-\cos (x+\pi / 2) \quad \ldots \ldots \ldots 70 \ldots \ldots$

7.1 Resultado dos passos 1-7 do $1^{\circ}$ modo da atividade 3

7.2 Gráfico da função $h(x)=f(x)+g(x)$, sendo $f(x)=\operatorname{sen}^{2}(x)$ e $g(x)=$ $\cos ^{2}(x)$ resultante da execução dos passos 1-4 da Atividade 1 - $2^{\circ}$ Modo 74

7.3 Resolução gráfica da equação $\operatorname{sen}(x)=0,5 \ldots \ldots$. . . . . . . . 76

7.4 Gráficos das funções $f(x)=\operatorname{sen}^{2}(x)$ e $g(x)=\cos (x) \ldots \ldots$. . . . . . 77

7.5 Gráfico da função $h(x)=f(x)-g(x)$ resultante da execução dos passos $4-14$ 


\section{Capítulo 1}

\section{Introdução}

Há uma gama de pesquisas e relatos de experiências de professores e alunos que indicam que o processo de ensino-aprendizagem em Matemática se fortalece quando se utiliza recursos tecnológicos em sala de aula. Entre as explicações, duas se destacam e se complementam: a primeira é que a tecnologia permite que algumas visualizações abstratas se tornem mais concretas, e a segunda é que os alunos vivem em meio à tecnologia, fazendo uso, entre outros, de videogames, computadores, tablets e smartphones.

As tecnologias são desenvolvidas por necessidade e pela criatividade humana, na busca por soluções de problemas encontrados no cotidiano. Essas tecnologias facilitam e aprimoram a execução de tarefas relacionadas ao trabalho ou ao convívio social, e muitas podem transformar processos estanques em processos criativos. Educação e tecnologias não são e nem podem ser estanques, precisam manter uma constância de permanente transformação. Transformação esta que só pode ser garantida pela existência da criatividade. Nessa linha em entrevista para a BBC BRASIL, em 02/05/2014 Idoeta (2014), Mitchel Resnick, do Laboratório de Mídia do MIT- Massachusetts Institute of Technology, afirmou que os jovens precisam criar e não somente interagir com novas tecnologias. Para ele, as habilidades de criação e design serão muito importantes para as sociedades futuras.

Para a escola, oferecer a oportunidade de trabalhar com novas tecnologias é adequarse ao perfil dos novos alunos. Os jovens da atualidade, em muitos momentos, esperam respostas rápidas, como em geral encontram no seu cotidiano. Mais ainda, é esperado que tais tecnologias, além de estarem presentes no cotidiano dos alunos, possibilitem aprendizagens significativas mesmo fora do ambiente escolar.

Para auxiliar no aprendizado do aluno, existem tecnologias acessíveis e bastante adequadas para o ensino em diversos ramos da Matemática. O software GeoGebra, por exemplo, é uma dessas tecnologias, além de ser gratuito, relativamente fácil de utilizar e bastante estudado em dissertações e projetos de pesquisa em geral. Os textos lidos durante o desenvolvimento deste projeto apontam para os benefícios da comple- 
mentação das aulas expositivas com atividades práticas no GeoGebra.

O software GeoGebra fornece aos alunos a possibilidade de enxergar com facilidade as etapas do processo de criação dos objetos, bem como perceberem o movimento gerado pela manipulação dos objetos criados, aumentando as possibilidades de aprendizagens significativas, uma vez que o processo de construção e desconstrução é muito simples e ágil.

Com as considerações acima, define-se o objetivo global deste projeto: contribuir para o desenvolvimento do raciocínio lógico do aluno por meio do ensino de Matemática agregando a utilização de tecnologia, neste caso, o software GeoGebra, de forma que o aluno não seja somente um expectador, mas sim, participante da construção da própria atividade.

Quanto ao assunto de Matemática, optou-se por Trigonometria, ramo que estuda, entre outros, os triângulos e seus elementos. Desse estudo podem derivar funções trigonométricas e seus gráficos, equações e inequações trigonométricas, entre outros. Em geral os alunos da educação básica apresentam dificuldades na compreensão desses conteúdos, agravada quando se estabelece relação entre os aspectos algébrico e gráfico. Em alguns casos, essa dificuldade está relacionada com a não percepção de padrões e regularidades. Em outros casos, reside no fato de o aluno não assimilar com naturalidade as alterações gráficas decorrentes da alteração de parâmetros. É preciso que o aluno compreenda que gráfico está associado a movimento.

Posto isso, este trabalho tem como objetivo específico apresentar atividades, elaboradas ou adaptadas pelo autor, de construções em trigonometria, que podem ser muito úteis para os professores utilizarem em sala de aula, com vista para melhoria das aprendizagens dos alunos. Tais atividades não precisam ser necessariamente utilizadas para introduzir os conceitos de trigonometria, mas se pretende que sejam capazes de enriquecer o tema trigonometria em sala de aula. Nesse sentido, é importante que o professor tenha a sensibilidade para encontrar o melhor momento de fazer a utilização das atividades propostas. Acredita-se que as atividades apresentadas terão maior êxito com uma condução planejada por parte do professor.

A inovação deste trabalho está no fato de que as atividades propostas têm alto grau de detalhamento, com objetivo de incentivar o uso por professores com pouco ou nenhum conhecimento do software, e também incentivar atividades que promovam a criação por parte dos alunos. A ideia é que os alunos construam suas próprias atividades, que aprendam a utilizar o software, que interajam movendo os objetos, e tirem suas conclusões pertinentes à atividade. As atividades apresentadas são flexíveis, cabendo ao professor adquequá-las à realidade dos alunos. A possibilidade de adequação reside no fato de que durante ou após a execução do passo a passo das construções, podem ser feitos questionamentos ou incrementos os quais aspirem a um estudo aprofundado. 
Outra inovação está na abordagem de equações trigonométricas. Este é um assunto mais avançado de trigonometria, e pouco explorado. O objetivo principal das atividades é mostrar graficamente ao aluno que, muitas vezes, equações trigonométricas apresentam infinitas soluções.

No Capítulo 2, encontra-se a Revisão Bibliográfica, na qual se comenta sobre o ensino de trigonometria na educação básica além de textos da literatura que tratam de trigonometria e tecnologia, bem como conceitos de trigonometria que serão utilizados neste trabalho.

No Capítulo 3, faz-se uma análise sobre as tecnologias de informação e comunicação no ambiente escolar, destacando a importância das novas tecnologias e sua disponibilidade nas escolas brasileiras. Outro ponto destacado nessa parte do trabalho será a forma como as novas tecnologias estão sendo utilizadas por alunos e professores.

O Capítulo 4 apresenta softwares de geometria dinâmica com características específicas e trata de forma detalhada do GeoGebra, explicitando os motivos que levaram a sua escolha como software para ser utilizado neste trabalho.

Nos três capítulos seguintes são apresentadas atividades elaboradas ou adaptadas pelo autor com a intenção de aplicar o GeoGebra em trigonometria básica, em funções trigonométricas e em equações trigonométricas, respectivamente. No Cap. 5, as atividades têm por finalidade introduzir funções básicas do GeoGebra e trabalhar conceitos básicos de trigonometria, com foco na construção e compreensão da circunferência trigonométrica. No Cap. 6, as atividades pretendem ajudar o aluno a compreender e relacionar grandezas, bem como analisar o comportamento de funções trigonométricas e, além disso, espera-se que o aluno visualize alterações gráficas obtidas através de modificações de parâmetros das funções. No Cap. 7, o objetivo principal é mostrar ao aluno que, em geral, equações trigonométricas podem apresentar infinitas soluções ao se observar essas soluções graficamente.

O texto termina com as considerações finais além de proposta para continuidade do trabalho. 


\section{Capítulo 2}

\section{Revisão Bibliográfica}

\subsection{Trigonometria e GeoGebra}

A palavra trigonometria é formada por três radicais gregos: tri (três), gonos (ângulos) e metron (medir). Porém, já se passou o tempo em que a trigonometria se restringia ao estudo dos elementos dos triângulos. Atualmente, além de estudar os elementos dos triângulos, a trigonometria também é aplicada em geometria, além de ser possível relacioná-la com eletricidade, mecânica, acústica, música, engenharia civil, astronomia, entre outros. Seguem abaixo breves comentários de algumas dessas aplicações.

- Trigonometria na acústica: o som se propaga por ondas, em diferentes ângulos a partir de uma fonte. No projeto de um teatro, por exemplo, o engenheiro escolhe os melhores ângulos para que as ondas reflitam e cheguem da melhor forma possível aos ouvidos dos espectadores.

- Trigonometria na música: os produtores musicais de estúdio têm a tarefa de buscar o equilíbrio para que as músicas soem de forma harmônica no ouvido humano. Utilizando programas de computador, as ondas de som são visualizadas rapidamente através de diferentes gráficos gerados com auxílio de equações trigonométricas.

- Trigonometria na eletricidade: entre outras aplicações, na eletricidade a trigonometria auxilia no cálculo da intensidade da força magnética que age sobre uma partícula. Por exemplo: suponha que uma partícula com uma certa carga seja lançada, com certa velocidade, de forma que sua direção forme com a direção do campo magnético um ângulo de $30^{\circ}$. Nesse caso, o seno é utilizado para o cálculo da intensidade da força magnética, que age sobre essa partícula. 
- Trigonometria na engenharia civil: na engenharia civil, a trigonometria tem grande importância. Para citar um exemplo, no cálculo estrutural, o engenheiro faz uma análise das forças que atuam em cada ponto, a fim de garantir estabilidade para a estrutura. As forças envolvidas podem agir sob diferentes ângulos.

- Trigonometria na astronomia: Na astronomia, são utilizadas triangulações para se fazer estimativas de distâncias astronômicas. As relações trigonométricas entre lados e ângulos de triângulos auxiliam no cálculo dessas distâncias.

A maioria dos autores de livros didáticos opta por trabalhar trigonometria no $1^{\circ}$ e no $2^{\circ}$ ano do ensino médio. Geralmente é feita uma introdução de trigonometria a partir das relações métricas do triângulo retângulo e a partir desse ponto são definidas as três razões trigonométricas mais utilizadas: seno, cosseno e tangente. Vários autores utilizam situações do cotidiano para enriquecer os estudos dessas três razões trigonométricas. São muitas as possibilidades de aplicações. Acertadamente, muitos autores optam por fazer a apresentação do ciclo trigonométrico no início dos estudos de funções e relações trigonométricas.

Este trabalho parte do suposto de que a abordagem feita pelos autores de livros didáticos para o desenvolvimento de trigonometria é adequada para o ensino médio. $\mathrm{Na}$ introdução, aborda-se a constância das razões entre os lados de triângulos retângulos semelhantes. Posteriormente, apresentam aplicações de razões trigonométricas no cotidiano. A grande maioria dessas aplicações está relacionada com o cálculo de comprimentos associados aos lados de triângulos. E, para finalizar, é dado um tratamento algébrico para equações, inequações e transformações trigonométricas. Esse modelo de desenvolvimento de trigonometria no ensino médio pode ser observado em Youssef, Soares e Fernandez (2008).

A proposta deste trabalho está baseada em diversos trabalhos científicos os quais mostram que o estudo de trigonometria pode ser mais atrativo e interessante aos jovens com a utilização de softwares de geometria dinâmica. Muitos estudos sobre utilização de pacotes matemáticos para a aprendizagem de Matemática foram feitos nos últimos 15 anos. Recentemente, uma grande quantidade desses estudos utilizaram o software GeoGebra tanto para tratar de tópicos relacionados à trigonometria, quanto para os mais variados assuntos de Matemática. Alguns desses textos foram selecionados para serem comentados a seguir.

Dentre os artigos que tratam exatamente da utilização do GeoGebra para a aprendizagem de trigonometria destacam-se Zengin, Furkan e Kutluca (2011), Lopes (2013), Bacelar Júnior(2013) e Fortis, Binzar e Laiu (2011).

A proposta do estudo de Zengin, Furkan e Kutluca (2011) é determinar os efeitos do software de geometria dinâmica GeoGebra na aprendizagem de funções trigonométricas 
e gráficos dessas funções trigonométricas. Os alunos foram submetidos a um pré-teste sobre trigonometria e separados em dois grupos semelhantes quanto ao conhecimento prévio no assunto, um grupo chamado Experimental e o outro Controle. O primeiro foi submetido a aulas preparadas com o GeoGebra, enquanto o outro grupo foi submetido a aulas elaboradas segundo as instruções construtivistas. Os resultados desse estudo mostram que existe uma diferença significativa nas notas dos alunos no pós-teste, em favor do grupo Experimental. Os autores concluem que a instrução computacional assistida como um complemento das aulas construtivistas é mais eficaz do que o método de ensino construtivista puro. Finalmente, concluíram que a utilização de softwares de aprendizagem de matemática tem um impacto positivo, reforçando a aprendizagem e a compreensão.

Lopes (2013) apresenta um caderno de atividades elaborado com base em atividades desenvolvidas com alunos da segunda série do ensino médio. Essas atividades abordam soma de ângulos internos de um triângulo, altura de triângulos e semelhança entre triângulos; razões trigonométricas nos triângulos retângulos, ciclo trigonométrico e funções trigonométricas (seno, cosseno e tangente). Concluiu, com base nos resultados da pesquisa, que, dentre as potencialidades apresentadas pelo software GeoGebra no ensino e na aprendizagem de trigonometria por meio de atividades investigativas estão, principalmente, a construção, o dinamismo, a investigação, a visualização e a argumentação. As limitações as quais se referem o artigo se devem ao aspecto estrutural, como por exemplo, poucos computadores para turmas muito grandes e a falta de conhecimento, pelos professores, do sistema operacional instalado na escola.

Fortis, Binzar e Laiu (2011) apresentam dois projetos didáticos com o uso do GeoGebra. O primeiro trata da construção do ciclo trigonométrico e explica as fórmulas de redução ao primeiro quadrante. O segundo exemplo não está relacionado com trigonometria, na verdade, os autores mostram como é possível usar o GeoGebra para checar a validade de uma propriedade sobre triângulos. A conclusão do artigo é de que as noções abstratas são mais facilmente entendidas porque os alunos podem visualizá-las no GeoGebra, e as lições se tornam mais atrativas. Os autores destacam ainda a importância de introduzir o GeoGebra no processo educacional, para criar aulas modernas com suporte visual aos conceitos teóricos apresentados.

Em outras áreas da matemática, mas apresentando resultados consistentes quanto ao uso do GeoGebra, destacam-se Reis (2010), tratando da introdução do conjunto dos Números Inteiros, Zengin e Tatar (2013), sobre o ensino de coordenadas polares; Thambi e Eu (2013), estudando o efeito na aprendizagem e absorção do conteúdo dos alunos em relação às frações; Jacyntho (2008) que apresenta atividades em uma sequência didática para auxiliar no aprendizado de Cálculo; e Lopes Junior (2013), explorando o GeoGebra no ensino de funções afins, quadráticas, exponencial, logarítmica 
e, inclusive, trigonométrica.

Um trabalho bastante amplo sobre Trigonometria com diversas metodologias e tecnologias foi realizado por Oliveira (2010), evidenciando a necessidade de criatividade na preparação dos planos de aula de Matemática pela escolha de metodologias variadas, a fim de conectar ideias e produzir significações. Para a autora, o envolvimento da tecnologia com a sala de aula pode facilitar o processo de ensino-aprendizagem, permitindo que algumas visualizações abstratas se tornem mais concretas aos alunos.

No que tange a importância das novas tecnologias no contexto educacional, há ainda uma forte motivação pessoal. O autor participou de um projeto no período de 2010 a 2012, durante o curso de Especialização Latu Sensu em Novas Tecnologias no Ensino da Matemática, junto a UFF - Universidade Federal Fluminense, Silva (2012), o que permitiu ter ainda mais convicção de que as novas tecnologias da informação e da comunicação auxiliarão permanentemente o processo educacional e devem, de forma concisa e organizada, ser incorporadas às atividades pedagógicas, uma vez que são ferramentas capazes de promover aprendizagens significativas para os alunos.

Como requisito parcial para obtenção junto a UFF do Grau de Especialista Em Novas Tecnologias no Ensino da Matemática, o autor desse projeto apresentou trabalho final de conclusão de curso (2012), abordando estudo de caso sobre a utilização do Excel $^{\circledR}$ na mediação da construção de competências e habilidades no ensino da matemática, utilizando os relatórios pedagógicos do SARESP - (Sistema de Avaliação do Rendimento Escolar do Estado de São Paulo dos anos de 2009 e 2010). O objetivo do trabalho era o estudo de exemplos práticos da utilização do Excel ${ }^{\circledR}$ em sala de aula, bem como a identificação de possíveis benefícios de sua utilização no processo de ensino e aprendizagem de matemática. Foram desenvolvidas atividades com dois grupos distintos de alunos, sendo que um grupo utilizou o Excel ${ }^{\circledR}$ e o outro grupo não utilizou. Ao final, foi aplicada uma mesma avaliação para esses dois grupos. Os resultados obtidos pelos alunos na avaliação levaram a concluir que a hipótese principal do estudo de caso foi comprovada, ou seja, a maioria dos dados obtidos convergiu para uma possível associação entre a melhoria do desempenho dos alunos em matemática, e a utilização do Excel ${ }^{\circledR}$ por estes alunos. Porém, os resultados não podem ser inferidos, uma vez que as atividades foram desenvolvidas com grupo restrito de alunos.

Kampff e Cavedini (2004) defendem que o computador é um instrumento valioso no processo de ensino e de aprendizagem, cabendo à escola utilizá-lo de forma coerente com uma proposta pedagógica atual e consistente. Além disso, o computador permite criar objetos concreto-abstratos. Concretos porque existem na tela do computador, e abstratos por se tratarem de realizações feitas a partir de construções mentais.

Do ponto de vista pedagógico, o trabalho realizado na UFF reforça o pensamento de Kampff e Cavedini (2004), uma vez que ficou perceptível que o grupo que utilizou 
planilhas eletrônicas teve mais concretude na construção de habilidades e competências. Nesse estudo de caso, as planilhas eletrônicas foram utilizadas na parte algébrica, dando aos alunos a possibilidade de enxergar os padrões e regularidades dos resultados numéricos.

A realização desse estudo de caso fortaleceu as inquietações do autor deste projeto sobre a importância das novas tecnologias na educação, especificamente como ferramenta auxiliadora das aprendizagens de matemática, além das contribuições na formação do cidadão para o mercado de trabalho.

As pesquisas citadas, entre outras, servem de motivação para que os professores preparem suas aulas utilizando as novas tecnologias. Além disso, dão suporte científico quanto à metodologia, à forma de organização das atividades e aos assuntos apropriados para desenvolver as aulas. Baseados na literatura, os professores podem utilizar sua criatividade com segurança. Consequentemente, o aprendizado do aluno passará a ser mais prazeroso e com maior retenção do assunto. Cabe a cada professor definir o nível de interação dos alunos com as tecnologias, respeitando as especificidades e necessidades de cada turma.

\subsection{Noções de trigonometria}

Para uma melhor compreensão deste trabalho, são apresentadas definições de trigonometria que serão utilizadas. As definições apresentadas são de Iezzi(1993).

\subsubsection{Arcos de circunferência}

Consideremos uma circunferência de centro $O$ e ângulo central AÔB, sendo A e $\mathrm{B}$ pontos que pertencem aos lados do ângulo e à circunferência. A circunferência fica dividida em duas partes, cada uma das quais é um arco de circunferência, como mostra a figura 2.1 .

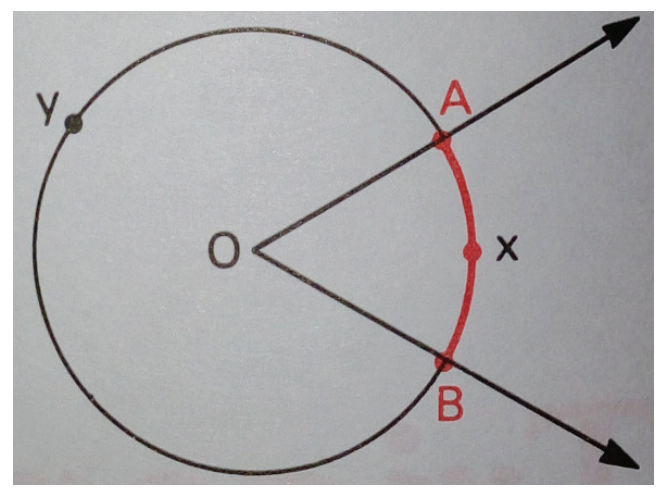

Figura 2.1: Arco de circunferência - Fonte: Iezzi (1993) 


\subsubsection{Medidas de arcos - graus}

Grau ( símbolo $^{\circ}$ ) é um arco unitário igual a $\frac{1}{360}$ da circunferência que contém o arco a ser medido. A medida (em graus) de um arco de circunferência é igual à medida do ângulo central correspondente. Considerando a figura 2.2, verificamos que AÔB é um ângulo central (porque tem o vértice no centro da circunferência), e $\widehat{A B}$ é um arco correspondente ao ângulo central AÔB.

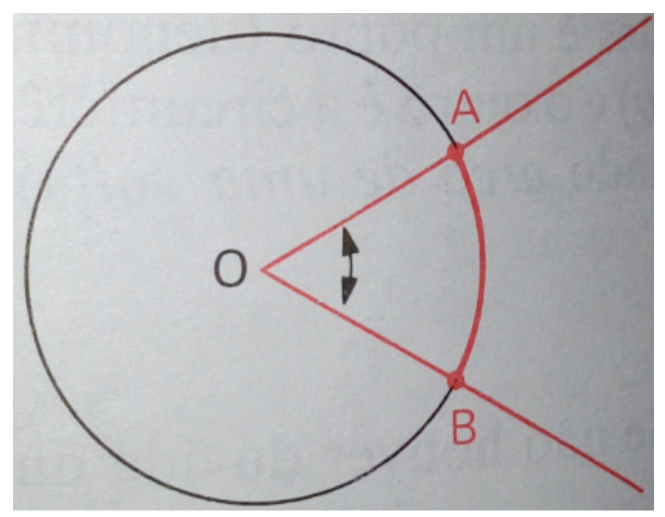

Figura 2.2: Medida de arcos - graus - Fonte: Iezzi (1993)

\subsubsection{Medidas de arcos - radianos}

Radiano (símbolo rad) é um arco unitário cujo comprimento é igual ao raio da circunferência que contém o arco a ser medido, como mostra a figura 2.3.

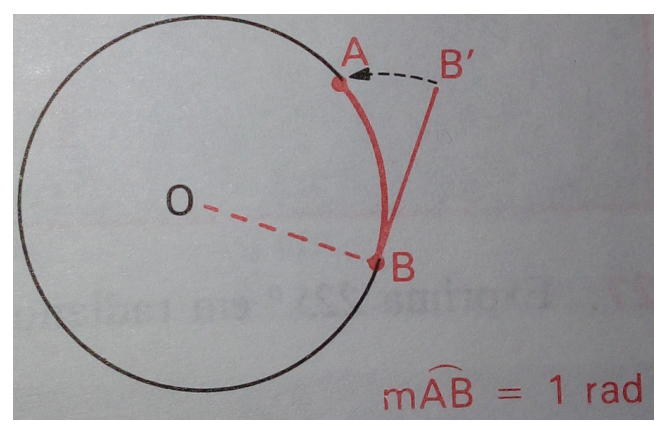

Figura 2.3: Medida de arcos - radianos - Fonte: Iezzi (1993)

\subsubsection{Ciclo trigonométrico}

Tomemos sobre um plano um sistema cartesiano ortogonal $u \mathrm{O} v$. Consideremos a circunferência $\lambda$ de centro $\mathrm{O}$ e raio $r=1$. Notemos que o comprimento dessa circunferência é $2 \pi$, pois $r=1$. Vamos agora associar a cada número real $x$ com $0 \leq x<$ $2 \pi$, um único ponto $\mathrm{P}$ da circunferência $\lambda$, como mostra a figura 2.4. 


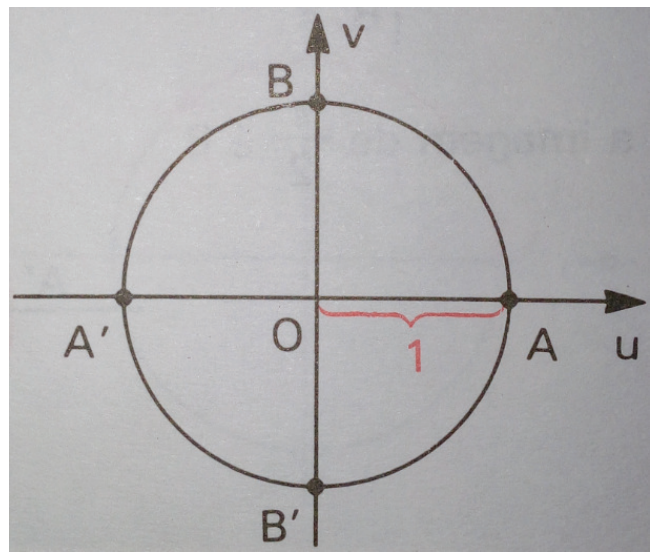

Figura 2.4: Ciclo trigonométrico - Fonte: Iezzi (1993)

A circunferência $\lambda$ acima definida, com origem em A, é chamada ciclo ou circunferência trigonométrica.

\subsubsection{Seno}

Dado um número real $x \in[0,2 \pi]$, seja $\mathrm{P}$ sua imagem no ciclo. Denominamos seno de $x$ (e indicamos sen $x$ ) a ordenada $O P_{1}$ do ponto $\mathrm{P}$ em relação ao sistema $u \mathrm{O} v$, como mostra a figura 2.5.

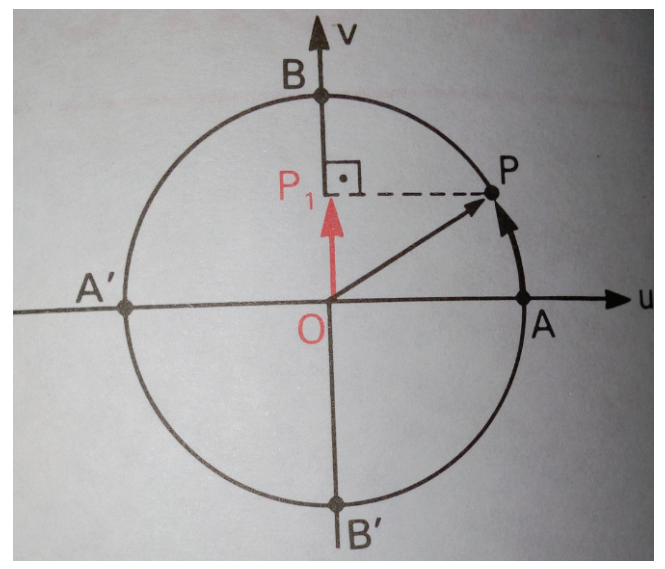

Figura 2.5: Seno - Fonte: Iezzi (1993)

- Se $x$ é do primeiro ou do segundo quadrante, então sen $x$ é positivo;

- Se $x$ é do terceiro ou do quarto quadrante, então sen $x$ é positivo;

- Se $x$ percorre o primeiro ou o quarto quadrante, então sen $x$ é crescente;

- Se $x$ percorre o segundo ou o terceiro quadrante, então sen $x$ é decrescente. 


\subsubsection{Cosseno}

Dado um número real $x \in[0,2 \pi]$, seja $\mathrm{P}$ sua imagem no ciclo. Denominamos cosseno de $x$ (e indicamos $\cos x$ ) a abscissa $O P_{2}$ do ponto $\mathrm{P}$ em relação ao sistema $u \mathrm{O} v$, como mostra a figura 2.6.

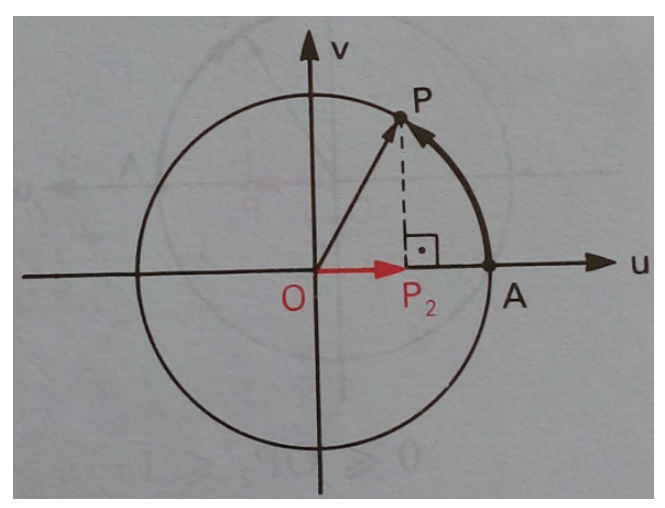

Figura 2.6: Cosseno - Fonte: Iezzi (1993)

- Se $x$ é do primeiro ou do quarto quadrante, então $\cos x$ é positivo;

- Se $x$ é do segundo ou do terceiro quadrante, então $\cos x$ é negativo;

- Se $x$ percorre o primeiro ou o segundo quadrante, então cos $x$ é decrescente;

- Se $x$ percorre o terceiro ou o quarto quadrante, então cos $x$ é crescente.

\subsubsection{Tangente}

Dado um número real $x \in[0,2 \pi], x \neq \frac{\pi}{2}$ e $x \neq \frac{3 \pi}{2}$, seja $\mathrm{P}$ sua imagem no ciclo. Consideremos a reta que contém os pontos $\mathrm{O}$ e $\mathrm{P}$ e seja $\mathrm{T}$ sua interseção com o eixo das tangentes. Denominamos tangente de $x$ (e indicamos $\operatorname{tg} x$ ) a medida algébrica do segmento com extremidades em A e T, como mostra a figura 2.7.

Note que, para $x=\frac{\pi}{2}$, P está sobre B e, para $x=\frac{3 \pi}{2}$, P está em B' e, então, a reta que contém os pontos $\mathrm{O}$ e $\mathrm{P}$ fica paralela ao eixo das tangentes. Como neste caso não existe o ponto $\mathrm{T}$, a $\operatorname{tg} x$ não está definida.

- Se $x$ é do primeiro ou do terceiro quadrante, então $\operatorname{tg} x$ é positiva;

- Se $x$ é do segundo ou do quarto quadrante, então $t g x$ é negativa;

- Se $x$ percorre qualquer um dos quatro quadrantes, então tg $x$ é crescente. 


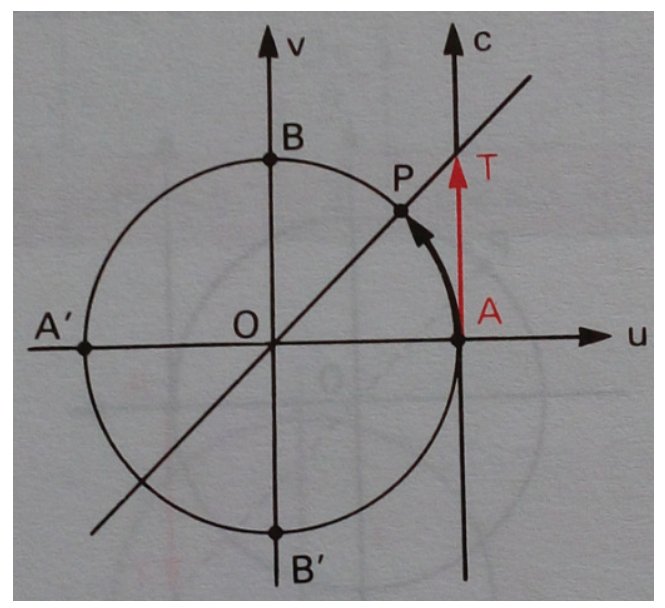

Figura 2.7: Tangente - Fonte: Iezzi (1993)

\subsubsection{Equações trigonométricas}

Sejam $f(x)$ e $g(x)$ duas funções trigonométricas de variável $x$ e sejam $D_{1}$ e $D_{2}$ seus respectivos domínios. Resolver a equação trigonométrica $f(x)=g(x)$ significa determinar o conjunto S, denominado conjunto solução ou conjunto verdade, dos números $r$ para os quais $f(r)=g(r)$ é uma sentença verdadeira. Observemos que uma condição necessária para que um certo $r$ seja uma solução da equação dada é que $r \in D_{1}$ e $r$ $\in D_{2}$. Quase todas as equações trigonométricas reduzem-se a uma sentença das três equações seguintes:

- $\operatorname{sen} \alpha=\operatorname{sen} \beta$

- $\cos \alpha=\cos \beta$

- $\operatorname{tg} \alpha=\operatorname{tg} \beta$

denominadas, por este motivo, equações fundamentais. Assim, antes de tudo, é necessário saber resolver equações fundamentais para poder resolver qualquer outra equação trigonométrica. Se sen $\alpha=\operatorname{sen} \beta=O P_{1}$, então as imagens de $\alpha$ e $\beta$ no ciclo estão sobre a reta $r$ que é perpendicular ao eixo dos senos no ponto $P_{1}$, isto é, estão em $P$ ou $P^{\prime}$. Há, portanto, duas possibilidades:

- $\left.1^{\mathrm{a}}\right) \alpha$ e $\beta$ têm a mesma imagem, isto é, são côngruos;

- $2^{\mathrm{a}}$ ) $\alpha$ e $\beta$ têm imagens simétricas em relação ao eixos dos senos, isto é, são suplementares.

esta resolução é ilustrada pela figura 2.8 . 


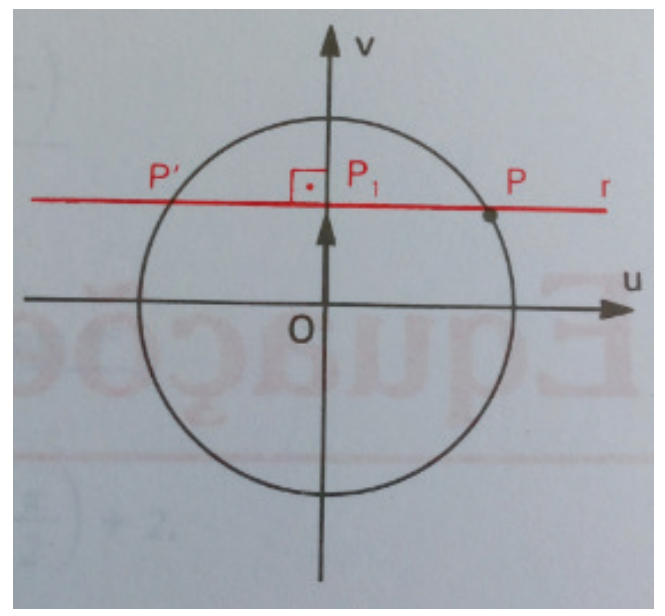

Figura 2.8: Resolução da equação sen $\alpha=\operatorname{sen} \beta=O P_{1}$ - Fonte: Iezzi (1993)

\subsubsection{Funções trigonométricas}

Noções básicas para o estudo de funções trigonométricas:

- Dados dois conjuntos, $A$ e $B$, chama-se relação binária de $A$ em $B$ todo subconjunto $R$ de $A x B$.

$R$ é a relação binária de $A$ e $B \Longleftrightarrow R \subset A \times B$.

- Dados dois conjuntos, $A$ e $B$, não vazios, uma relação $f$ de $A$ em $B$ recebe o nome de aplicação de $A$ em $B$ ou função em $A$ com imagens em $B$ se, e somente se, para todo $x \in A$ existe um só $y \in B$ tal que $(x, y) \in f$.

$f$ é aplicação de $A$ em $B \Longleftrightarrow(\forall x \in A, \exists|y \in B|(x, y) \in f)$.

- Geralmente, existe uma sentença aberta $y=f(x)$ que expressa a lei mediante a qual, dado $x \in A$, determina-se $y \in B$ tal que $(x, y) \in f$.

Então:

$\mathrm{f}=\{(\mathrm{x}, \mathrm{y}) \mid \mathrm{x} \in \mathrm{A}, \mathrm{y} \in \mathrm{B}$ e $\mathrm{y}=\mathrm{f}(\mathrm{x})\}$

Isso significa que, dados os conjuntos $A$ e $B$, a função $f$ tem a lei de correspondência $y=f(x)$.

- Para definirmos uma função $f$, definida em $A$ com imagens em $B$ segundo a lei de correspondência $y=f(x)$, usaremos uma das seguintes notações:

$$
\begin{aligned}
\mathrm{f}: \mathrm{A} & \longrightarrow \mathrm{B} \\
\mathrm{x} & \longrightarrow \mathrm{f}(\mathrm{x})
\end{aligned}
$$

- Chamamos de domínio o conjunto $D$ dos elementos $x \in A$ para os quais existe $y$ $\in B$ tal que $(x, y) \in f$. Como, pela definição de função, todo elemento de $A$ tem essa propriedade, então $D=A$. 
- Chamamos de imagem o conjunto $I m$ dos elementos $y \in B$ para os quais existe $x \in A$ tal que $(x, y) \in f$. Portanto, $\operatorname{Im} \subset B$.

\subsubsection{Gráficos de funções trigonométricas}

Para exemplificar, será feito o gráfico da função $f(x)=\operatorname{sen} x$. Fazendo um diagrama com $x$ em abscissas e sen $x$ em ordenadas, podemos construir o gráfico denominado senóide que indica como varia a função $f(x)=\operatorname{sen} x$, como mostra a figura 2.9 .

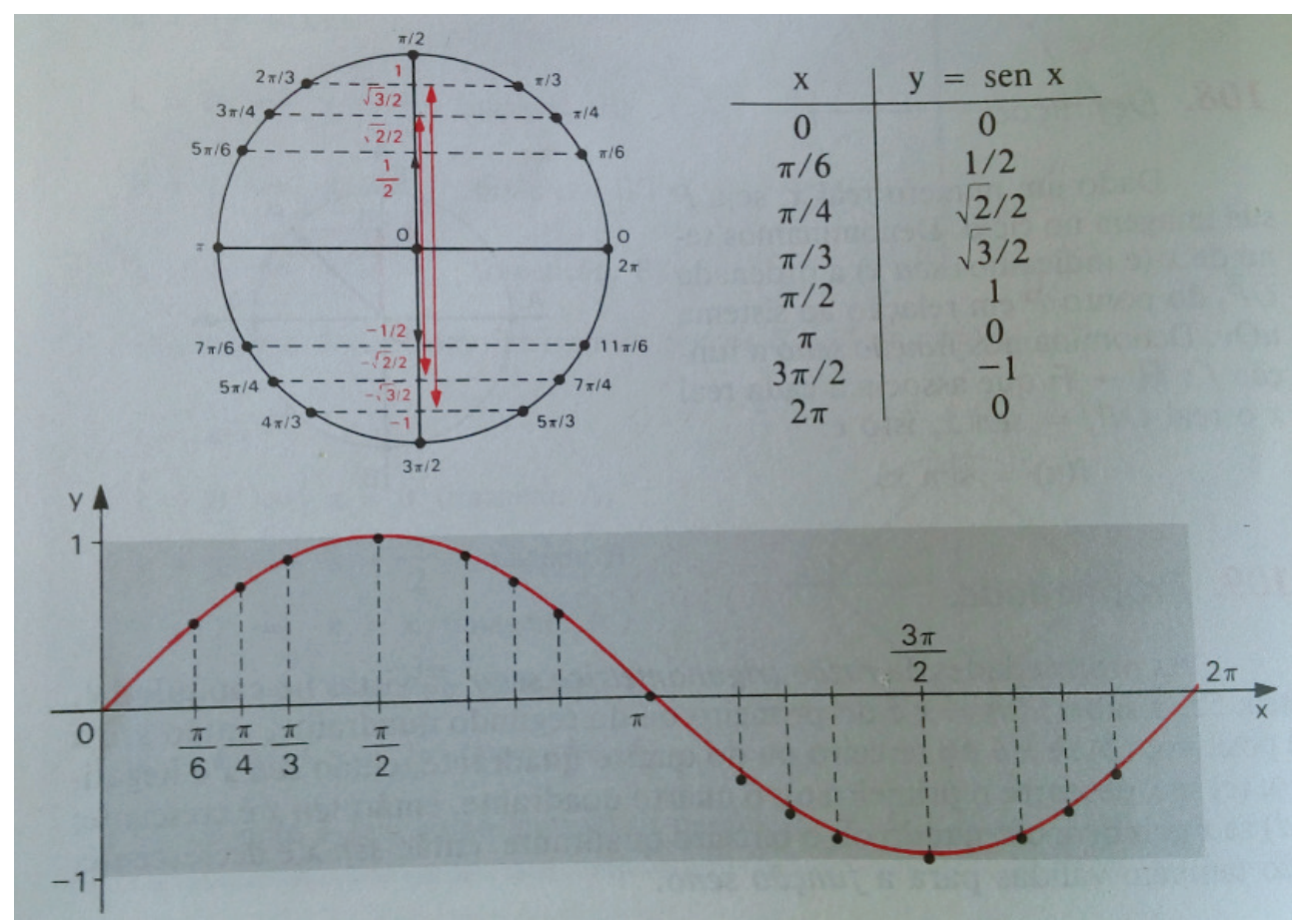

Figura 2.9: Gráfico da função $f(x)=\operatorname{sen} x$ - Fonte: Iezzi (1993)

Observemos que, como o domínimo da função seno é $\mathbb{R}$, a senóide continua para a direita de $2 \pi$ e para a esquerda de 0 . No retângulo em destaque está representado, apenas um período da função. Notemos ainda que as dimensões desse retângulo são $2 \pi \times 2$, isto é, aproximadamente, $6,28 \times 2$. 


\section{Capítulo 3}

\section{As Tecnologias de Informação e Comunicação no ambiente escolar}

Este capítulo explora dados sobre as tecnologias de informação e comunicação (TICs), e faz uma análise da importância das novas tecnologias no contexto escolar e sua disponibilidade nas escolas brasileiras, bem como analisar como as novas tecnologias estão sendo utilizadas por alunos e professores.

\subsection{Tecnologias e a missão da escola}

Mas, afinal, o que é tecnologia? Kenski (2003), em seu trabalho sobre tecnologias e ensino presencial e à distância, define tecnologia da seguinte forma:

Ao conjunto de conhecimentos e princípios científicos que se aplicam ao planejamento, à construção e à utilização de um equipamento em um determinado tipo de atividade nós chamamos de tecnologia.

Vale ressaltar que o conceito de tecnologia é atemporal. No campo educacional, as tecnologias têm um papel ainda mais importante: são criações humanas para humanos com o objetivo de promover uma ampliação das possibilidades de aprendizagens dos alunos. Ou seja, tecnologia é uma parte inerente ao ser humano. Essa humanização e atemporalidade das tecnologias é muito clara para Kenski (2007):

A evolução social do homem confunde-se com as tecnologias desenvolvidas e empregadas em cada época. Diferentes períodos da história da humanidade são historicamente reconhecidos pelo avanço tecnológico correspondente. As idades da pedra, do ferro e do ouro, por exemplo, correspondem ao momento histórico-social em que foram criadas novas tecnologias para o aproveitamento desses recursos da natureza, de forma a garantir melhor qualidade de vida. O avanço científico da humanidade amplia o conhecimento sobre esses recursos e cria permanentemente novas tecnologias cada vez mais sofisticadas. 
Atualmente, o desenvolvimento de novas tecnologias, o aprimoramento e surgimento de novas técnicas de produção além da acelerada e contínua substituição da força de trabalho humano pelas máquinas e equipamentos, estão entre os principais fatores responsáveis por uma mudança significativa no cenário econômico, social e educacional. Essas mudanças trazem para a sociedade a necessidade de formar profissionais cada vez mais qualificados e capazes de interagir, no sentido mais amplo, com tais tecnologias. Kenski(2003), acredita que já estamos imersos nessas novas tecnologias:

... ela está em todo lugar, já faz parte de nossas vidas. Nossas atividades cotidianas mais comuns como dormir, comer, trabalhar, ler, conversar, deslocarmo-nos para diferentes lugares e divertirmo-nos são possíveis graças às tecnologias a que temos acesso.

Nesse cenário, com as máquinas assumindo a execução de tarefas mecânicas, o homem passa a ter maior importância no desenvolvimento de atividades de cunho intelectual, levando-o por um processo natural a uma supervalorização do conhecimento. É justamente neste momento que o domínio de habilidades matemáticas, aliado ao conhecimento tecnológico pode fazer diferença em prol do indivíduo.

A escola, além de ser instituição educacional, tem o dever de fornecer subsídios necessários para o desenvolvimento social, intelectual e afetivo dos indivíduos. A Lei de Diretrizes e Bases da Educação Nacional - LDB (1996) salienta que a educação básica forneça meios do indivíduo prosseguir seus estudos e associa o exercício da cidadania com uma formação comum indispensável:

A educação básica tem por finalidades desenvolver o educando, assegurar-lhe a formação comum indispensável para o exercício da cidadania e fornecer-lhe meios para progredir no trabalho e em estudos posteriores.

Especificamente para o Ensino Médio, a LDB (1996) estabelece que para a organização do currículo deverá, entre outras diretrizes, observar que:

... destacará a educação tecnológica básica, a compreensão do significado da ciência, das letras e das artes; o processo histórico de transformação da sociedade e da cultura; a língua portuguesa como instrumento de comunicação, acesso ao conhecimento e exercício da cidadania e adotará metodologias de ensino e de avaliação que estimulem a iniciativa dos estudantes.

Para alcançar os objetivos da LDB, a escola deve, de forma organizada e concisa, aperfeiçoar seu modelo educacional com mudanças que visem adequá-lo ao novo cotidiano tecnológico, assim como salienta Miskulin (1999): 
No âmbito educacional, o uso de novas tecnologias, por exemplo, de computadores, poderia colocar os alunos de classes menos privilegiadas em contato com as ferramentas utilizadas, em grande escala, nos países do primeiro mundo. Os computadores passariam a ser um fator de abertura para novas possibilidades, novas transformações na vida das pessoas e, consequentemente, na concepção de mundo dos sujeitos.

As novas Tecnologias da Informação e Comunicação (TICs), através de ambientes informatizados, trazem consigo a possibilidade de ampliar cada vez mais o desenvolvimento de múltiplas habilidades e capacidades cognitivas, entre elas as habilidades matemáticas. E o domínio dessas habilidades, aliado ao acesso e à capacidade de interação com essas novas tecnologias, permitem maior inserção no mercado de trabalho, além de propiciar contribuições para o desenvolvimento pessoal e para o exercício da cidadania. Essas conclusões também são compartilhadas por Miskulin (1999):

\begin{abstract}
. . acredita-se e preconiza-se a introdução e a utilização reflexiva e consciente da tecnologia, mais especificamente, de computadores na educação, principalmente nas escolas públicas, pois, se seus alunos não usufruírem desse novo recurso tecnológico que permeia alguns segmentos da sociedade, não terão, quem sabe, oportunidade de vivenciá-lo fora do contexto escolar. Desse modo, não se integra o indivíduo ao que é por ele produzido, fora da escola, e consequentemente, infere-se que esses indivíduos não estarão preparados para exercerem um trabalho digno e nem tampouco uma função que lhes dê condições dignas de existência.
\end{abstract}

Valente (1999) afirma que o ensino tradicional de Matemática não tem produzido resultados satisfatórios, principalmente pela não adequação dos métodos de ensino à realidade do cotidiano do aluno. Realidade esta, permeada por novas tecnologias. Consoante a isso, Machado (1999) salienta que há um descontentamento com o ensino da Matemática em todos os níveis de escolaridade. Isso faz com que sua função no currículo escolar passe a ser questionada.

Essa decadência no ensino de matemática pode ser verificada em um estudo do $\mathrm{INEP}^{1}$, com dados do $\mathrm{SAEB}^{2}$ em exame aplicado no ano 2001, evidenciando que $52 \%$ dos estudantes brasileiros de $4^{\mathrm{a}}$ série estariam no estágio muito crítico e crítico de habilidades de matemática. Este dado é importante porque detecta uma falha grave no ensino de matemática, no nível intermediário do ensino fundamental, ensino este que é

\footnotetext{
${ }^{1}$ Instituto Nacional de Estudos e Pesquisas Educacionais Anísio Teixeira, autarquia federal vinculada ao Ministério da Educação (MEC) cuja missão é promover estudos, pesquisas e avaliações sobre o Sistema Educacional Brasileiro.

${ }^{2}$ Sistema Nacional de Avaliação da Educação Básica que é aplicado a cada dois anos, desde 1990 e avalia o desempenho dos alunos brasileiros da $4^{\mathrm{a}}$ e da $8^{\mathrm{a}}$ séries do ensino fundamental e da $3^{\mathrm{a}}$ série do ensino médio, nas disciplinas de Língua Portuguesa (Foco: Leitura) e Matemática (Foco: resolução de problemas).
} 
um dos alicerces para o sucesso educacional. Posteriormente em 2003 o PISA ${ }^{3}$, mostrou que mesmo tendo uma pequena melhora com relação ao exame de 2000, o Brasil foi o último colocado entre 41 países pesquisados, no que se refere ao desenvolvimento de habilidades matemáticas. Já no Pisa de 2012, o Brasil ocupou a posição 58 entre 65 países que participaram do exame. Os resultados de 2012 mostram uma evolução nominal do score do Brasil, mas este ainda tem 67,1\% dos estudantes abaixo do nível 2 na escala de proficiência em matemática, ou seja, estão incluídos nos níveis abaixo de 1 e 1. Essa escala de proficiência de Matemática é composta pelos níveis: abaixo de $1,1,2,3,4,5$ e 6 . Para compreendermos melhor esse dado, vejamos o que o Relatório Nacional do Pisa 2012 diz sobre as habilidades dos níveis 1 e 6:

No nível 1, os estudantes são capazes de responder a questões definidas com clareza, que envolvem contextos conhecidos, nas quais todas as informações relevantes estão presentes. Conseguem identificar informações e executar procedimentos rotineiros de acordo com instruções diretas em situações explícitas. São capazes de executar ações obvias e dar continuidade imediata ao estímulo dado. No nível 6, os estudantes são capazes de conceituar, generalizar e utilizar informações com base em suas investigações e em modelagem de situaçõesproblema complexas. Conseguem estabelecer ligações entre diferentes fontes de informação e representações, e de transitar entre elas com flexibilidade. Os estudantes situados neste nível utilizam pensamento e raciocínio matemáticos avançados. São capazes de associar sua percepção e sua compreensão a um domínio de operações e relações matemáticas simbólicas e formais, de modo a desenvolver novas abordagens e estratégias para enfrentar novas situações. Os estudantes situados neste nível são capazes de formular e comunicar com precisão suas ações e reflexões relacionadas a constatações, interpretações e argumentos, bem como de adequá-las às situações originais.

Outro dado importante do PISA de 2003, que justifica de maneira contundente a relevância deste trabalho, é o fato de que os alunos que não têm acesso a um computador tiveram o pior desempenho em Matemática.

Perrenoud (2000) afirma que a escola não pode ignorar o que se passa no mundo, pois as novas tecnologias da informação e da comunicação transformam de forma espetacular não só nossas maneiras de comunicar, mas também de trabalhar, de decidir e de pensar.

Existe uma cultura de que o conhecimento deve ser transmitido. Essa é a filosofia da escola tradicional, que tenta, a cada dia com menos sucesso, transmitir os conhecimentos acumulados pela sociedade ao longo do tempo. Esse conhecimento que se

\footnotetext{
${ }^{3}$ Programa Internacional de Avaliação de Alunos que é um programa internacional de avaliação comparada, cuja principal finalidade é produzir indicadores sobre a efetividade dos sistemas educacionais, avaliando comparativamente o desempenho de alunos na faixa dos 15 anos. Esse programa é desenvolvido e coordenado internacionalmente pela Organização para Cooperação e Desenvolvimento Econômico (OCDE), havendo em cada país participante uma coordenação nacional. No Brasil, o PISA é coordenado pelo Inep.
} 
busca transmitir assume uma forma fragmentada, sem elos de ligação com o cotidiano do aluno. Muitas das inquietações dos alunos não são atendidas pelo modelo tradicional de ensino, que de certa forma, principalmente na rede pública, está parado no tempo. O que vai de encontro ao pensamento de Paulo Freire, (1996), sobre respeito que se deve ter à autonomia do ser do educando:

O professor que desrespeita a curiosidade do educando, o seu gosto estético, a sua inquietude, a sua linguagem, mais precisamente, a sua sintaxe e a sua prosódia; o professor que ironiza o aluno, que minimiza, que manda que "ele se ponha em seu lugar" ao mais tênue sinal de sua rebeldia legítima, tanto quanto o professor que se exime do cumprimento de seu dever de ensinar, de estar respeitosamente presente à experiência formadora do educando, transgride os princípios fundamentalmente éticos de nossa existência. É neste sentido que o professor autoritário, que por isso mesmo afoga a liberdade do educando, amesquinhando o seu direito de estar sendo curioso e inquieto.

Os alunos utilizam as novas tecnologias para se comunicar fora do ambiente da sala de aula por meio de mensagens instantâneas, telefones celulares, redes sociais, entre outros meios digitais. No entanto, a escola tem se mostrado pouco atrativa e desconectada do mundo real, não reconhecendo os benefícios que esses instrumentos podem trazer para a educação. A implementação das TICs é uma oportunidade para ajudar as escolas a se transformarem e, como consequência, engajar os alunos nas atividades de aprendizagem, Brasil (2013).

Em virtude do exposto acima, podemos dizer que uma das possíveis características da educação moderna será o uso de novas tecnologias, amparadas por práticas pedagógicas ousadas e eficientes, exigindo assim docentes cada vez mais preparados e qualificados.

\subsection{O atual uso das TICs no ambiente escolar}

A pesquisa TIC Educação ${ }^{4} 2012$ identificou que quase a totalidade das escolas públicas possuía algum computador (99\%), sendo que todas as escolas que possuíam o equipamento declararam ter ao menos um computador de mesa. Essa pesquisa verificou ainda que, em média, as escolas públicas brasileiras possuem 22 computadores de mesa, dos quais 19 estão em funcionamento. Ao constatar que no Ensino Médio, por exemplo, há em média 35 alunos por turma, o número de computadores se mostra insuficiente para atender às necessidades dos diferentes níveis de ensino. A pesquisa TIC Educação

${ }^{4}$ TIC EDUCAÇÃO é uma pesquisa sobre o uso das tecnologias de informação e comunicação nas escolas brasileiras. A pesquisa é elaborado anualmente pelo Comitê Gestor da Internet no Brasil. Disponível em www.cgi.br. 
2012 também identificou que há, em média, dois alunos por computador nas escolas públicas brasileiras em área urbana.

O tema da infraestrutura também aparece como o principal elemento limitador do uso do computador e da Internet na escola pública, segundo a percepção dos educadores. Para $79 \%$ dos docentes e $71 \%$ dos coordenadores, o número limitado de computadores por aluno dificulta a utilização das TICs no cotidiano das práticas de ensino. Esse é o fator que mais dificulta o uso das novas tecnologias digitais com os alunos na visão dos professores e coordenadores de escolas públicas, seguido pelo número de computadores conectados à internet.

\subsection{Aprendizado para uso das TICs}

Os professores das escolas públicas estão relativamente aptos a utilizarem o computador em suas aulas. Essa aptidão pode ser observada em Brasil(2013), nos dados da pesquisa TIC Educação 2012:

. . a maioria dos professores de escolas públicas declara realizar com facilidade atividades elementares no computador e na Internet: 93\% dizem não ter nenhuma dificuldade para fazer pesquisa de informações na Internet; 83\% para escrever em editores de texto como o Microsoft Word e 71\% para armazenar um arquivo em uma pasta no sistema de diretório. Ações como a preparação de apresentações e o uso de programas multimídia que exigem habilidades mais complexas e que são úteis para a preparação de aulas expositivas são realizadas sem dificuldade por $49 \%$ a $46 \%$ dos professores, respectivamente.

Analisando os resultados gerais da pesquisa TIC Educação 2012,(professores de escolas públicas e particulares), é possível observar que as atividades realizadas com os alunos não sofreram grandes oscilações ao longo dos anos:

As atividades mais frequentes ainda são: exercícios para a prática do conteúdo (67\%), aula expositiva (49\%) e interpretação de textos (47\%). Assim, as atividades mais realizadas no cotidiano entre professor e aluno contam com uma incidência menor de uso do computador e Internet.

Por outro lado, aumentou o número de professores que utilizam computador com internet para realizar atividades e avaliações com seus alunos. Os dados da pesquisa TIC Educação 2012 mostram esse aumento e sugerem uma tendência de crescimento na utilização do computador e internet para realizar atividades e avaliações. Esse aumento pode ser associado ao maior acesso dos professores a computadores e internet.

As Figuras 3.1 e 3.2 apresentam gráficos dos resultados da pesquisa TIC Educação que representam a proporção de professores de escolas públicas quanto ao uso de computador e internet nas atividades realizadas com alunos. 


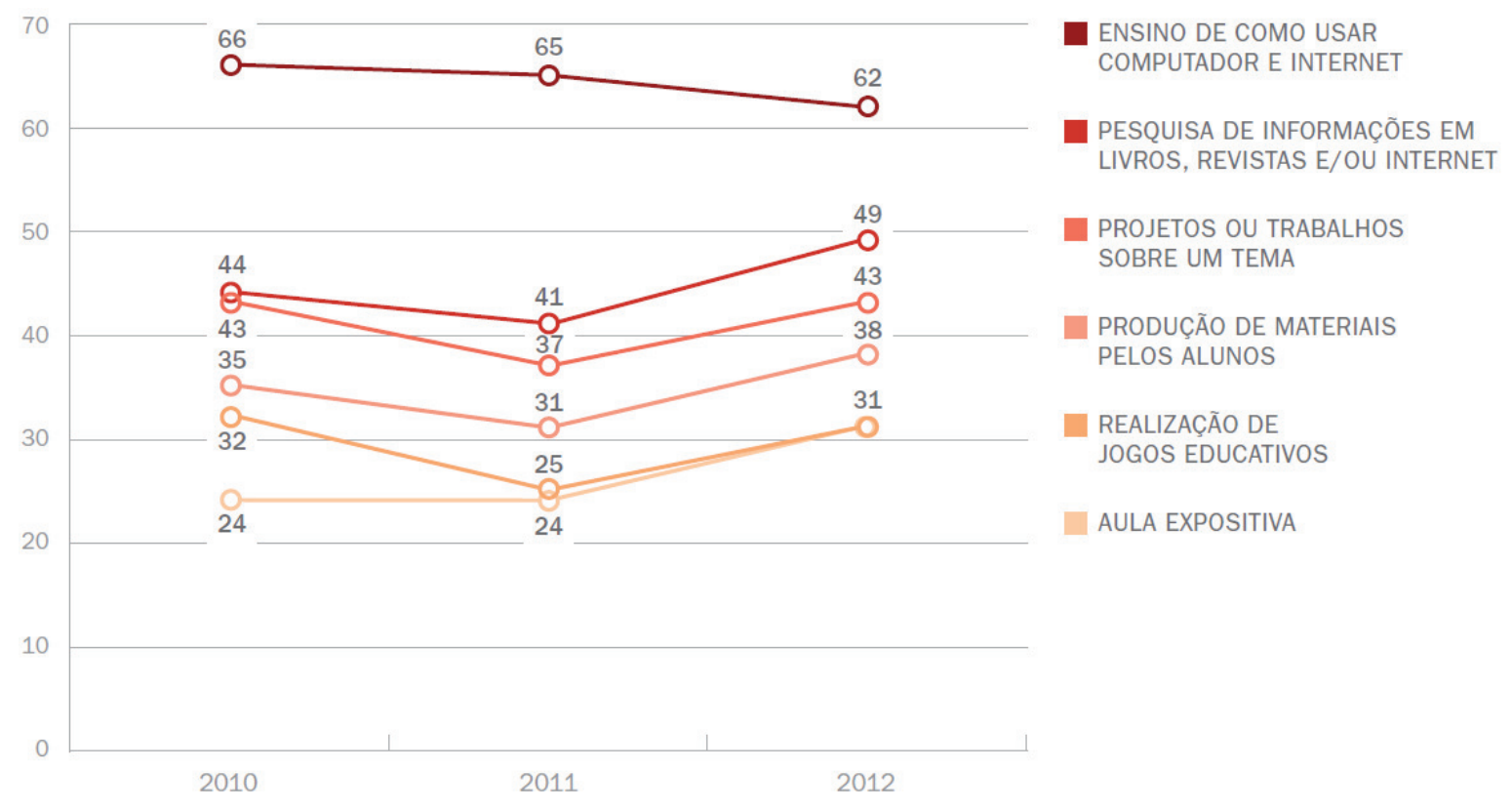

Figura 3.1: Proporção de professores de escolas públicas, por uso do computador e internet nas atividades realizadas com aluno - Percentual sobre o total de professores de escolas públicas que costumam realizar a atividade - Parte 1 - Fonte: Brasil (2013)

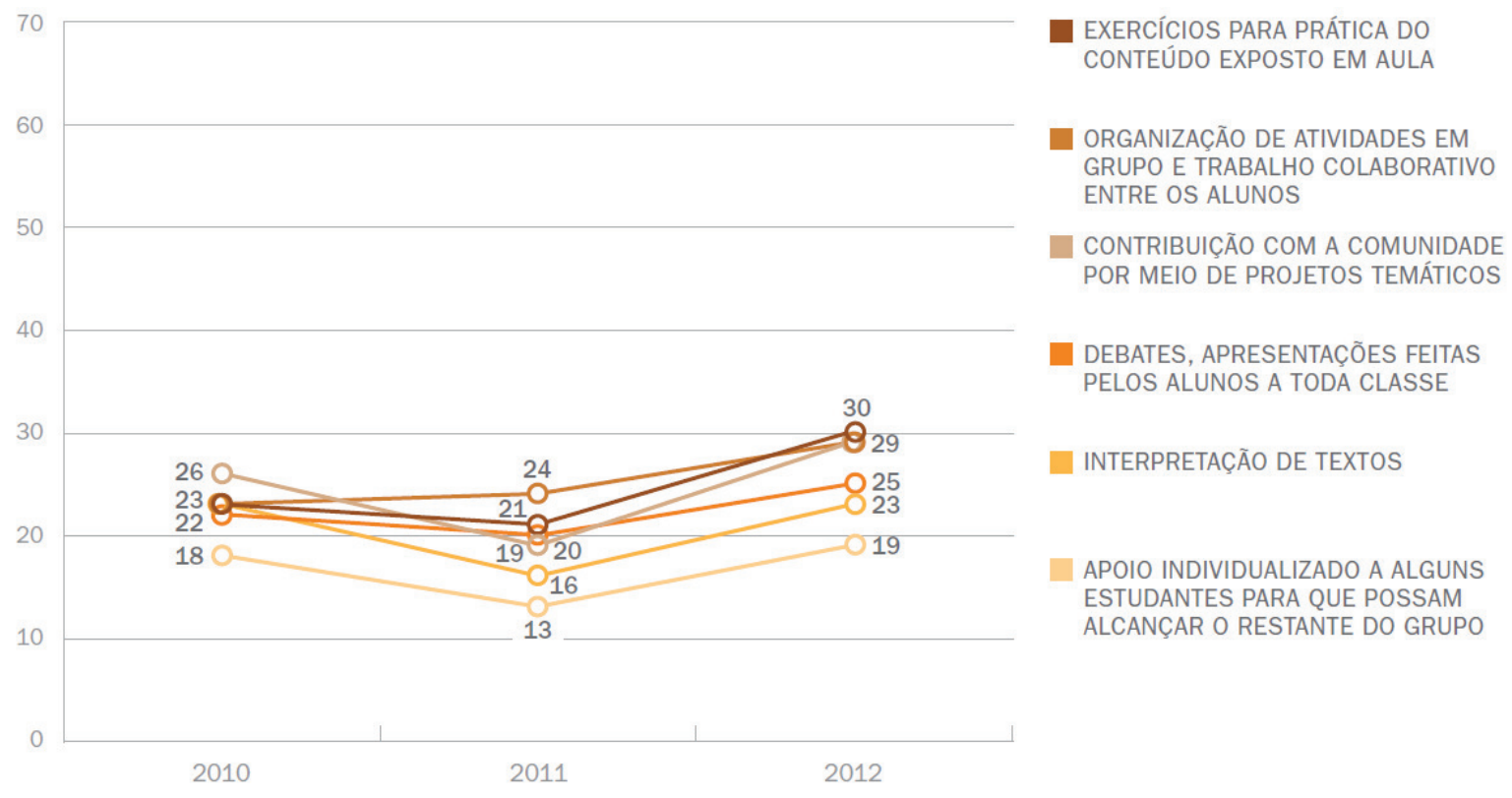

Figura 3.2: Proporção de professores de escolas públicas, por uso do computador e internet nas atividades realizadas com alunos - Percentual sobre o total de professores de escolas públicas que costumam realizar a atividade - Parte 2 - Fonte: Brasil (2013)

A pesquisa TIC Educação 2012 mostra que a proporção de alunos de escolas públicas que possuem computador em seu domicílio passou de 56\% em 2011 para 62\% em 2012. O gráfico da Figura 3.1 mostra uma tendência de queda na proporção de professores que nas atividades com alunos ensinam os alunos a utilizar computador e internet. 
Ou seja, o computador está cada vez mais fazendo parte do cotidiano dos alunos das escolas públicas.

\subsection{Os alunos das escolas brasileiras}

A pesquisa TIC Educação 2012 mostra claramente que houve aumento percentual no número de alunos da escola pública que declaram possuir computador em seu domicílio e ter acesso a internet, no período de 2010 a 2012. O acesso à internet passou de $44 \%$ em 2010 para 54\% em 2012. E o percentual de alunos de escolas públicas que declaram possuir computador em seu domicílio passou de $54 \%$ para $62 \%$ no mesmo período. Esse aumento no número de alunos de escolas públicas que declaram possuir computador em seu domicílio pode ser observado no gráfico da Figura 3.3. Já nas escolas particulares, $94 \%$ dos alunos declararam possuir computador em seu domicílio e 91\% dos alunos declararam que possuem acesso à internet em seu domicílio. Além disso, os dados da pesquisa TIC Educação 2012 mostram que 99\% dos alunos das escolas particulares têm acesso à internet.

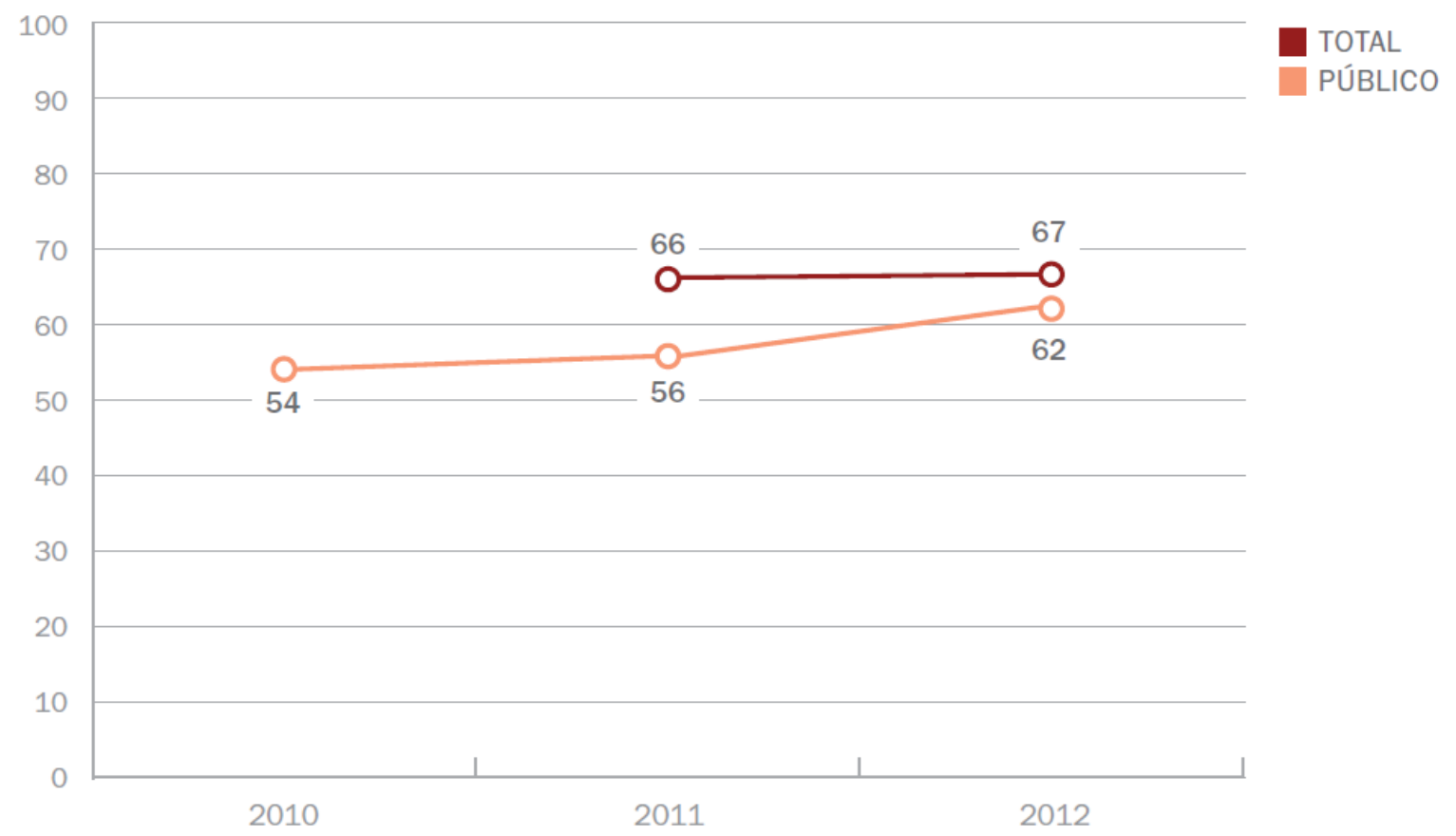

Figura 3.3: Proporção de alunos de escolas públicas que possuem computador em seu domicílio. Percentual sobre o total de alunos de escolas públicas - Fonte: Brasil (2013)

Escrever um texto utilizando um editor de texto é a atividade realizada no computador a qual alunos das escolas públicas apresentam menor dificuldade, sendo que $38 \%$ dos alunos do $5^{\circ}$ ano afirmaram que a fazem sem dificuldades. Já no $9^{\circ}$ ano e no Ensino Médio esse número atinge $67 \%$. 
A pesquisa TIC Educação 2012 mostra que 25\% dos alunos do $9^{\circ}$ ano e Ensino Médio das escolas públicas declararam que não têm dificuldade em trabalhar com planilhas eletrônicas. Porém, por outro lado, 31\% dos alunos não responderam a pergunta ou nunca utilizaram planilhas eletrônicas.

Os dados apresentados apontam para melhora no acesso a computadores e à internet, tanto nas escolas públicas, quanto nas escolas particulares. No que tange ao uso do computador, alunos e professores estão preparados para fazer amplo uso das possibilidades de aprendizagem que as novas tecnologias oferecem. 


\section{Capítulo 4}

\section{Geometria dinâmica e o GeoGebra}

Este capítulo inicia-se com considerações sobre geometria dinâmica, contemplando as vantagens de sua utilização em comparação com construções geométricas feitas com instrumentos tradicionais (lápis, régua, compasso, etc.). Em seguida, lista os principais softwares de geometria dinâmica com uma breve discussão de cada um. Finalmente, traz justificativas pela opção de uso neste trabalho do GeoGebra, acompanhada de uma descrição detalhada desse software.

\subsection{Geometria Dinâmica}

A Geometria, com seus postulados e teoremas, é compreendida de forma diferente por alunos diferentes. A capacidade de abstrair e imaginar construções mentais varia de aluno para aluno. Nesse contexto, construções feitas com lápis, papel e instrumentos de desenho atendem muito bem a demanda de alunos que dominam de forma satisfatória o entendimento e a abstração de postulados e teoremas da Geometria. Porém, não tem uma contribuição significativa para uma grande parcela dos alunos que precisa de algo mais concreto para compreender e abstrair de forma satisfatória.

As construções com lápis e papel são desprovidas de movimento e sua manipulação em geral é trabalhosa. O tempo usado nas construções poderia ser melhor aproveitado em observações, em manipulações, em formulação de hipóteses, etc. Assim sendo, ter algo que agilize as construções se torna importante para o ensino e principalmente para a aprendizagem dos alunos. No GeoGebra, as construções seguem o mesmo modelo da construção tradicional. A vantagem é que é feita uma construção que pode ser salva e editada posteriormente, de acordo com a necessidade. Vale salientar que as construções feitas no GeoGebra, respeitando-se as propriedades do processo construtivo, são facilmente manipuladas, o que permite dar grande ênfase ao fator movimento da construção. Ou seja, pode-se mudar a forma da construção sem alterar suas propriedades.

Além do mais, com o avanço das tecnologias, o acesso às informações e aos co- 
nhecimentos acumulados pela sociedade está cada vez mais fácil e rápido. Assim, não faz mais sentido entender o professor como centralizador, cuja autoridade é oriunda da posse do conhecimento. Atualmente, a escola está mais voltada para as aprendizagens, e nesse contexto, espera-se do professor um papel de mediação, motivação e mobilização dessas aprendizagens. Segundo Freire (1996):

\footnotetext{
Ensinar não é transferir conhecimento, mas criar as possibilidades para a sua própria produção ou a sua construção. Quando entro em uma sala de aula devo estar sendo um ser aberto a indagações, à curiosidade, às perguntas dos alunos, a suas inibições, um ser crítico e inquiridor, inquieto em face da tarefa que tenho - a ele ensinar e não a de transferir conhecimento.
}

Para assumir esse novo papel é necessário que o professor busque novas ferramentas e linguagens mais adequadas para uma aprendizagem mais construtiva e investigativa.

Nesse sentido, com o desenvolvimento da informática e com a melhoria da qualidade dos hardwares, foram desenvolvidos muitos softwares com foco em Geometria. Especificamente, este trabalho considera os softwares que são classificados como ambientes de geometria dinâmica. O termo "geometria dinâmica" é associado a softwares que permitem a criação e manipulação de figuras por meio de propriedades da Geometria. Não se trata de uma nova geometria e sim de novas ferramentas para o auxílio da aprendizagem da geometria euclidiana.

Em geral, os softwares de geometria dinâmica têm um princípio muito simples de funcionamento. Utilizam conceitos elementares de geometria como ponto, reta e segmento, e as construções baseiam-se no vínculo e dependência desses conceitos elementares. As manipulações características de um ambiente dinâmico carregam as propriedades estruturais da criação. Nesse sentido, é possível verificar as implicações em cada passo de manipulação e enxergar padrões com mais facilidade. Como exemplo, o quadrado da Figura 4.1 foi construído utilizando-se um software de geometria dinâmica, o GeoGebra, com o auxílio de uma circunferência e retas perpendiculares. Essa construção preserva as características do problema, ao aproximar ou distanciar o ponto B do ponto A, o quadrilátero continuará sendo um quadrado. Do lado esquerdo, vê-se a construção original, com os pontos A e B posicionados a uma distância de 7,84 $\mathrm{cm}$, enquanto que do lado direito, o ponto B foi arrastado de modo que ficasse a uma distância de 11,22 cm do ponto A. É interessante notar que os pontos C e D acompanharam o deslocamento e o quadrilátero ABCD continuou sendo um quadrado. Ou seja, o GeoGebra é dinâmico e mantém as propriedades da construção. Esse dinamismo favorece o processo de ensino e aprendizagem. 


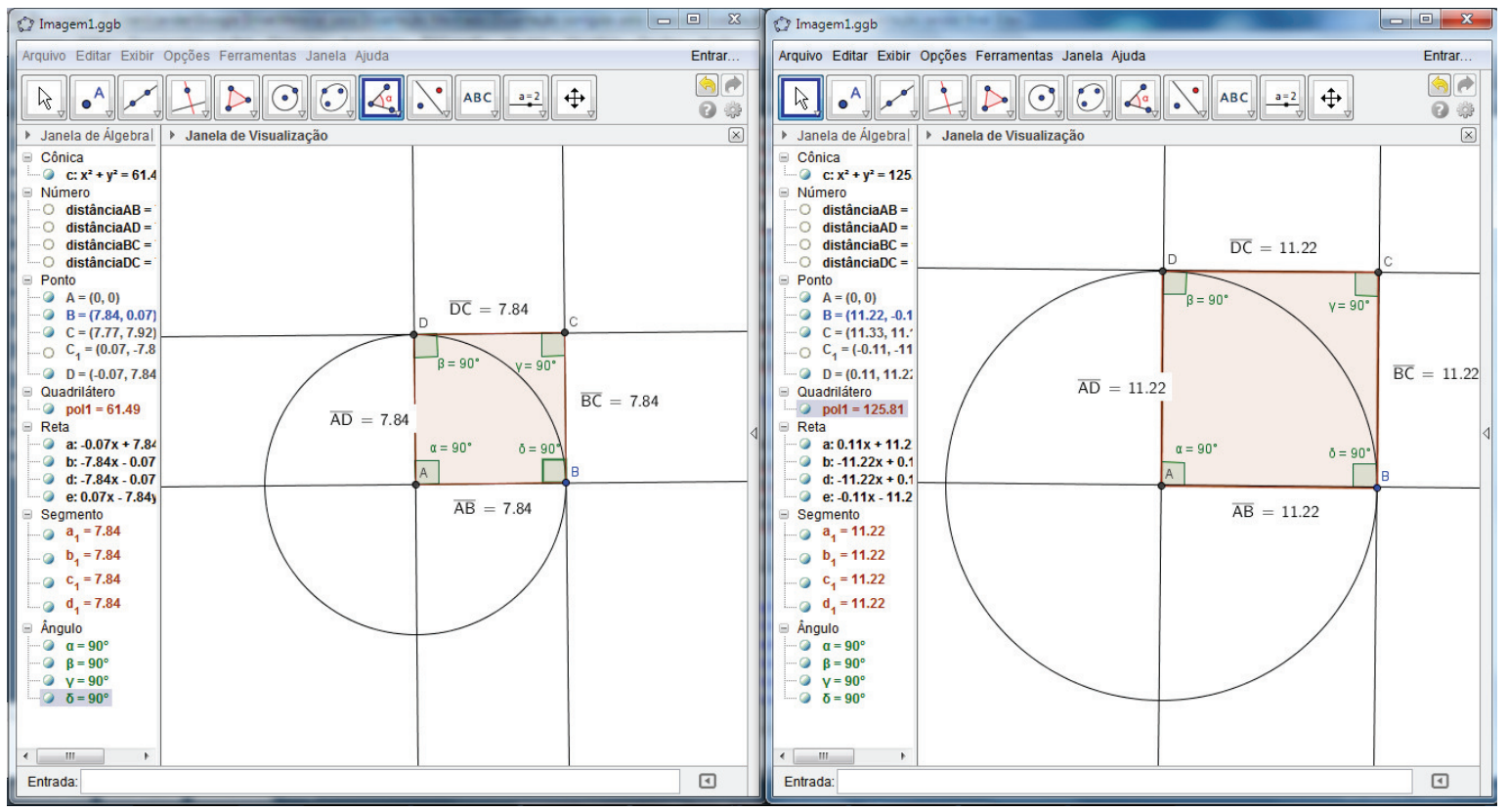

Figura 4.1: Quadrado construído no GeoGebra utilizando-se circunferência e retas perpendiculares

\subsection{Softwares de geometria dinâmica}

Existem muitos softwares de geometria dinâmica disponíveis e que atendem satisfatoriamente as necessidades de professores e alunos em sala. Em geral, não têm um bom apelo comercial e são desenvolvidos e mantidos por universidades. Por esse motivo, a maior parte é do tipo freeware, ou seja, de acesso gratuito para uso de quem precise. Os softwares também podem ser livres ou do tipo shareware. Vejamos na sequência uma breve descrição desses três tipos principais:

- Softwares Livres - É uma definição criada pela Free Software Foundation, para softwares que podem ser utilizados, copiados, redistribuídos e modificados sem nenhum tipo de custo ou restrição. Uma das vantagens é que qualquer pessoa pode modificá-lo, o que em geral traz benefícios para toda a sociedade.

- Softwares Gratuitos ou Freeware - São distribuídos gratuitamente, mas que diferentemente dos softwares livres não podem ser modificados e redistribuídos. Em geral, eles não expiram e são disponibilizados por download na internet.

- Softwares Shareware - São gratuitos para uso, mas com algum tipo de limitação. As limitações podem ser de tempo de uso ou de funcionalidades. São geralmente utilizados para divulgação, com o objetivo do usuário testá-lo antes da aquisição. 
A seguir, o texto apresenta alguns dos softwares de geometria dinâmica mais utilizados, bem como uma breve descrição de cada um deles.

\subsubsection{Régua e compasso}

Do tipo freeware, o software Régua e Compasso (C.a.R., sigla em inglês) foi desenvolvido pelo Professor René Grothmann, da Universidade Católica de Berlim, na Alemanha. É um software de geometria dinâmica plana que funciona em qualquer plataforma. Diversos trabalhos acadêmicos são realizados utilizando esse software, entre eles Gonçalves (2009), que fez um estudo sobre as potencialidades do software régua e compasso. A Figura 4.2 mostra a tela inicial do Régua e Compasso com exemplos de construções geométricas feitas no software.

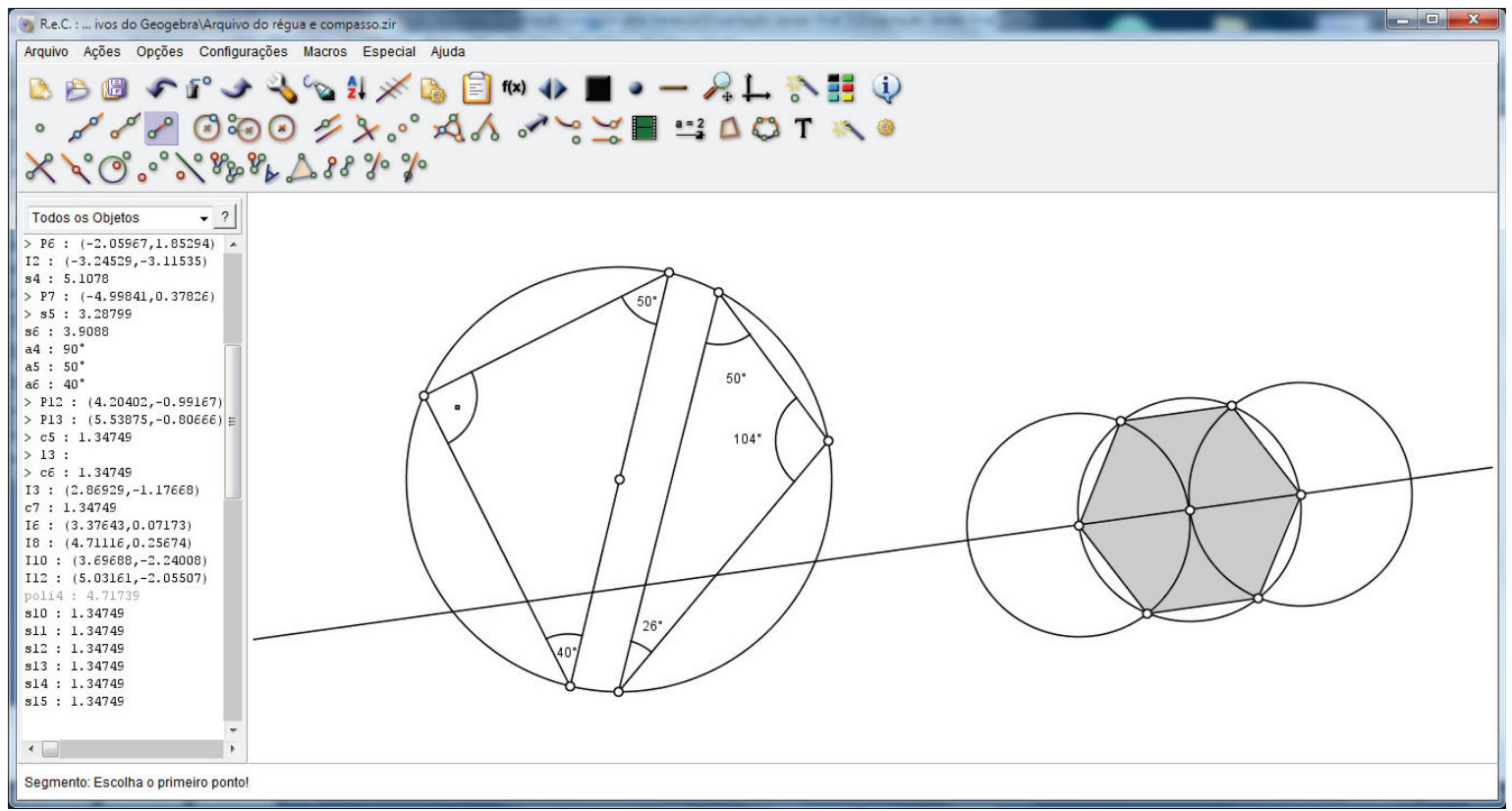

Figura 4.2: Tela inicial do Régua e Compasso com exemplos de construções geométricas

\subsubsection{Tabulae}

O Tabulae é um software do tipo freeware que permite gerar applets ${ }^{1}$ que podem ser usados como ferramenta de autoria para redes locais e através da internet. Por ser escrito na linguagem Java, apresenta a facilidade de ser compatível com diferentes sistemas operacionais, tais como Windows, Linux e Macintosh. No trabalho Geometria Dinâmica: um estudo de seus recursos, potencialidades e limitações através do software Tabulae, Alves (2003) mostra os principais recursos, potencialidades e limitações da

\footnotetext{
${ }^{1}$ Uma applet é uma pequena aplicação executada em uma janela de uma aplicação. Tem por finalidade estender as funcionalidades de browsers, adicionando som, animação, etc.
} 
geometria dinâmica através do software Tabulae. A Figura 4.3 mostra a tela inicial do Tabulae e exemplos de construções geométricas que foram feitas no software.

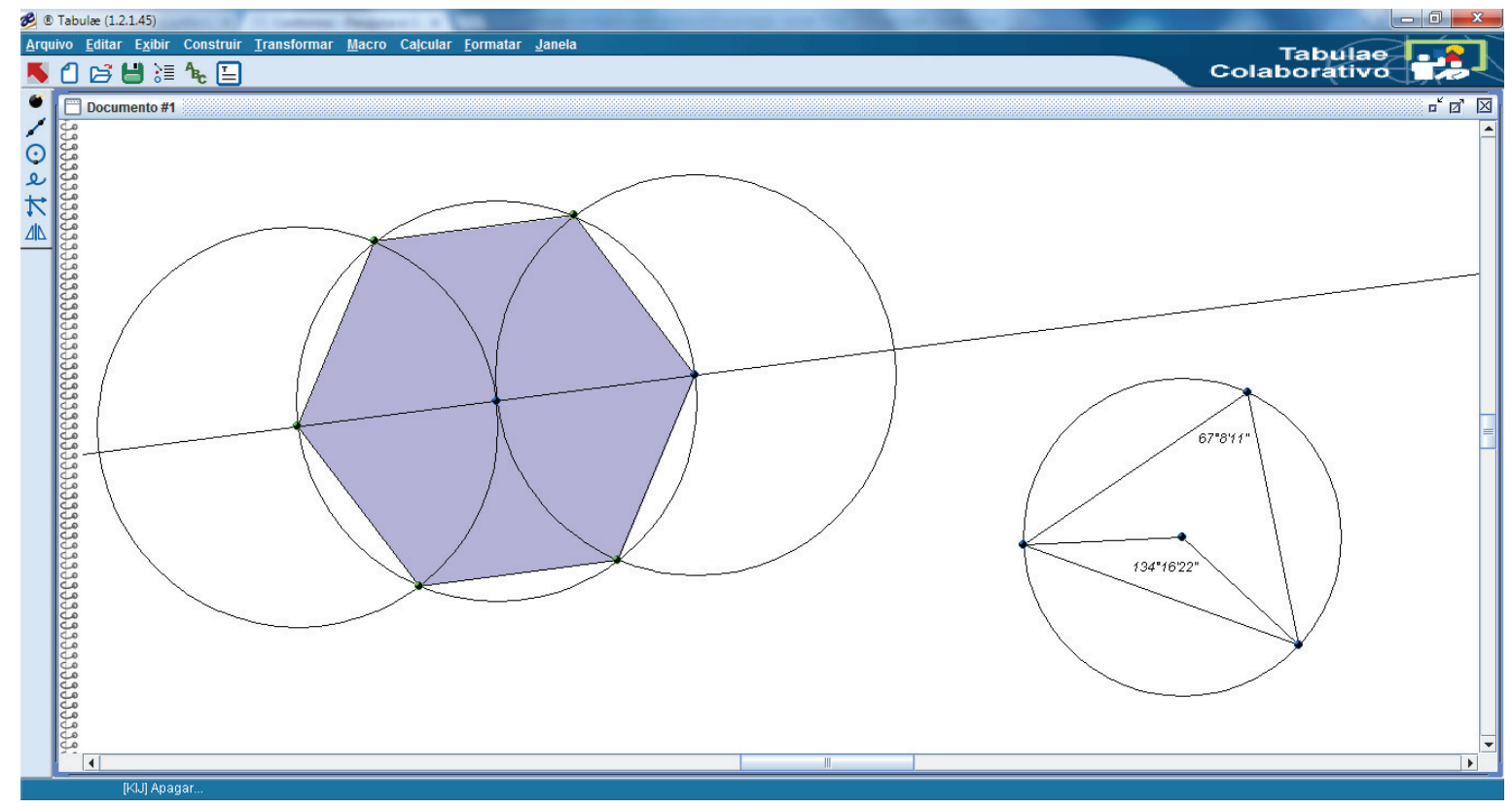

Figura 4.3: Tela inicial do Tabulae com exemplos de construções geométricas

\subsubsection{Cabri-Géomètre}

Cabri é a abreviatura de Cahier de Brouillon Interactif(Caderno de Rascunho Interativo). Cabri-Géomètre é um software de geometria dinâmica do tipo shareware desenvolvido pelo Institut d'Informatiqe et de Mathematiques Appliquees em Grenoble (IMAG) e é o resultado da colaboração de cientistas da informática, especialistas em educação e professores. Cabri-Géomètre é marca registrada da Universidade Joseph Fourier. É um software de construção que nos oferece régua e compasso eletrônicos, sendo a interface de menus de construção em linguagem clássica da geometria. Dentre vários trabalhos que abordam as potencialidades do Cabri-Géomètre, podemos citar Brandão (2004) que fez um estudo sobre as pontencialidades do software. A Figura 4.4 mostra a tela inicial do Cabri-Géomètre e exemplos de construções geométricas que foram feitas no software.

\subsubsection{Cinderella}

O Cinderella é um software de geometria dinâmica desenvolvido por Jürgen RichterGebert \& Ulrich Kortenkamp e comercializado por Sun Microsystems, Inc. Permite a construção e manipulação de formas planas em geral, de cônicas e de fractais. Além da Geometria Euclidiana, o software permite o trabalho com as geometrias hiperbólica e 


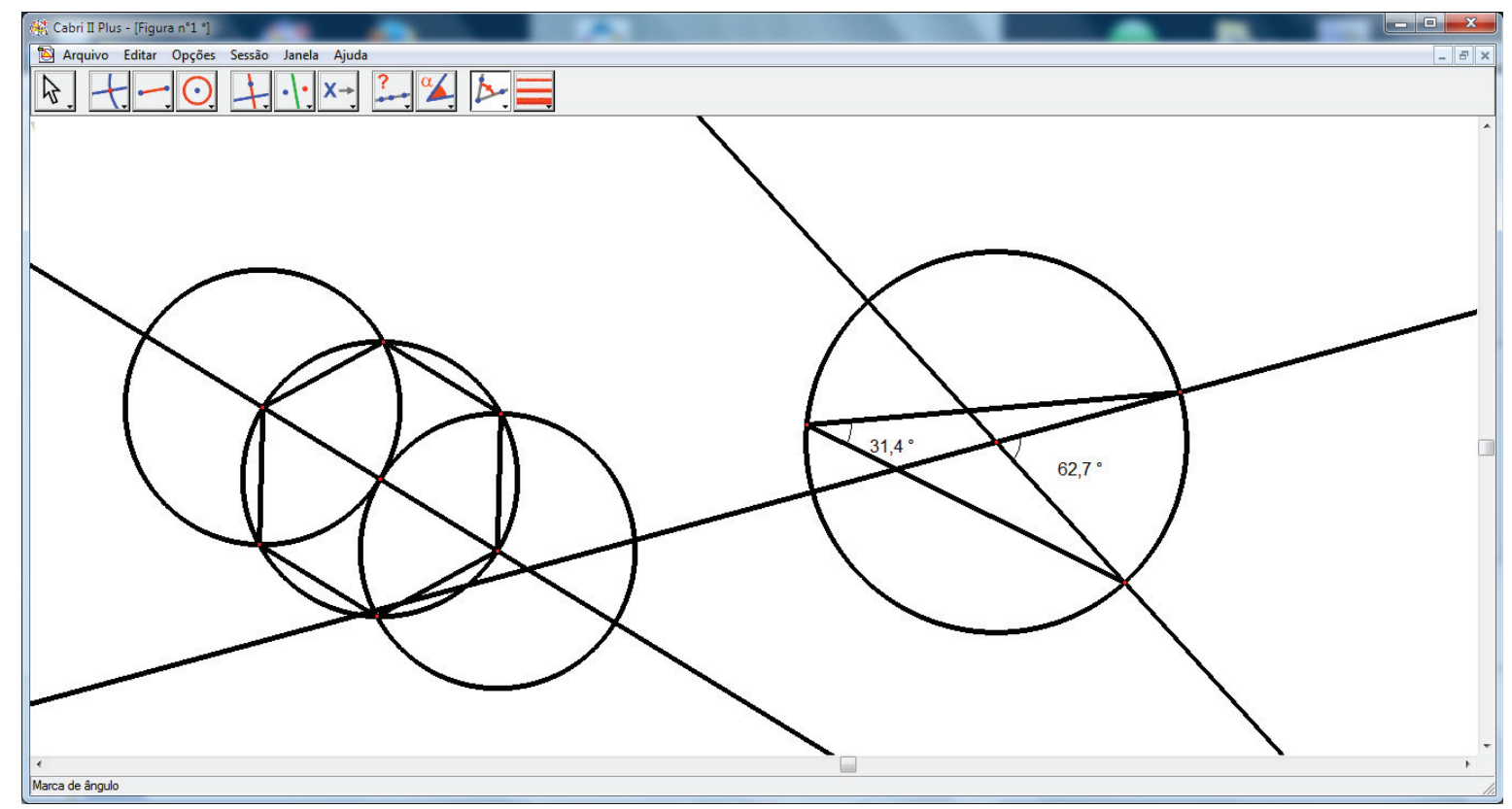

Figura 4.4: Tela inicial do Cabri-Géomètre com exemplos de construções geométricas

esférica. Rocha e Miranda (2011) apresentam uma sequência didática para o estudo da geometria hiperbólica. A Figura 4.5 mostra a tela inicial do Cinderella e exemplos de construções geométricas que foram feitas no software. Do lado esquerdo, visualiza-se a construção do ponto de vista Euclidiano e, do lado direito-se visualiza-se a mesma construção através do ponto de vista Esférico.

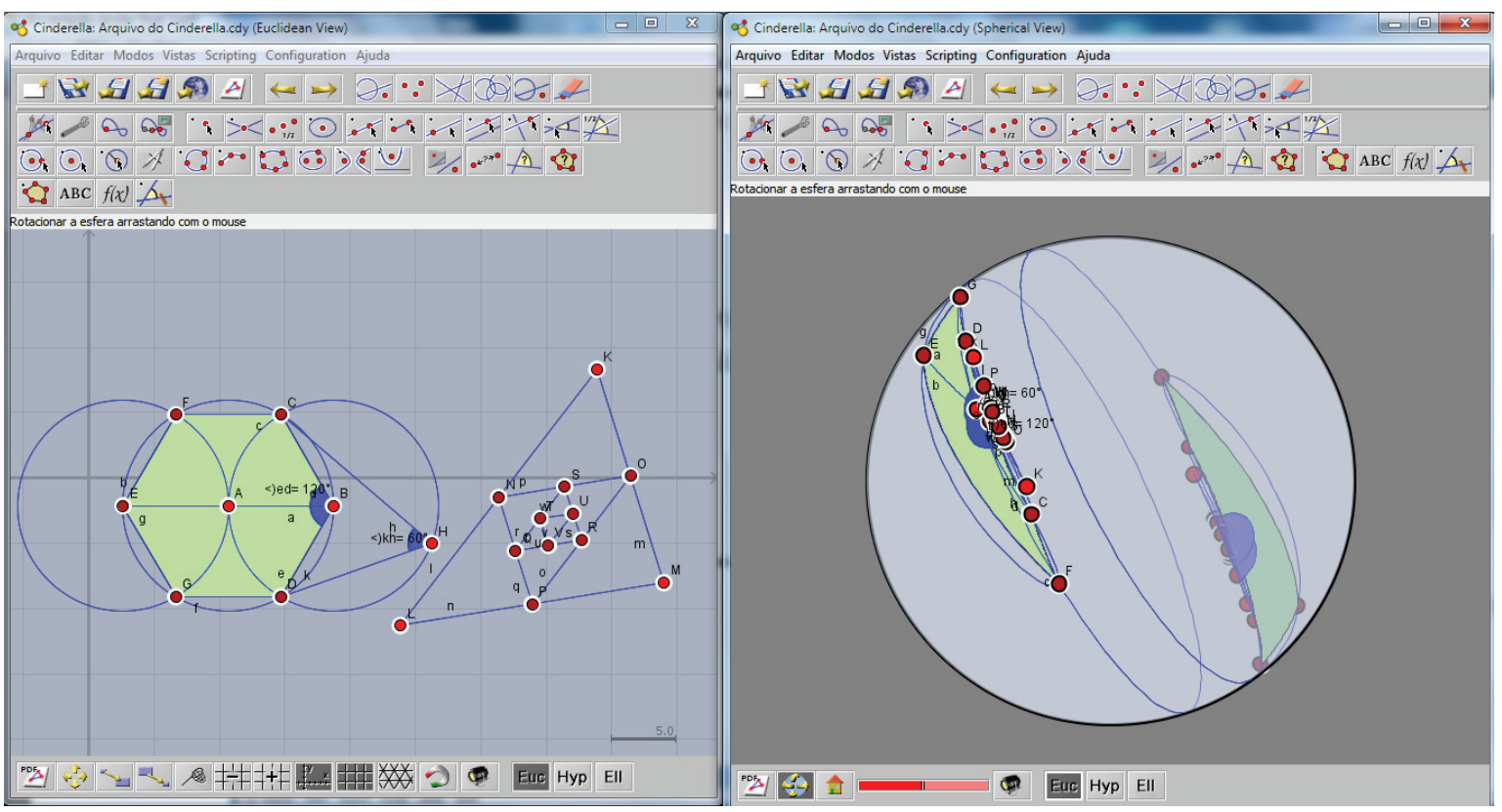

Figura 4.5: Tela inicial do Cinderella com exemplos de construções geométricas 


\subsubsection{GeoGebra}

O GeoGebra é um software de geometria dinâmica do tipo freeware que relaciona Geometria, Álgebra e Cálculo. Foi desenvolvido em 2001 pelo professor austríaco Markus Hohenwarter e uma equipe internacional de programadores, com objetivo de servir como ferramenta para aprender e ensinar Matemática.

A opção pelo GeoGebra para execução deste projeto se deve a três fatores: as experiências do autor com a utilização desse software em sala de aula para no estudo de propriedades da Geometria e gráficos de funções; ao fato de ser um software livre e, por atender especificamente as particularidades do projeto. A seguir, esse software é detalhado.

GeoGebra é uma fusão entre as palavras geometria e álgebra, por trabalhar com esses dois conceitos em uma só ferramenta. Ele foi inicialmente desenvolvido em 2001 pelo Professor Markus Hohenwarter, para ser utilizado em ambiente de sala de aula. Assim como muitos softwares, o GeoGebra surgiu de necessidades específicas e devido à sua qualidade, acabou sendo disponível para toda a sociedade. Koch e Ghiggi (2013) afirmam que atualmente o GeoGebra é utilizado em 190 países e está disponível em 55 idiomas. Além disso, conta com 62 Institutos que dão suporte para seu uso em 44 países. É um software livre e por estar escrito em Java, está disponível em várias plataformas. Outra grande vantagem para os dias atuais é que o GeoGebra pode ser utilizado em tabletes. Por ser um software muito popular, existem muitos tutoriais disponíveis sobre sua utilização, além de contar com um fórum permanente na página oficial do software (www.geogebra.org). Relacionados com este trabalho, Lima (2013) e Lopes Júnior (2013) apresentam considerações sobre aplicações do GeoGebra no estudo de funções.

Para ter acesso ao software, basta acessar o link: http://www.geogebra.org/cms/ ptbr/ download/, escolher a plataforma, baixar o arquivo de instalação e seguir os passos de instalação. Este trabalho utilizou a versão 4.4.45.0 do GeoGebra para Windows.

\subsection{Explorando o GeoGebra}

A Figura 4.6 mostra a tela incial do GeoGebra com um exemplo de construção. A construção refere-se a uma verificação do Teorema de Pitágoras. A tela está dividida em 5 campos: barra de menus, barra de ferramentas de acesso rápido, janela de álgebra, janela de visualização e caixa de entrada. Verifica-se que é um layout propício para construções geométricas, visto que a parte algébrica e visual estão lado a lado. 


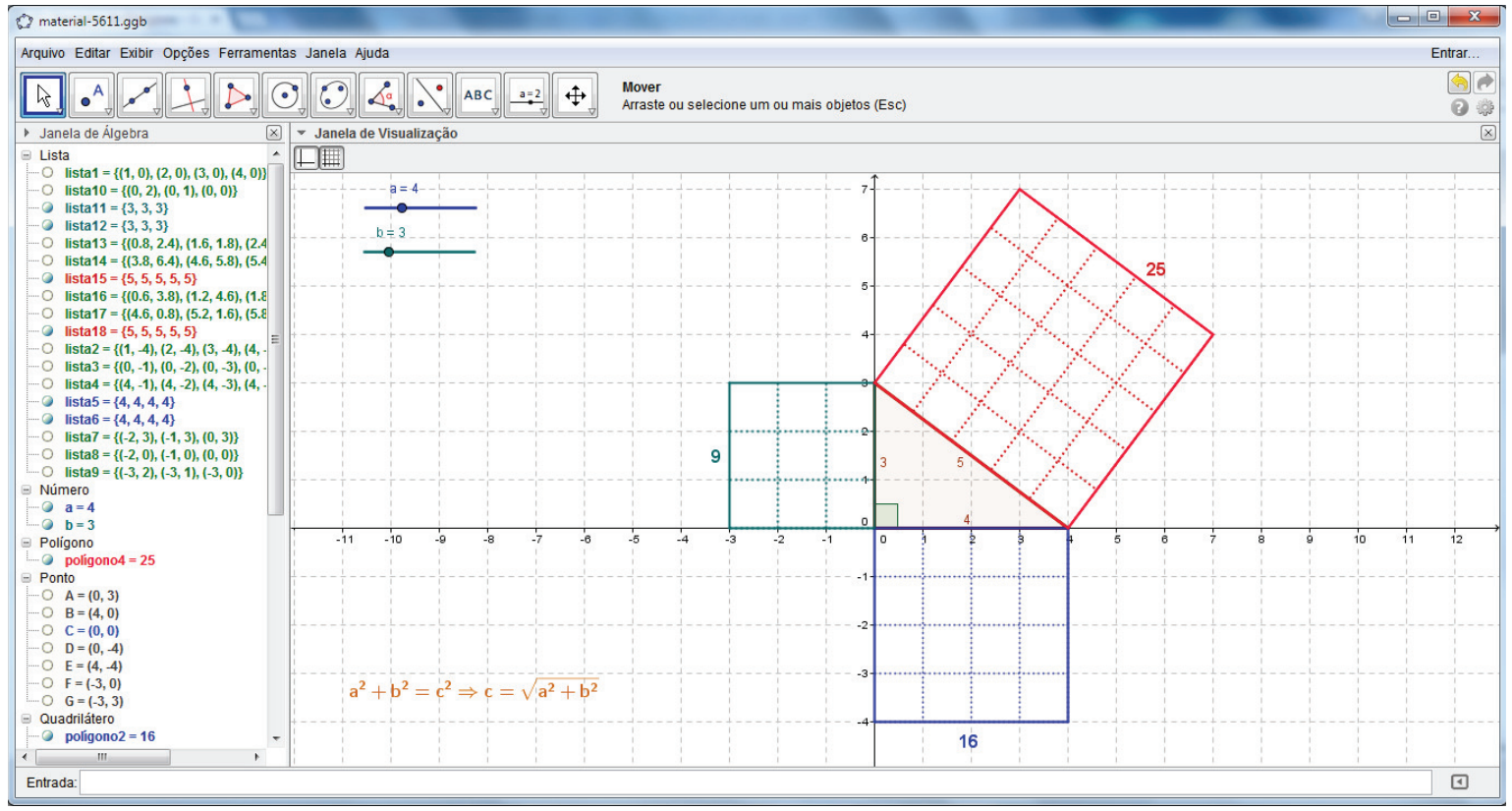

Figura 4.6: Tela inicial do GeoGebra mostrando uma verificação do Teorema de Pitágoras - Fonte: www.tube.geogebra.org/material/show/id/5611

Os campos da tela inicial têm as seguintes funcionalidades:

- Barra de menus (Figura 4.7): disponibiliza funções para salvar o projeto e controlar configurações gerais. Nela estão disponíveis as funções: Arquivo, Editar, Exibir, Opções, Ferramentas, Janela e Ajuda.

- Barra de ferramentas de acesso rápido (Figura 4.8): possui 12 grupos de botões, cada grupo é associado a um conjunto de funções(botões) relacionadas a construções: ponto, reta, triângulo, círculo, polígonos, etc. Neste trabalho, os botões são denominados por seu nome completo disponível no GeoGebra. Essas denominações são utilizadas nas construções das atividades dos capítulos 5-7 e são visualizadas nas Figuras 4.9-4.12. Nas Figuras 4.9-4.12 cada grupo de botões será representado pelo primeiro botão do grupo disponível no GeoGebra.

- Janela de álgebra (Figura 4.13): localizada na terceira linha da tela, disponibiliza todas as informações algébricas das construções. Todas as construções do GeoGebra são feitas tendo o plano cartesiano como referência.

- Janela de visualização (Figura 4.14): localiza-se ao lado da Janela de álgebra, mostra a parte gráfica da construção. Tudo o que for construído poderá ser visto nesta janela.

- Caixa de Entrada: (Figura 4.15) Localizada na parte inferior da tela, consiste em uma linha para digitação de comandos com informações algébricas da construção que deseja realizar. É muito útil para se fazer construções com precisão. 


\section{Arquivo Editar Exibir Opções Ferramentas Janela Ajuda}

Figura 4.7: Barra de menus

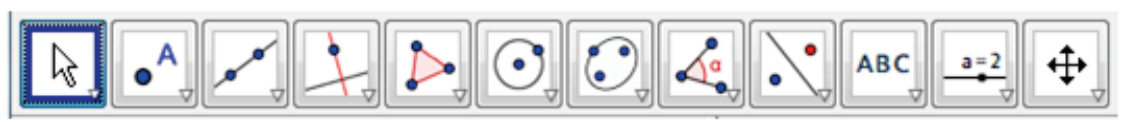

Figura 4.8: Barra de ferramentas de acesso rápido

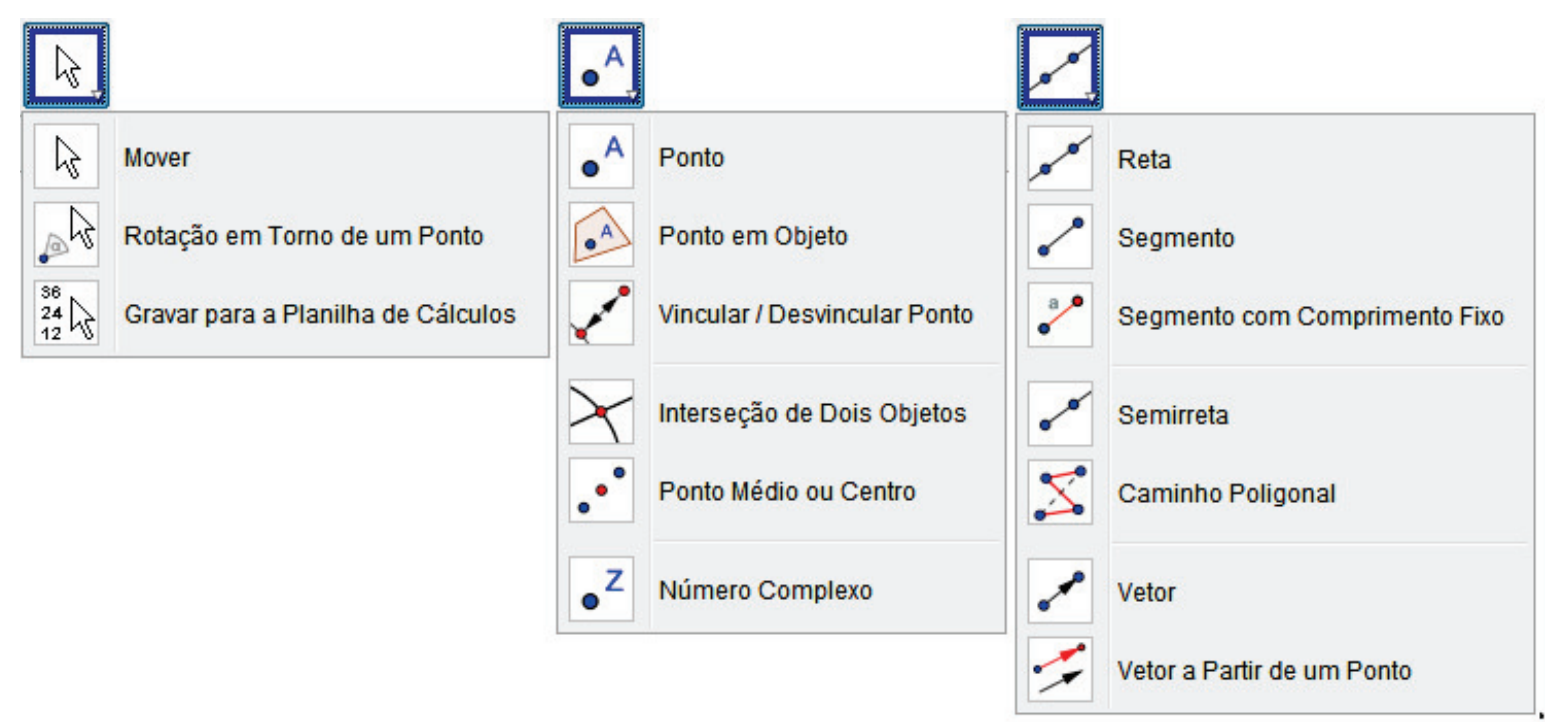

Figura 4.9: (esquerda) Grupo Mover, (centro) Grupo Ponto e (direita) Grupo Reta

No GeoGebra, o botão direito do mouse é utilizado para acessar propriedades de objetos específicos. Ao acionar o botão direito sobre um objeto, abre-se uma janela com opções e propriedades referentes ao objeto em destaque. Vejamos na Figura 4.16 a janela com as opções e propriedades referentes ao ponto A.

O GeoGebra, apesar de ser um ambiente de fácil utilização, com botões, menus, barras de ferramentas, etc., possui algumas peculiaridades, em especial no que se trata de digitar comandos na Caixa de Entrada, e verificar graficamente o que foi gerado. Quando o aluno digita informações na Caixa de Entrada, está trabalhando com uma abordagem algébrica. Nesse sentido, é necessário que o aluno tenha conhecimentos básicos de trigonometria para conseguir construir os objetos com precisão e de forma que funcionem conforme o esperado. Mas, não tendo esses conhecimentos básicos, o aluno terá, com o auxílio do professor, a possibilidade de trabalhar tendo o erro como aliado. Digitar comandos de forma incorreta pode ser uma ferramenta de aprendizagem ao passo que se faz correção e verificação. 


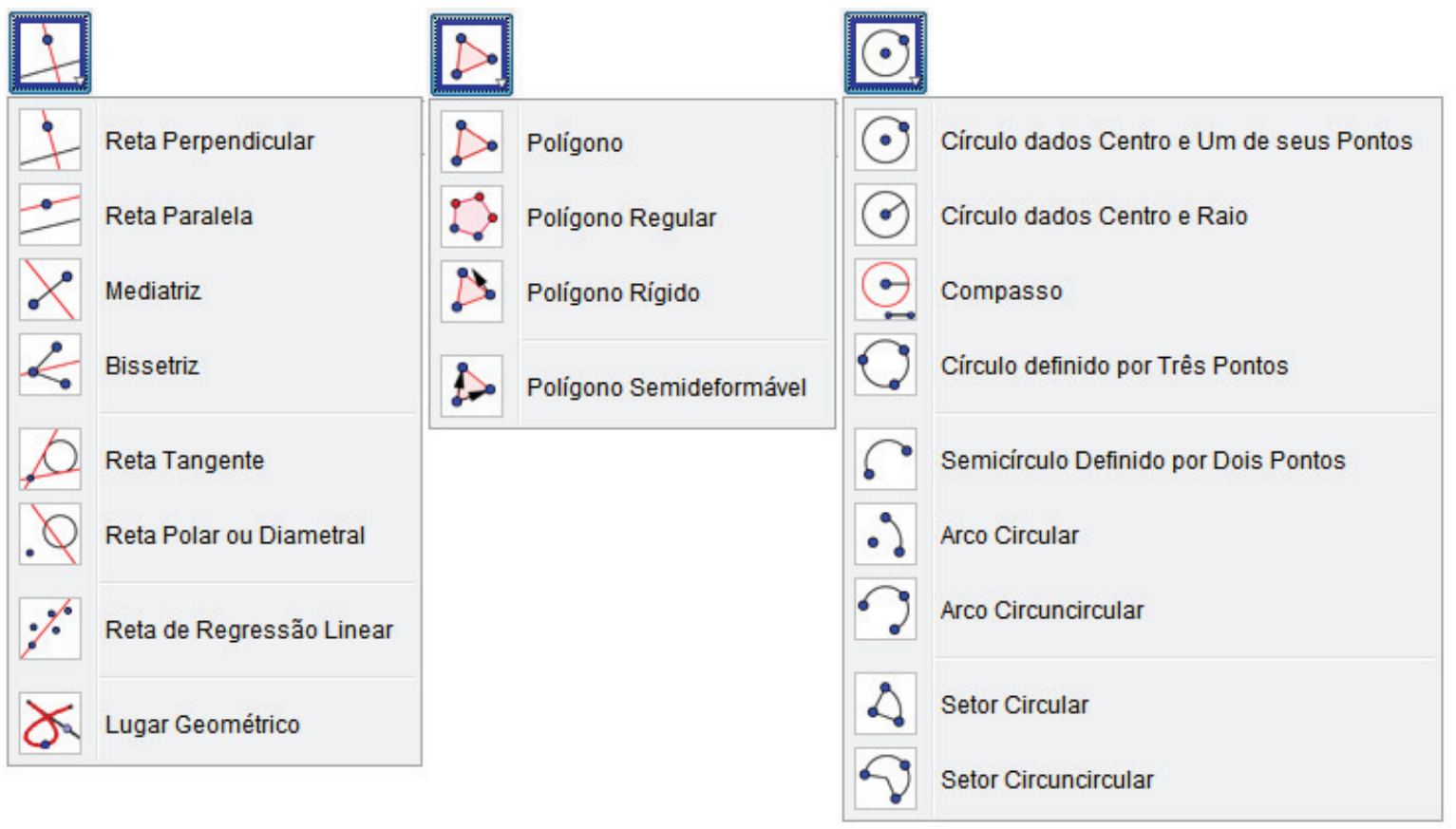

Figura 4.10: (esquerda) Grupo Reta Perpendicular, (centro) Grupo Polígono e (direita) Grupo Círculo Dados Centro e Um de Seus Pontos

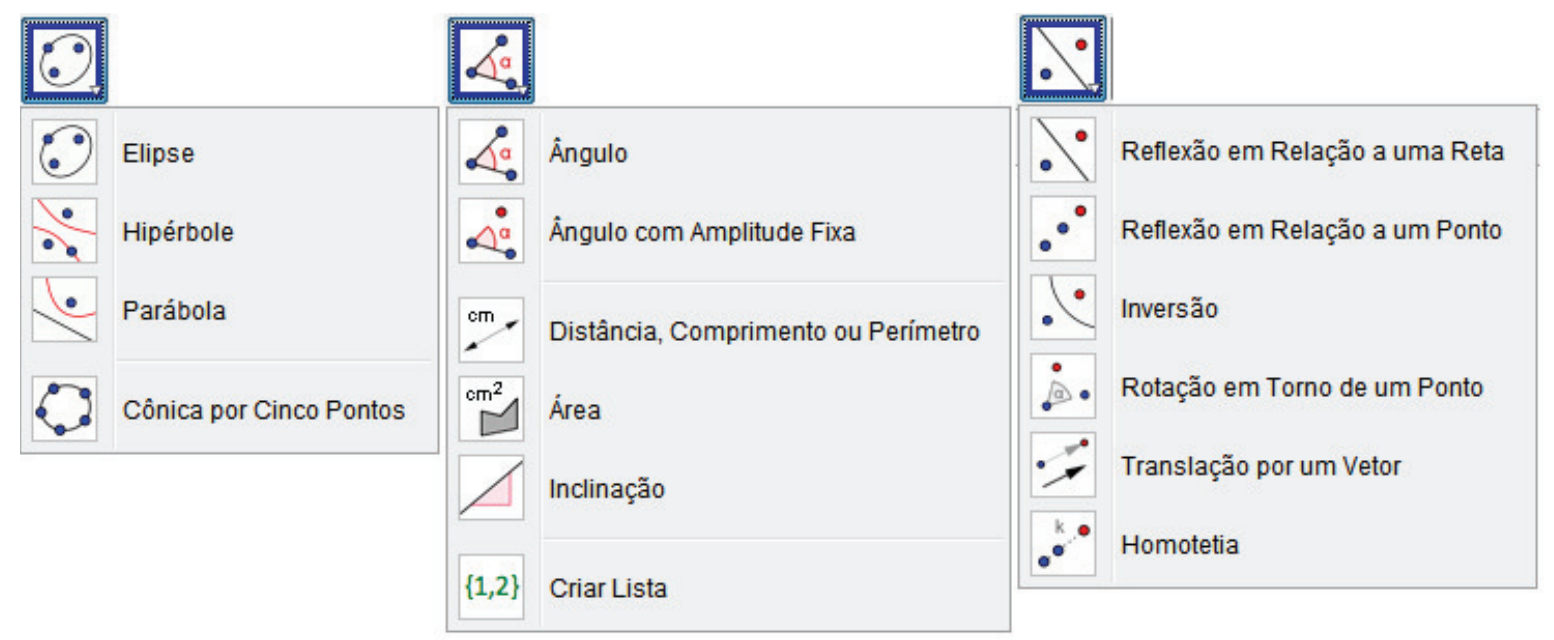

Figura 4.11: (esquerda) Grupo Elipse, (centro) Grupo Ângulo e (direita) Grupo Reflexão em Relação a Uma Reta

Geometria dinâmica está relacionada com movimento. No GeoGebra, duas funções destacam essa característica: Mover e animar. Mover significa alterar a forma sem alterar as características iniciais da construção. Neste trabalho, a translação completa do objeto construído não será entendida como ação da função mover, uma vez que há preservação total do objeto construído. Suponhamos que sejam marcados os pontos não colineares $\mathrm{A}, \mathrm{B}$ e $\mathrm{C}$. Com estes pontos, é construído o triângulo ABC. Com a função mover, é possível arrastar os pontos A, B ou C, de forma que se altere a forma, mas que seja mantido o formato de triângulo. É possível também, nesse caso, arrastar 


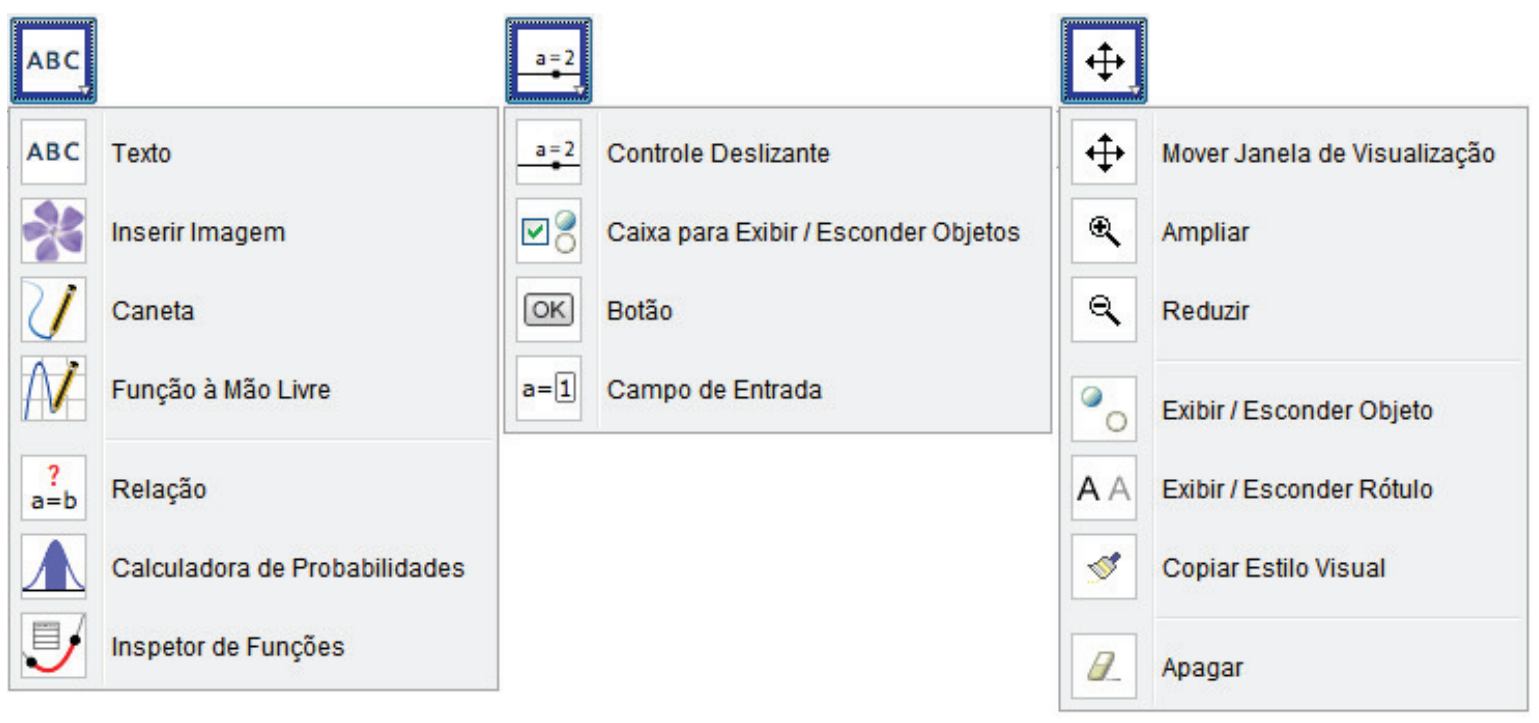

Figura 4.12: (esquerda) Grupo Texto, (centro) Grupo Controle Deslizante e (direita) Grupo Mover Janela de Visualização

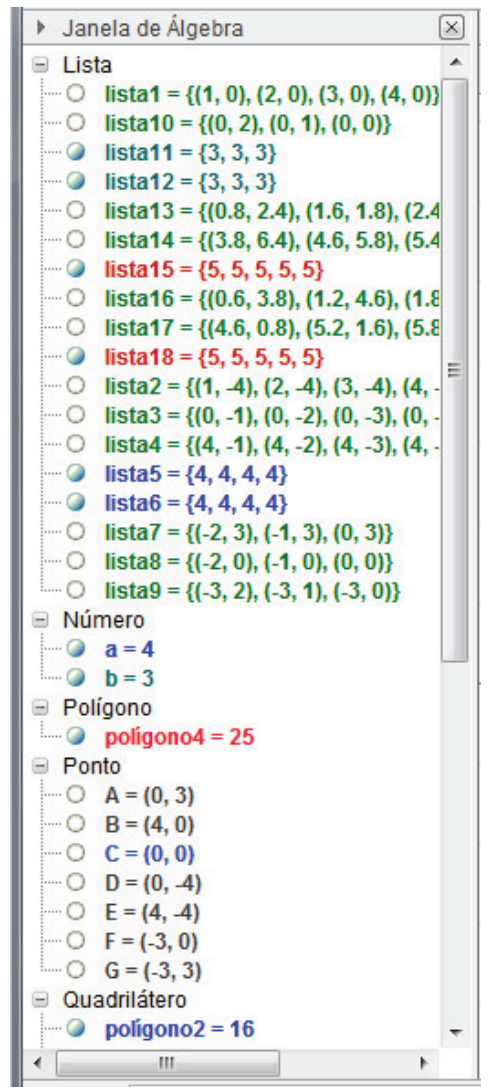

Figura 4.13: Janela de álgebra

os segmentos $\mathrm{AB}, \mathrm{BC}$ ou $\mathrm{CA}$ de forma que seja mantido o formato de triângulo. Já a função animar pode ser entendida como um "arrasto" ordenado. É utilizado com a função controle deslizante, que fornece um parâmetro para a construção ou quando se tem um ponto livre sobre o objeto. Para exemplificar o caso em que é utilizado o 


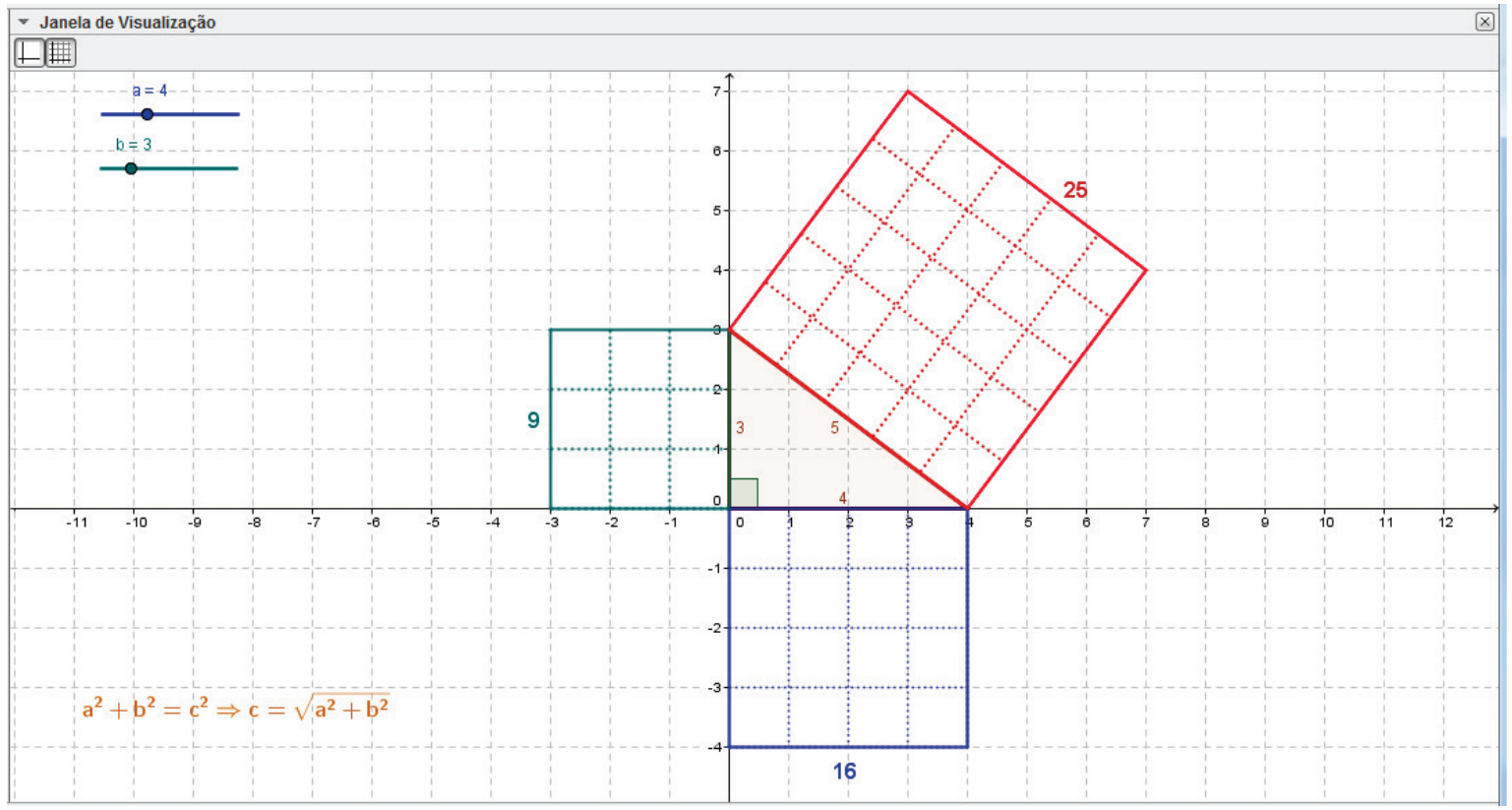

Figura 4.14: Janela de visualização

Figura 4.15: Caixa de entrada

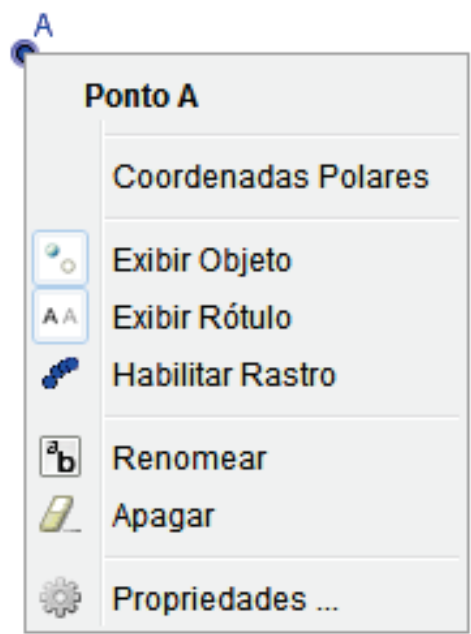

Figura 4.16: Opções e propriedades do botão direito, referentes ao ponto A

controle deslizante, suponhamos que seja construído o ponto A de coordenadas (a,5). Com o controle deslizante, é possível estabelecer um intervalo para o valor de a. Consideremos que seja definido o intervalo [-5,5]. Assim, o ponto A(a,5) pode ser qualquer ponto do segmento formado pelo pontos $(-5,5)$ e $(5,5)$. Escolhendo-se a função animar o ponto $\mathrm{A}$, o representante gráfico de $\mathrm{A}(\mathrm{a}, 5)$ será um ponto que percorrerá automaticamente toda a extensão(ida e volta) do segmento formado pelos pontos $(-5,5)$ e $(5,5)$. 
Esse movimento de vai e vem do ponto só cessará quando a função Animar for cessada. A visualização desse movimento ajudará o aluno a compreender o significado de parâmetro. Por outro lado, entendamos como ponto livre sobre objeto, o ponto que pode assumir outras posições nesse objeto, e que não esteja travado com nenhum outro elemento da construção. Nesse caso, deve-se clicar com o botão direito do mouse sobre o ponto e escolher "Animar". Assim, o ponto se movimentará automaticamente, em ritmo contínuo sobre o objeto, assumindo as outras posições possíveis sobre esse.

O rastro é outra função importante do GeoGebra. O Rastro marca o caminho percorrido pelo objeto o qual pode ser um ponto, um segmento, uma reta, ou até a construção inteira. A Figura 4.17 mostra uma construção no GeoGebra na qual se tem uma circunferência com um ponto D sobre ela. Fora da circunferência, observa-se o ponto fixo C. Foi construído o segmento DC. Foram habilitados o rastro do segmento DC e a animação do ponto D. Com isso, o ponto D percorre toda extensão da circunferência, o que gera alterações de comprimento e posição do segmento DC. Como o rastro do segmento DC foi habilitado, foi marcada a superfície por onde se locomoveu o segmento DC.

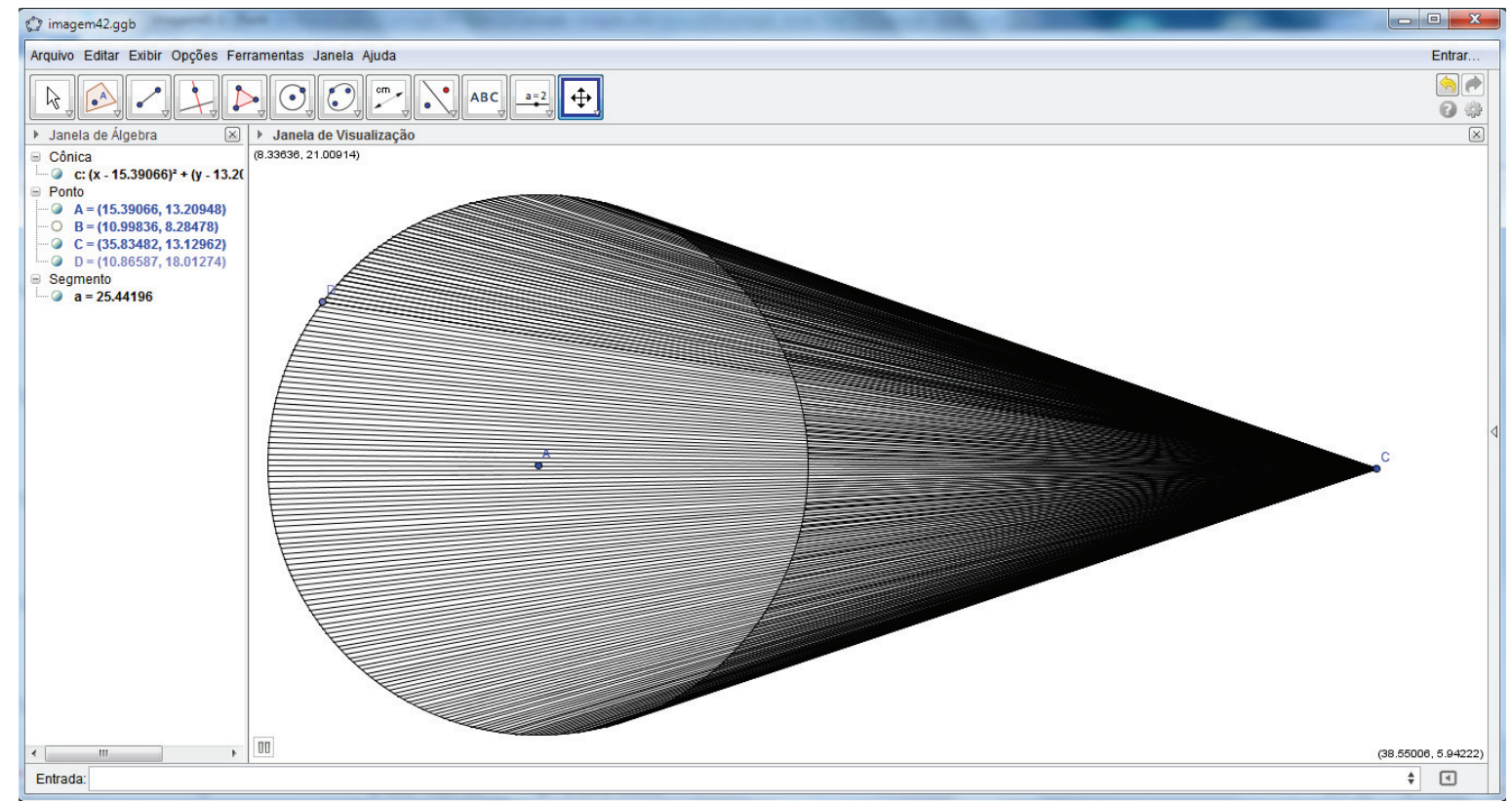

Figura 4.17: Rastro de segmento habilitado

Este trabalho não tem o objetivo de fazer um tutorial para utilização do GeoGebra. No entanto, a proposta é detalhar passo a passo cada atividade. Assim, nos Capítulos 5 - 7, nos quais as atividades são apresentadas, conforme novas ferramentas são utilizadas, são disponibilizados os comentários pertinentes. Vários vídeos e tutoriais podem ser encontrados facilmente em uma rápida pesquisa na internet. 


\section{Capítulo 5}

\section{Trigonometria básica com o auxílio do GeoGebra}

Série de aplicação das atividades: De acordo com São Paulo(2012), as atividades propostas neste capítulo são indicadas para a $2^{\mathrm{a}}$ série do ensino médio para o estudo de fenômenos periódicos.

Neste capítulo são apresentadas três atividades:

- Atividade 1 - Construindo uma circunferência - Medidas de arcos;

- Atividade 2 - Construindo a circunferência trigonométrica;

- Atividade 3 - Definindo a tangente na circunferência trigonométrica.

São atividades elementares voltadas para um primeiro contato dos alunos com ferramentas e funções do GeoGebra. Para serem utilizadas em sala de aula, as atividades deste capítulo não dependem de grande conhecimento das potencialidades e aplicações do GeoGebra, mas sim de conceitos elementares de Geometria euclidiana. Neste capítulo, os alunos já poderão utilizar o botão "Mover" para arrastar elementos e verificar que as características iniciais da construção são mantidas.

\subsection{Atividade 1 - Construindo uma circunferência - Medidas de arcos}

Seja uma circunferência de centro $O$ e raio 1. Sobre essa circunferência são marcados os pontos distintos $\mathrm{A}$ e B. Se o segmento $\mathrm{AB}$ não coincidir com um diâmetro dessa circunferência, teremos dois arcos $\mathrm{AB}$ de comprimentos diferentes. Nesse ponto, surge uma dúvida: como medir esses arcos? Nesta atividade, o GeoGebra auxilia mostrando 
duas maneiras de mensurar arcos. A primeira maneira relaciona a medida do arco com a abertura do ângulo central correspondente, ou seja, o ângulo AÔB. A segunda maneira relaciona o comprimento do arco com a medida do raio da circunferência, que no caso da circunferência trigonométrica sempre será igual a 1. Na primeira maneira, a unidade de medida será o grau e, na segunda, o radiano. Nas construções, é importante que antes de cada passo o botão "Mover" esteja selecionado.

\subsubsection{Passo a passo da construção - $1^{\mathrm{a}}$ Parte - Graus}

Este passo a passo mostra uma construção no GeoGebra na qual é possível visualizar a associação entre arco e ângulo central.

- Passo 1: Construir uma circunferência de raio 1. Para isso, clique no botão "Círculo Dados Centro e Raio" e construa uma circunferência de raio 1. Renomeie o centro da circunferência como O. Para renomear, basta clicar com o botão direito do mouse sobre o ponto e escolher "Renomear";

- Passo 2: Construir pontos sobre a circunferência. Para isso, clique no botão "Ponto em Objeto" e construa sobre a circunferência os pontos distintos A e B;

- Passo 3: Construir os segmentos OA e OB. Para isso, clique no botão "Segmento" e clique nos pontos $\mathrm{A}$ e $\mathrm{O}$ e, em seguida, nos pontos $\mathrm{O}$ e B;

- Passo 4: Medir o ângulo central AÔB. Para isso, clique no botão "Ângulo" e clique respectivamente nos pontos $\mathrm{A}, \mathrm{O}$ e $\mathrm{B}$;

- Passo 5: Identificando o menor arco AB. Para isso, clique no botão "Arco Circular" e clique respectivamente nos pontos O, A e B. Caso esse não seja o arco menor, clique respectivamente nos pontos $\mathrm{O}, \mathrm{B}$ e A;

- Passo 6: Para melhorar a apresentação da construção, altere a cor e o estilo dos objetos criados e oculte os rótulos de objetos não mencionados na construção. Para alterar cor e estilo, clique com botão direito do mouse sobre o objeto e escolha "Propriedades". Na caixa que se abre, as alterações podem ser feitas clicando-se nas guias "Cor" e "Estilo". Para ocultar um rótulo, basta clicar com o botão direito sobre o objeto e escolher "Exibir Rótulo" (a cada clique alterna-se em exibir ou ocultar). Oculte também os eixos das abscissas e ordenadas. Para ocultar os eixos, basta clicar com o botão direito do mouse sobre algum ponto vazio da janela de visualização e escolher "Eixos".

A Figura 5.1 mostra a construção obtida executando-se os passos 1-6. Do lado esquerdo, está a construção original e, do lado direito, está a construção original na qual 
foram arrastados os pontos A e B com a utilização do botão "Mover". É interessante observar que as características originais da construção foram preservadas, o que revela o caráter dinâmico do GeoGebra.

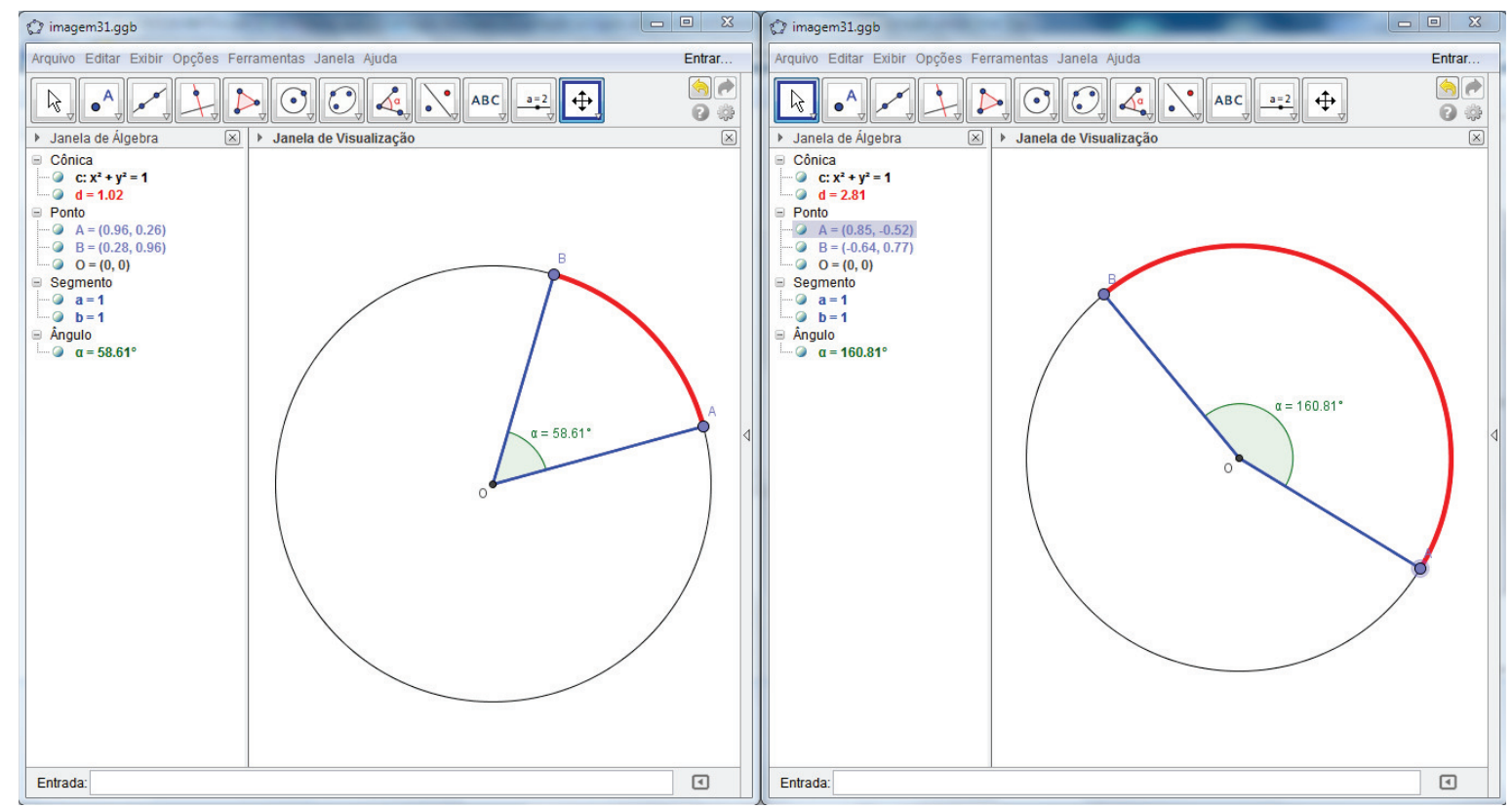

Figura 5.1: Arco de uma circunferência obtido através da execução dos passos 1-6 da Atividade $1-1^{\text {a }}$ Parte

\subsubsection{Passo a passo da construção - $2^{\mathrm{a}}$ Parte - Radianos}

- Passo 1: Construir uma circunferência de raio 1. Para isso, clique no botão "Círculo Dados Centro e Raio" e construa uma circunferência de raio 1. Renomeie o centro da circunferência para $\mathrm{O}$;

- Passo 2: Traçar uma reta passando pelo centro da circunferência. Para isso, clique no botão "Reta" e clique respectivamente no centro da circunferência e em algum ponto da circunferência;

- Passo 3: Encontrar os pontos de interseção entre a circunferência e a reta. Para isso, clique no botão "interseção Entre Dois Objetos" e clique respectivamente na circunferência e na reta. Renomeie os pontos de interseção para A e B. Deixe visíveis apenas os rótulos dos pontos de interseção e do centro da circunferência;

- Passo 4: Dividir a circunferência em 6 partes iguais. Para isso, clique no botão "Círculo Dados Centro e Um de Seus Pontos" e clique respectivamente nos pontos, A, O, B e O. Observe em sua tela que foram criadas duas circunferências. Pela construção, é possível observar que todas as três circunferências construídas têm o mesmo raio, 1 ; 
- Passo 5: Encontrar os pontos de interseção entre as circunferências. Para isso clique no botão "interseção Entre Dois Objetos" e clique respectivamente nas circunferências de centros $\mathrm{O}$ e $\mathrm{A}$ e, em seguida, nas circunferências de centros $\mathrm{O}$ e B;

- Passo 6: Ocultar objetos. Para isto, clique com o botão direito do mouse sobre a circunferência de centro A e escolha "Exibir Objeto". Repita o mesmo procedimento para a circunferência de centro B e para a reta;

- Passo 7: Renomear pontos. Renomeie os 6 pontos sobre a circunferência para se ter na sequência e no sentido anti-horário os pontos A, B, C, D, E e F;

- Passo 8: Construir segmentos. Para isso, clique no botão "Segmento" e construa os segmentos AD, FC, EB, AB, BC, CD, DE, EF e FA. Oculte os rótulos de todos os segmentos criados. Utilizando princípios de geometria plana, é possível perceber que foi construído no interior da circunferência um hexágono regular.Pode-se verificar que todos os segmentos da construção têm medida 1. Para isso, clique no botão "Distância, Comprimento ou Perímetro" e clique nas extremidades de cada segmento. O resultado encontrado é o comprimento desse segmento. Esse hexágono é formado por 6 triângulos equiláteros de lado 1. O arco AB, por exemplo, está associado a um ângulo central de $60^{\circ}$;

- Passo 9: Alterar a cor e o estilo do segmento AB. Para isso, clique com o botão direito do mouse sobre o segmento AB e escolha "Propriedades";

- Passo 10: Construa o arco AB. Para isso, clique no botão "Arco Circular" e clique respectivamente nos pontos $\mathrm{O}, \mathrm{A}$ e $\mathrm{B}$;

- Passo 11: Alterar a cor e o estilo do arco AB. Para isso, clique com o botão direito do mouse sobre o arco AB e escolha "Propriedades". Altere também o estilo dos demais segmentos e da cirunferêcia;

- Passo 12: Medir o ângulo AÔB. Para isso, utilize o botão "Ângulo" e clique respectivamente nos pontos $\mathrm{A}, \mathrm{O}$ e $\mathrm{B}$;

- Passo 13: Ocultar todos os rótulos de objetos não mencionados.

Pela construção, sabemos que o segmento AB tem medida igual a 1. Como a menor distância entre dois pontos é um segmento de reta, pode-se concluir que o comprimento do arco AB é maior do que 1. Ou seja, o arco AB é maior do que o raio da circunferência. Mas, quanto exatamente vale? Para responder a essa pergunta, o professor pode recorrer à relação entre raio e comprimento da circunferência: $C=2 \pi r$, 


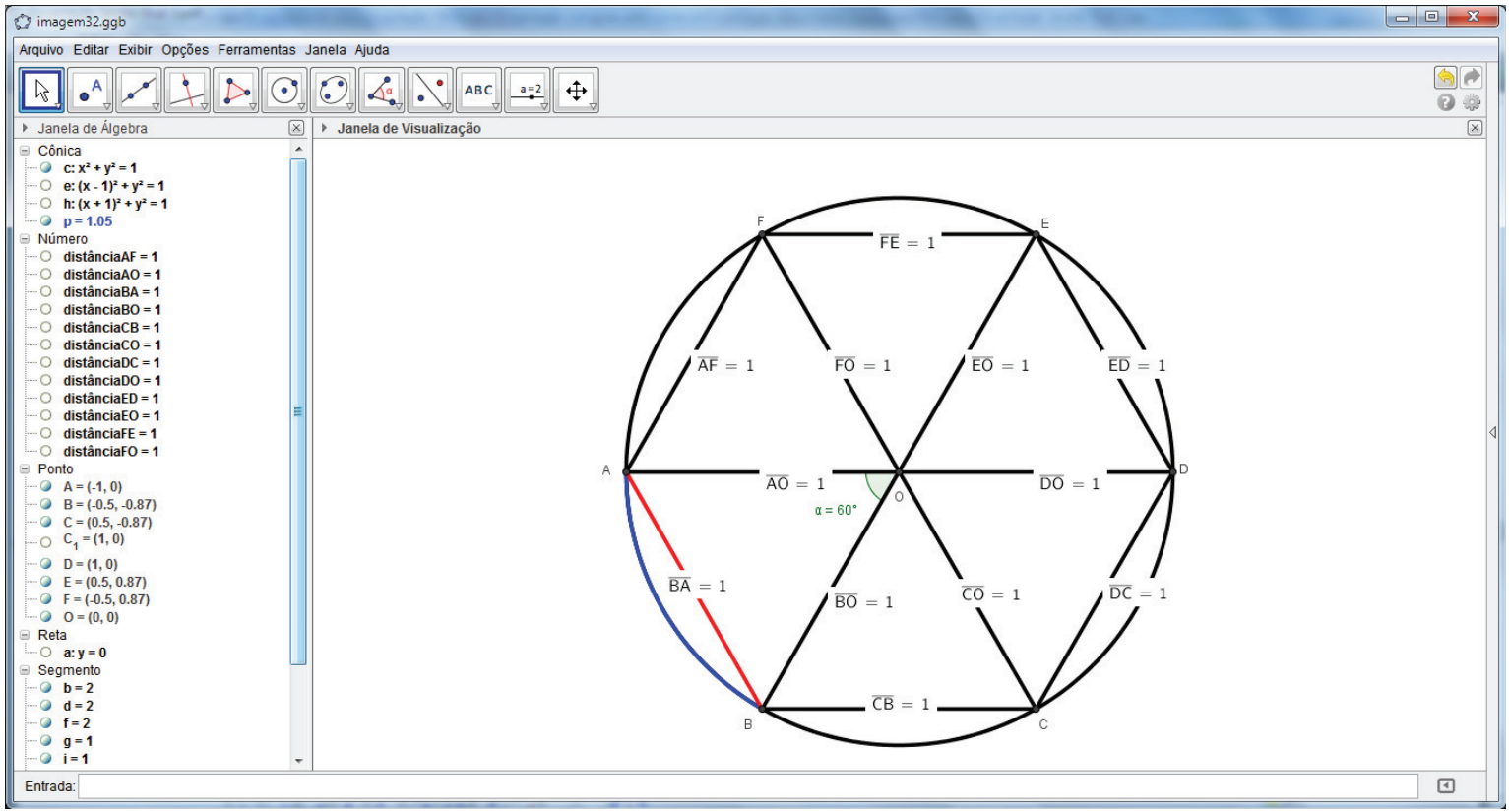

Figura 5.2: Circunferência dividida em 6 partes iguais obtida executando-se os passos 1-13 da Atividade 1 - $2^{\text {a }}$ Parte

em que $C$ refere-se ao comprimento da circunferência e $r$ é seu raio. Assim, o comprimento da circunferência é igual a $2 \pi$. Ou seja, $360^{\circ}$ equivalem a $2 \pi$ rad. Aplicando uma regra de três, pode-se concluir que o arco $\mathrm{AB}$, cujo ângulo central é $60^{\circ}$, tem comprimento de $\pi / 3 \mathrm{rad}$ que dá aproximadamente 1,0472. Esse procedimento auxilia na compreensão de que o radiano é uma relação entre o comprimento da circuferência e seu raio, ou seja, a razão entre o comprimento da circunferência e seu raio é igual a $2 \pi$.

Vale salientar que nesta segunda parte, não é possível utilizar o botão "Mover" pois no passo 1, para facilitar a compreensão foi construída uma circunferência de raio fixo 1. No entanto, toda a construção pode ser refeita alterando-se a circunferência do passo 1 para uma circunferênica de raio qualquer. Neste caso, deve ser utilizado o botão "Círculo Dados Centro e Um de Seus Pontos". O resultado da construção executando-se os passos 1-13 está na Figura 5.2. Já a figura 5.3 mostra a mesma construção alterando-se o passo 1. Notemos que a construção da Figura 5.3 manteve as propriedades originais da construção.

\subsection{Atividade 2 - Construindo a circunferência tri- gonométrica}

Esta é uma atividade simples de ser desenvolvida, a qual mostra de forma bastante prática para o aluno que as medidas do seno e do cosseno relacionam-se com 


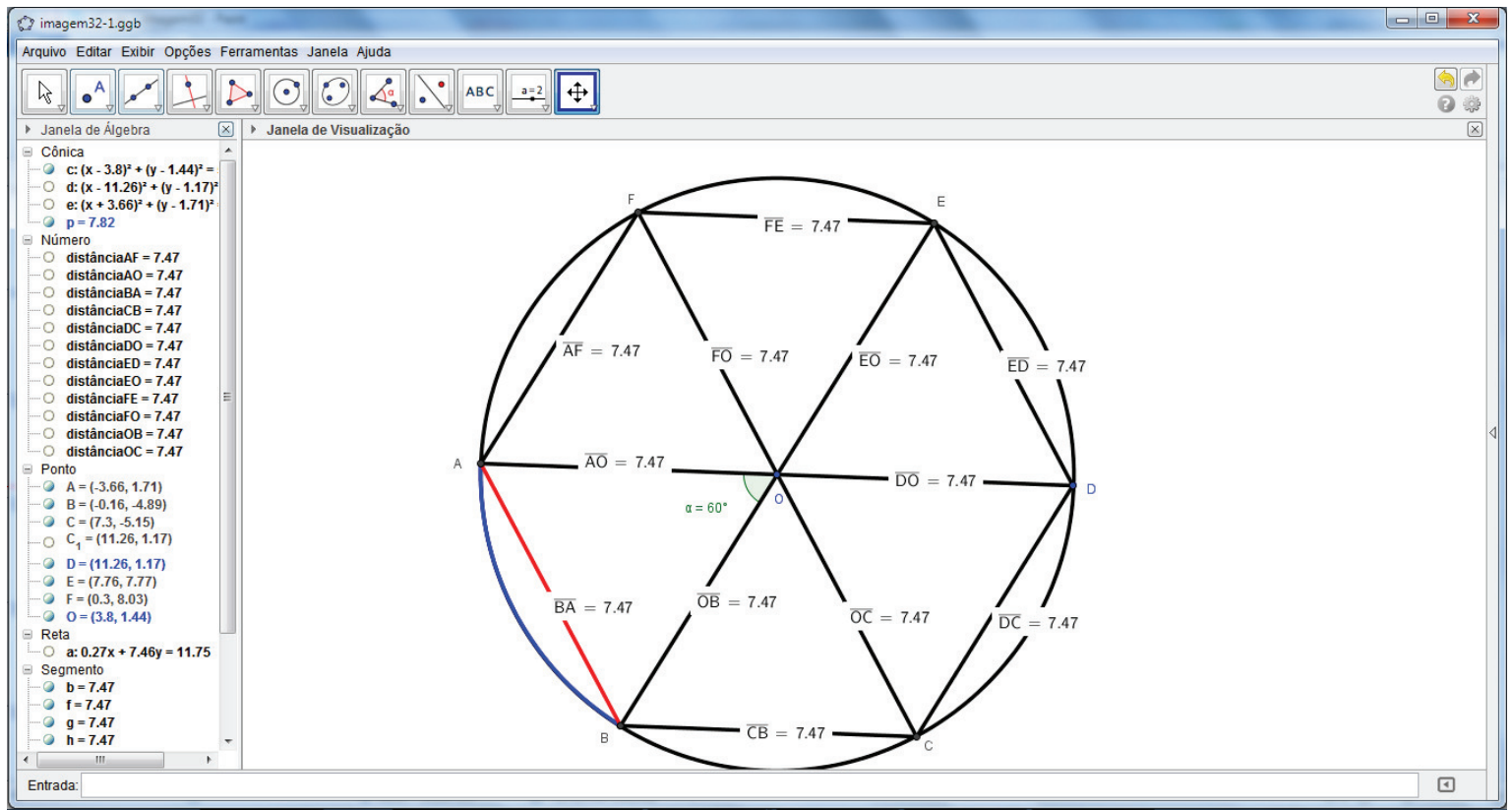

Figura 5.3: Circunferência dividida em 6 partes iguais obtida executando-se os passos 1-13 da Atividade 1 - 2a Parte - Com alteração do passo 1

as distâncias das projeções de um ponto da circunferência trigonométrica, respectivamente nos eixos $y$ e $x$, ao centro desta circunferência. Esta atividade é adaptação da atividade desenrolando o seno de Giraldo, Caetano e Mattos (2012).

Para aplicação desta atividade, não é requerido que o aluno tenha conhecimentos prévios das definições de seno e cosseno. Com o desenvolver da atividade e com a animação do ponto A, espera-se que o discente perceba que o seno e o cosseno estão compreendidos em um intervalo que varia de -1 a 1 e, como o raio da circunferência é 1, então seno e cosseno são, na realidade, os valores da ordenada e da abscissa respectivamente, do ponto sobre a circunferência.

Além disso, o passo a passo da construção da circunferência trigonométrica oferece ao aluno a possibilidade de compreender que um passo executado de forma incorreta terá reflexos no resultado final. Esse é um mecanismo de aprendizagem, visto que o aluno terá a possibilidade de analisar o objeto construído e corrigir os possíveis erros.

\subsubsection{Passo a passo da construção}

- Passo 1: Construir uma circunferência centrada na origem e de raio 1. Para isso, na caixa de entrada digite: círculo $[(0,0), 1]$;

- Passo 2: Construir dois segmentos, um horizontal e um vertical, com 3 unidades de comprimento, com seus respectivos pontos médios fixados na origem. Para isso, digite separadamente na caixa de entrada os comandos: segmento $[(-1.5,0)$, $(1.5,0)]$ e em seguida segmento $[(0,-1.5),(0,1.5)]$; 
- Passo 3: Ocultar os eixos. Para isso, clique com o botão direito do mouse sobre a parte branca da janela de visualização e com o botão esquerdo do mouse, clique em "Eixos";

- Passo 4: Ocultar os rótulos de todos os elementos criados. Para isso, clique com botão direito do mouse sobre o segmento horizontal e com o botão esquerdo do mouse, escolha exibir rótulo. Repita o processo para o segmento horizontal e para a circunferência;

- Passo 5: Criar um ponto no centro da circunferência. Esse será o ponto O. Para isso, na caixa de entrada, digite o comando: $0=(0,0)$. Outra possibilidade é renomear o ponto já criado no centro da circunferência para $\mathrm{O}$;

- Passo 6: Criar um ponto sobre a circunferência. Para isso, clique no botão "Ponto em Objeto" e clique em algum ponto da circunferência. Foi criado o ponto A;

- Passo 7: Criar um ponto B em $(1,0)$. Para isso, digite na caixa de entrada o comando: $\mathrm{B}=(1,0)$;

- Passo 8: Criar uma semirreta que tenha origem em O e passe por A. Para isso, digite na caixa de entrada o comando: semirreta $[0, A]$. Oculte o rótulo da semirreta criada;

- Passo 9: Criar um arco de circunferência que tenha centro em $\mathrm{O}$ e extremidades em A e B. Para isso, escolha o botão "Arco Circular" e clique em O, depois em B e em seguida em A. Oculte o rótulo do arco criado;

- Passo 10: Alterar cor e espessura da linha do arco AB. Para isso, clique com o botão direito do mouse sobre o arco AB e escolha "Propriedades". Na guia "Cor" altere a cor da linha e, na guia "Estilo", altere a espessura da linha;

- Passo 11: Criar no eixo horizontal um ponto que tenha a mesma abscissa do ponto A. Para isto, digite na caixa de entrada o comando: $C=(x(A), 0)$. Foi criado o ponto C. Observe que ao movimentar o ponto A o ponto $\mathrm{C}$ também se movimentará acompanhando verticalmente o ponto A. Se encontrar dificuldades na criação deste ponto, verifique se foi criado algum outro ponto nomeado com C;

- Passo 12: Criar no eixo vertical um ponto que tenha a mesma ordenada do ponto A. Para isso, digite na caixa de entrada o comando: $D=(0, y(A))$. Foi criado o ponto D. Observe que ao movimentar o ponto A, o ponto D também se movimentará, acompanhando o ponto A. Se encontrar dificuldades na criação deste ponto, verifique se foi criado algum outro ponto nomeado com D; 
- Passo 13: Criar os segmentos OC, OD, DA e CA. Para isso, escolha o botão "Segmento" e clique em O depois em C, em O depois em D, em D, depois em A e em $\mathrm{C}$, depois em A. Oculte o rótulo desses segmentos. Altere a cor e a espessura dos segmentos OC e OD. Altere o estilo de linha dos segmentos DA e CA para tracejado. Observe que os pontos $\mathrm{C}$ e D são as projeções do ponto A sobre os eixos horizontal e vertical, respectivamente. O comprimento do segmento OC é igual ao módulo do valor do cosseno do arco $\mathrm{AB}$, e o comprimento do segmento OD é igual ao módulo do valor do seno do arco AB;

- Passo 14: Marcar o ângulo BÔA. Para isso, escolha o botão "Ângulo" e clique nos pontos B, O e A, respectivamente. Oculte o rótulo do ângulo BÔA;

- Passo 15: Encontrar os comprimentos do segmentos OD e OC que relacionam respectivamente com seno e cosseno do arco AB. Para isso, utilize o botão "Distância, Comprimento ou Perímetro";

- Passo 16: Animar o ponto A. Para isso, clique com o botão direito sobre o ponto A e escolha "Animar". Com isso, o ponto A percorrerá automaticamente toda a extensão da circunferência trigonométrica. Note que os segmentos OC e OD alteram seus comprimentos a medida que o ponto A percorre à circunferência trigonométrica.

A Figura 5.4 mostra a construção resultante da execução dos passos 1-16 da Atividade 2 com dois momentos dessa movimentação. Do lado esquerdo, o ponto A está no $1^{\circ}$ quadrante e os valores do seno e do cosseno do arco $\mathrm{AB}$ são positivos. Do lado direito, o ponto A está no $3^{\circ}$ quadrante e os valores do seno e do cosseno do arco AB são negativos. A movimentação do ponto A permite uma melhor compreensão dos valores do seno e do cosseno do arco AB.

\subsection{Atividade 3 - Definindo a tangente na circun- ferência trigonométrica}

Esta atividade complementa a Atividade 2. Na Atividade 2, já foi mostrado que seno e cosseno são os valores da abscissa e da ordenada resultantes da projeção de um ponto pertencente à circunferência sobre os eixos. Será mostrado que a projeção de um ponto pertencente à circunferência trigonométrica em relação ao centro dessa circunferência na reta paralela ao eixo das ordenadas que passa pelo ponto $(1,0)$ está relacionada com a definição de tangente. 


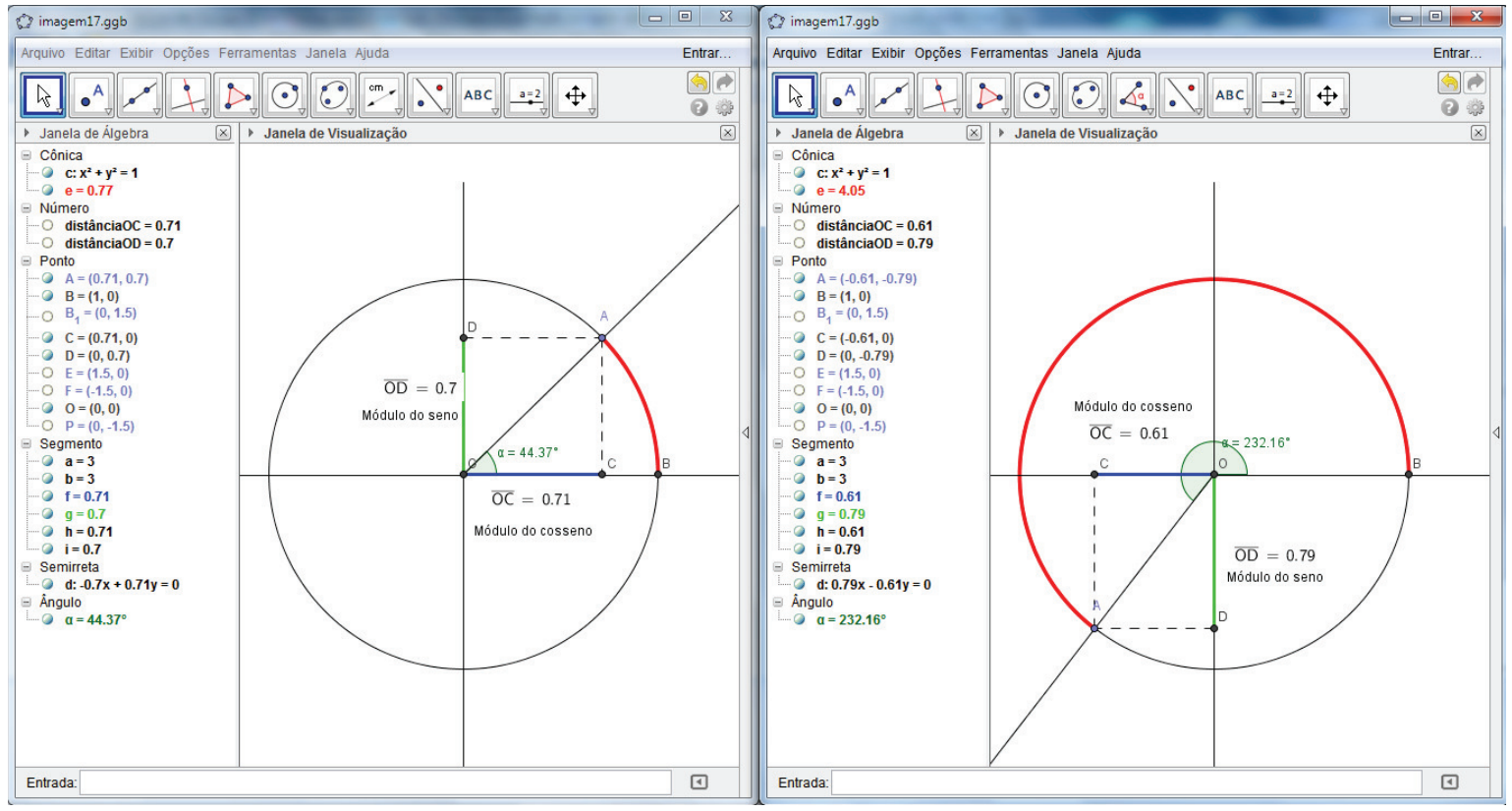

Figura 5.4: Construção resultante da execução dos passos 1-16 da Atividade 2

\subsubsection{Passo a passo da construção}

- Passo 1: Construir uma circunferência centrada na origem e de raio 1. Para isso, na caixa de entrada digite: círculo $[(0,0), 1]$;

- Passo 2: Construir dois segmentos, um horizontal e um vertical, com 3 unidades de comprimento, com seus respectivos pontos médios fixados na origem. Para isso, digite separadamente na caixa de entrada os comandos: segmento $[(-1.5,0)$, $(1.5,0)]$ e segmento $[(0,-1.5),(0,1.5)]$;

- Passo 3: Ocultar os eixos. Para isso, clique com o botão direito do mouse sobre a parte branca da janela de visualização e com o botão esquerdo do mouse clique em "Eixos";

- Passo 4: Ocultar os rótulos de todos os elementos criados;

- Passo 5: Criar um ponto no centro da circunferência. Esse será o ponto O. Para isso, na caixa de entrada, digite o comando: $0=(0,0)$;

- Passo 6: Criar um ponto sobre a circunferência. Para isso, escolha o botão "Ponto em Objeto" e clique em algum ponto da circunferência. Foi criado o ponto A;

- Passo 7: Criar um ponto B em $(1,0)$. Para isso, digite na caixa de entrada o comando: $\mathrm{B}=(1,0)$; 
- Passo 8: Criar um arco de circunferência que tenha centro em O e extremidades em A e B. Para isso, escolha a ferramenta "Arco Circular" e clique em O, depois em B e em seguida em A. Ocultar o rótulo do arco criado;

- Passo 9: Criar uma reta que passa pelos pontos O e A. Para isso, digite na caixa de entrada o comando: reta $[\mathrm{O}, \mathrm{A}]$. Ocultar o rótulo da reta criada. Renomeie essa reta para $\mathrm{r}$;

- Passo 10: Construir uma reta paralela ao eixo das ordenadas passando pelo ponto B. Para isso, escolha o botão "Reta Paralela" e clique no segmento vertical e no ponto $\mathrm{B}$ respectivamente. Renomeie essa reta para t;

- Passo 11: Encontrar os pontos de interseção das retas r e t. Para isso, escolha o botão "Interseção de Dois Objetos" e clique nas retas r e t, não necessariamente nessa ordem. Renomeie esse ponto para $\mathrm{T}$.

- Passo 12: Construir o segmento TB: Para isso, escolha o botão "Segmento" e clique nos pontos T e B. Altere a cor e o estilo deste segmento;

- Passo 13: Construir o ângulo AÔB. Para isso, utilize o botão "Ângulo" e clique respectivamente nos pontos $\mathrm{B}, \mathrm{O}$ e $\mathrm{A}$.

- Passo 14: Encontrar o comprimento do segmento BT. Para isso, utilize o botão "Distância, Comprimento ou Perímetro" e clique respectivamente nos pontos B e T.

- Passo 15: Animar o ponto A. Para isso, clique com o botão direito do mouse sobre o ponto A e escolha "Animar".

A tangente de um arco está diretamente relacionada ao comprimento do segmento BT. A tangente é positiva para arcos do $1^{\circ}$ e $3^{\circ}$ quadrantes e negativa para $\operatorname{arcos}$ do $2^{\circ}$ e $4^{\circ}$ quadrantes. Ou seja, a tangente do arco AB é, na realidade, o valor da ordenada do ponto T. Vale salientar que o valor da tangente será zero para arcos com medida zero e múltiplos $k \pi$ com $k$ pertencente a $\mathbb{Z}$, e a tangente não existe quando a projeção do ponto A sobre o eixo das abscissas coincidir com o centro da circunferência trigonométrica. A Figura 5.5 mostra a construção resultante da execução dos passos 1-15 em dois momentos do ponto A. Com a animação, o ponto A percorre automaticamente toda a extensão da circunferência trigonométrica. Do lado esquerdo, o ponto A pertence ao $1^{\circ}$ quadrante e tem projeção sobre a reta $t$ acima do eixo das abscissas e, do lado direito, o ponto A pertence ao $4^{\circ}$ quadrante e a projeção sobre a reta t está abaixo do eixo das abscissas. 


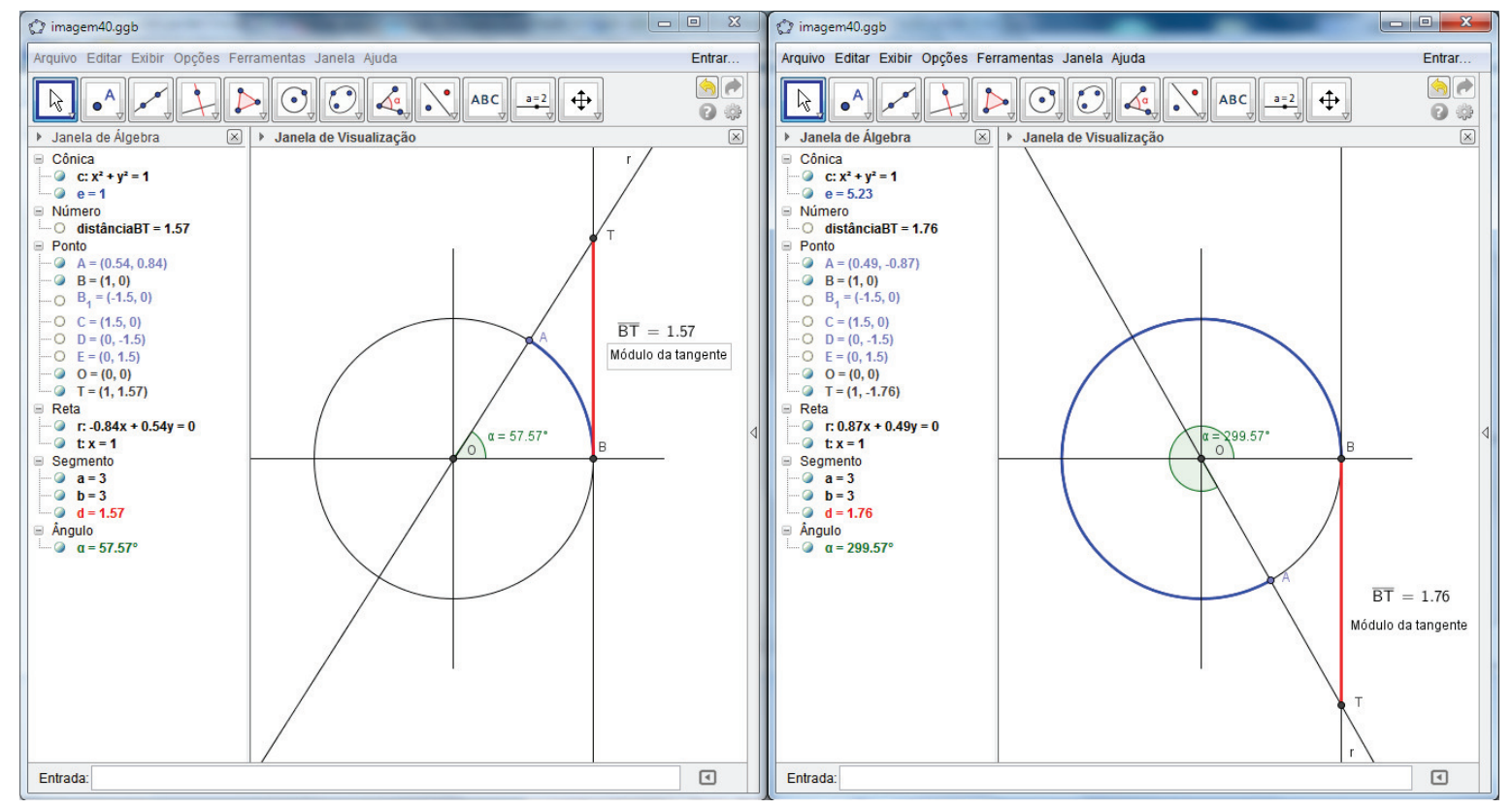

Figura 5.5: Construção resultante da execução dos passos 1-15 da Atividade 3 em dois momentos do ponto A 


\section{Capítulo 6}

\section{Funções trigonométricas com o auxílio do GeoGebra}

Série de aplicação das atividades: De acordo com São Paulo(2012), as atividades propostas neste capítulo são indicadas para a $2^{\mathrm{a}}$ série do ensino médio para o estudo de funções trigonométricas.

Neste capítulo, são apresentadas três atividades:

- Atividade 1: - Construindo os gráficos das funções seno e cosseno;

- Atividade 2: - Explorando a função $f(x)=a \cdot \operatorname{sen}(b \cdot x+c)+d$, através dos parâmetros $a, b, c$ e $d$;

- Atividade 3: - Comparando as funções $f(x)=\operatorname{sen}(x)$ e $g(x)=\cos (x+\pi / 2)$.

Já foi visto, no capítulo anterior, que os valores do seno e do cosseno oscilam dentro de um intervalo. Neste capítulo, será mostrado que é possível representar essa oscilação graficamente e que se pode comparar o formato de gráficos gerados por diferentes funções trigonométricas.

Na Atividade 1, é feita uma interpretação gráfica dos valores do seno e do cosseno de um arco, obtidos na circunferência trigonométrica. Nela, será observado o caráter periódico das funções seno e cosseno.

$\mathrm{Na}$ Atividade 2, é feita a análise de uma função trigonométrica genérica. Nessa atividade, o gráfico depende de valores dados a parâmetros. Essa atividade possibilita a análise de alterações gráficas geradas a partir de alterações de parâmetros da função genérica.

Na Atividade 3, é proposta uma análise comparativa de duas funções trigonométricas. O objetivo principal é analisar semelhanças e diferenças entre essas funções e, ao final, verificar a possível existência de simetria. 


\subsection{Atividade 1 - Construindo os gráficos das funções seno e cosseno}

Esta atividade adaptada do texto de Giraldo, Caetano e Mattos (2012), complementará a Atividade 2 do Capítulo 5, e por isso será realizada em uma janela adicional ao lado da janela, onde a circunferência trigonométrica foi construída.

Esta atividade tem por objetivo mostrar ao aluno que informações obtidas na circunferência trigonométrica geram gráficos de funções. Como o ponto B é fixo e o ponto A vai na circunferência, observa-se inicialmente a existência do arco AB. Será associado o comprimento do arco $\mathrm{AB}$ com o do segmento $\mathrm{OC}$, em que $\mathrm{C}$ é a projeção do ponto $\mathrm{A}$ no eixo das abscissas e essa projeção será denominada cosseno. Por outro lado, existe associação do comprimento do arco AB com o segmento OD, em que D é a projeção do ponto A sobre o eixo das ordenadas. Essa associação será denominada seno. Nesse momento, espera-se que o aluno seja capaz de perceber que as projeções sobre os eixos das abscissas e ordenadas estarão compreendidas no intervalo $[-1,1]$.

Além disso, é possível mostrar que as projeções do ponto A sobre o eixo das abscissas e ordenadas pode ser associado ao ângulo central formado pelos pontos A e B.

\subsubsection{Passo a passo da construção}

- Passo 1: Criar uma janela de visualização adicional. Para isso, no menu exibir, escolha "Janela de Visualização 2";

- Passo 2: Alterar os incrementos dos eixos x e y. Para isso, na parte branca da janela de visualização 2, clique com o botão direito do mouse. Na guia eixo x, vá em distância e escolha $\pi / 2$. Na guia eixo y, vá em distância e escolha 1;

- Passo 3: Criar um ponto no eixo x, cuja abscissa seja o comprimento do arco AB da circunferência trigonométrica. Para isto, ative a janela de visualização 2, vá à caixa de entrada e digite: $E=(e, 0)$. Se apresentar dificuldade para a criação deste ponto, verifique se já existe um ponto E criado;

- Passo 4: Criar o segmento OE: Para isso, na caixa de entrada digite: segmento $[0, E]$. Note que o segmento foi construído na janela de visualização 1. Para visualizá-lo na janela 2 , vá em propriedades do segmento, na guia avançado, vá em localização e marque apenas janela de visualização 2. Se estiver com a janela de visualização 2 ativa, o segmento ficará visível nela, mas com a ausência do ponto O. Para visualizar o ponto $\mathrm{O}$ na janela de visualização 2, vá na janela de álgebra e clique com o botão direito do mouse sobre o ponto O, escolha "Propriedades". Na guia avançado, marque a janela de visualização 2; 
- Passo 5: Copiar o estilo visual do arco AB para o segmento OE. Para isso, vá na barra de ferramentas de acesso rápido e escolha botão "Copiar Estilo Visual". Clique no arco $\mathrm{AB}$ e na sequência no segmento OE;

- Passo 6: Criar, na janela de visualização 2, um ponto que associe o comprimento do arco AB com o abscissa do ponto A. Note que a abscissa do ponto A é, na realidade, o valor do cosseno do Arco AB. Para isso, na caixa de entrada, digite: $\mathrm{F}=(\mathrm{e}, \mathrm{x}(\mathrm{A}))$;

- Passo 7: Habilitar o rastro do ponto F: Para isso, clique com o botão direito sobre o ponto $\mathrm{F}$ e clique em habilitar rastro. O rastro deixa o caminho no qual o ponto se movimenta, visível.

- Passo 8: Animar o ponto A. Vá na janela de visualização 1 e clique com o botão direito do mouse sobre o ponto A e escolha "Animar". Veja que na janela de visualização 2 , ficou descrito o gráfico da função $f(x)=\cos (x)$ no intervalo $[0,2 \pi]$

- Passo 9: Ocultar o ponto F.

- Passo 10: Criar um ponto que associe o comprimeto do arco AB com o ordenada do ponto A. Note que a ordenada do ponto A é, na realidade, o valor do seno do arco AB. Para isso, na caixa de entrada, digite: $G=(e, y(A))$;

- Passo 11: Habilitar o rastro do ponto G: Para isso, clique com o botão direito sobre o ponto F e escolha em "Habilitar Rastro";

- Passo 12: Animar o ponto A: Vá na janela de álgebra e clique com o botão direito do mouse sobre o ponto A e escolha "Animar". Veja que na janela de visualização 2 , ficou descrito o gráfico da função $f(x)=\operatorname{sen} x$ no intervalo $[0,2 \pi]$;

As Figuras 6.1 e 6.2 mostram as construções resultantes dos passos 1-12 da Atividade 1.

Para efeito de comparação, os gráficos das funções cosseno e seno podem ser colocados em uma mesma janela de visualização. Para isto basta exibir simultaneamente os pontos $\mathrm{F}$ e $\mathrm{G}$.

Note que na figura 6.3 existem pontos de interseção entre os esboços das funções $\operatorname{sen}(x)$ e $\cos (x)$. Isso mostra que existem valores de $x$ para os quais é verdadeira a expressão $\operatorname{sen}(x)=\cos (x)$. Pelo gráfico acima, o aluno poderá questionar se existirão outros pontos de interseção entre as funções seno e cosseno. Com um olhar mais atento, poderá ainda questionar se existe uma periodicidade entre essas intersecções. 


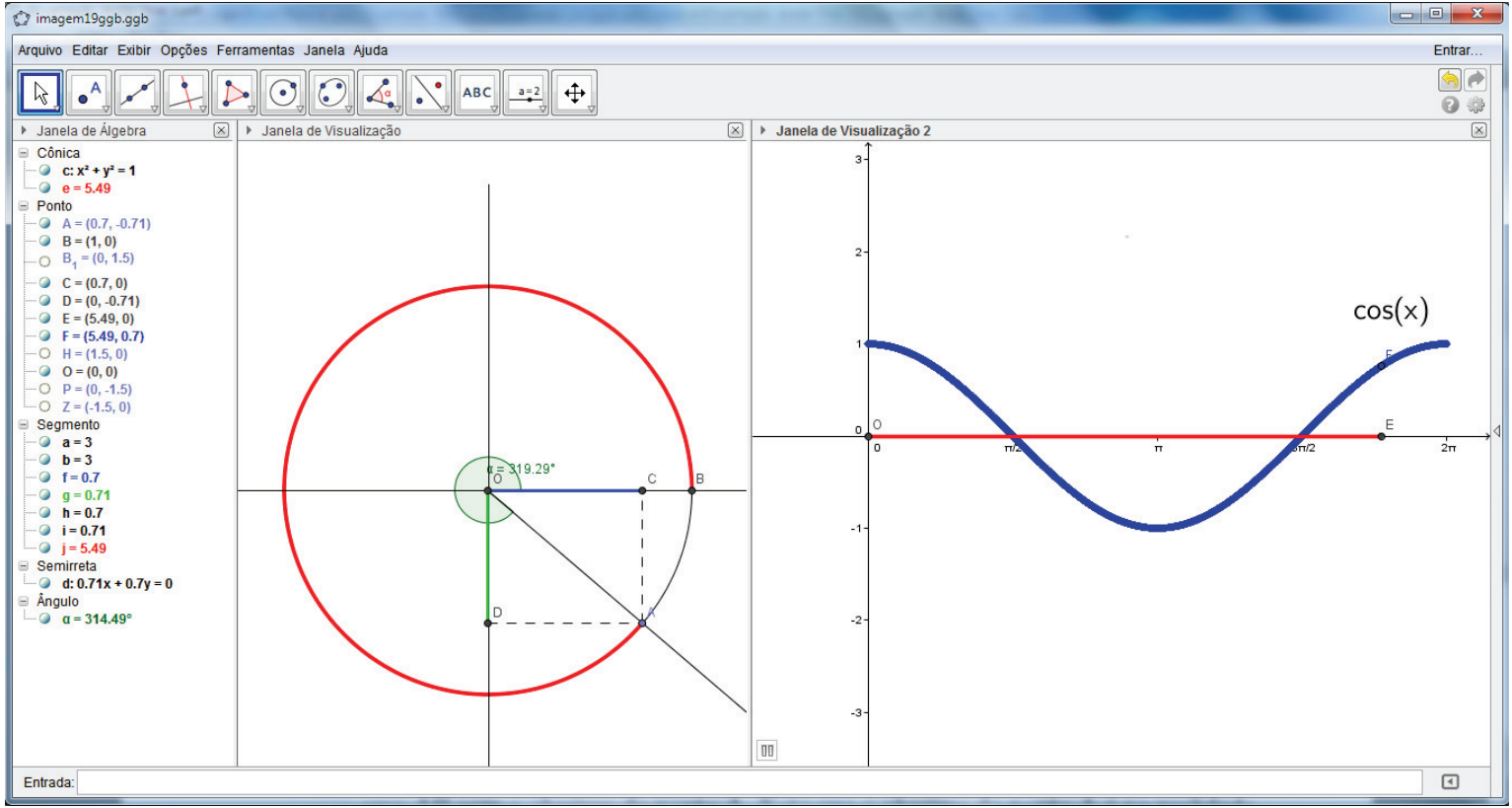

Figura 6.1: Gráfico da função $\cos (\mathrm{x})$ no intervalo $[0,2 \pi]$ resultado da construção dos passos de 1 a 8 da Atividade 1

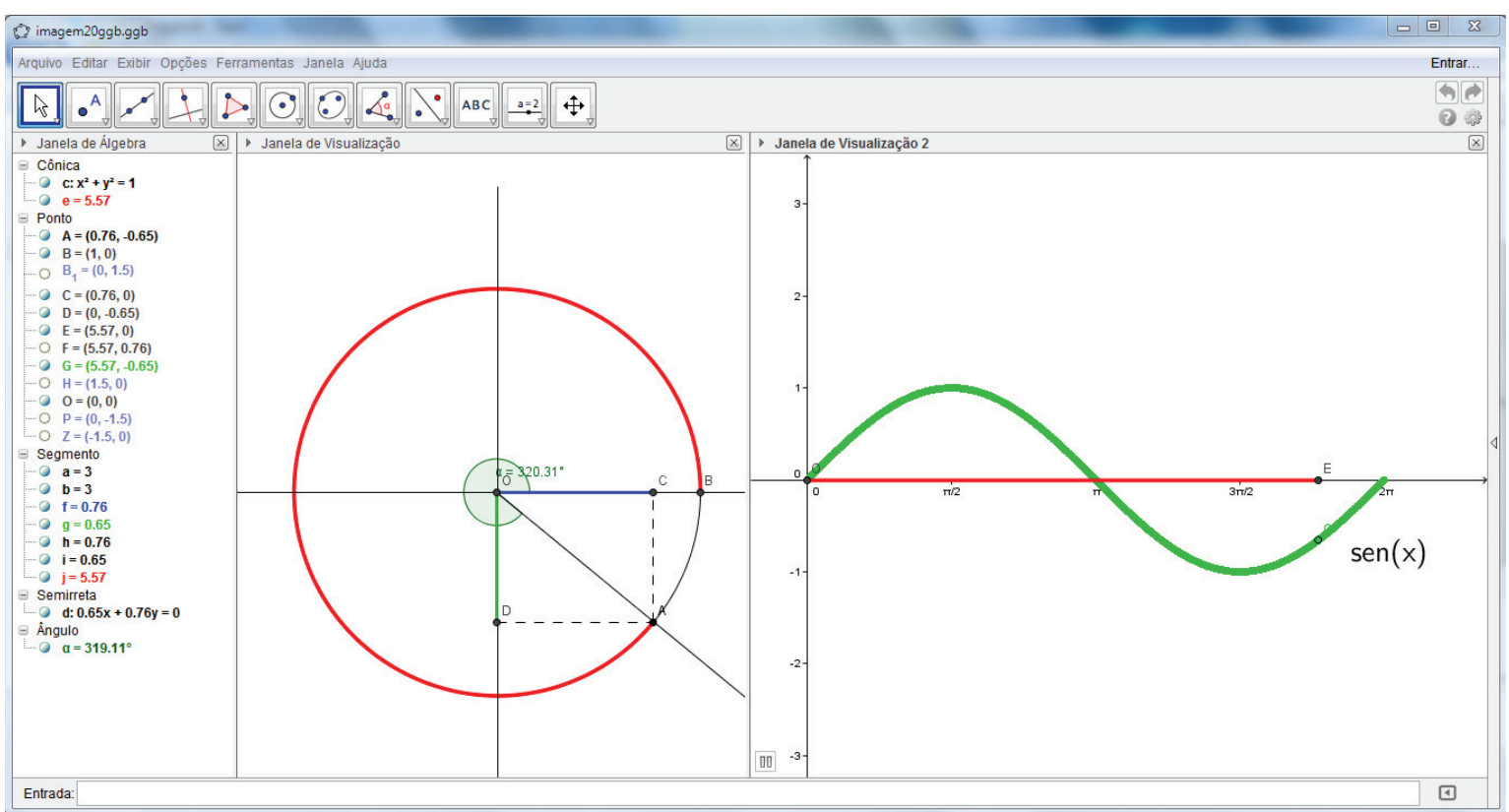

Figura 6.2: Gráfico da função sen(x) no intervalo de $[0,2 \pi]$ resultado da construção dos passos de 9 a 12 da Atividade 1

Apesar da limitação do intervalo $[0,2 \pi]$, o aluno poderá entender que ao dar voltas com o ponto A sobre a circunferência trigonométrica, estará de forma indireta justificando a continuação das funções seno e cosseno. Além disso, a limitação das projeções do ponto A sobre os eixos das abscissas e ordenadas ao intervalo de $[-1,1]$ justifica, também de forma indireta, a limitação da imagem da função a esse mesmo intervalo. 


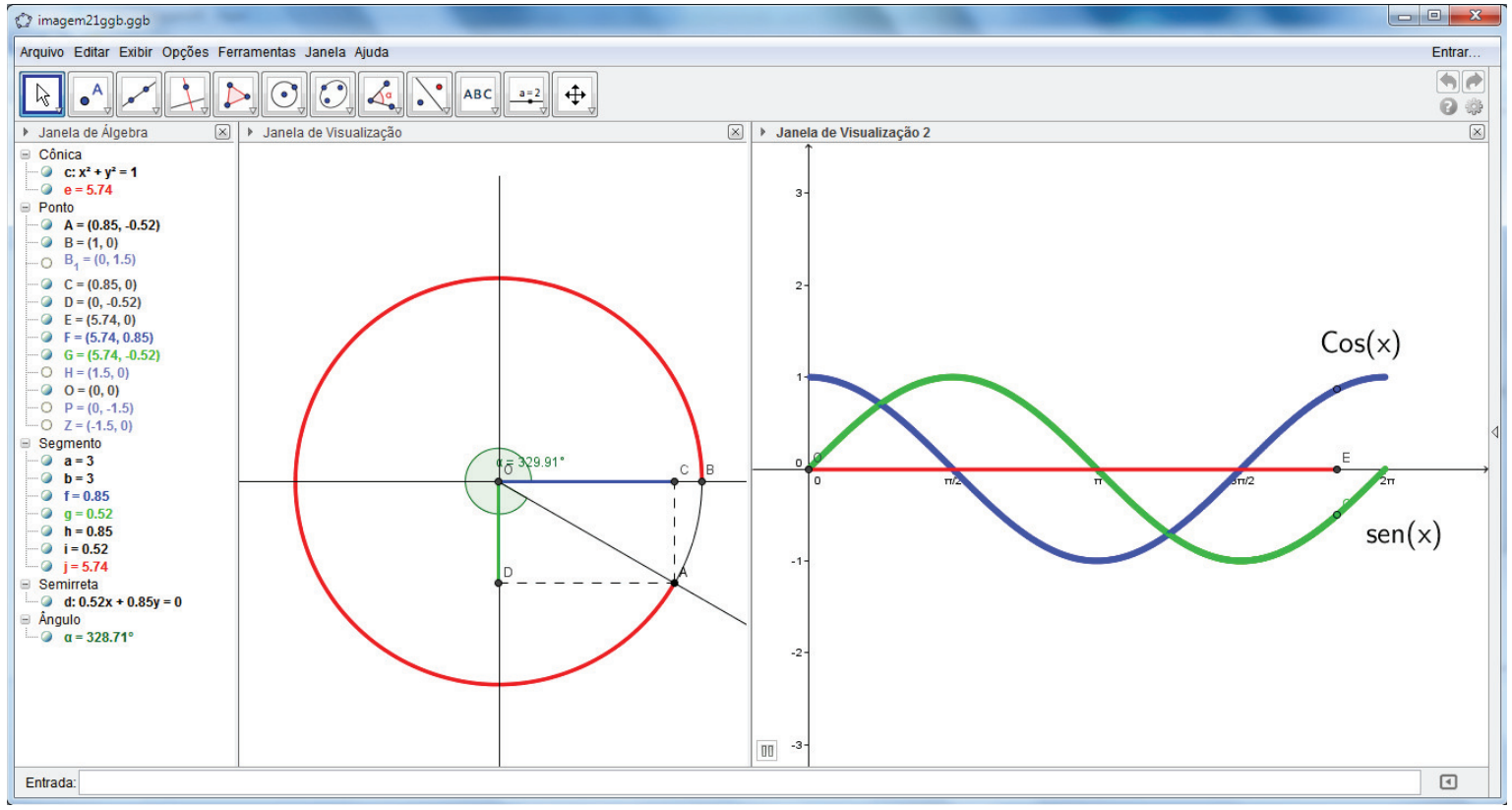

Figura 6.3: Gráfico das funções $\operatorname{sen}(\mathrm{x})$ e $\cos (\mathrm{x})$ no intervalo de $[0,2 \pi]$ na mesma janela de visualização

\subsection{Atividade 2: Explorando a função $f(x)=a \cdot \operatorname{sen}(b . x+$ $c)+d$, através dos parâmetros $a, b, c$ e $d$}

Esta atividade não será desenvolvida com a utilização da circunferência trigonométrica. Para desenvolvê-la, será utilizada a caixa de entrada, ou seja, será inserida algebricamente a função, e o GeoGebra gerará automaticamente o gráfico dessa função.

Com esta função, o professor poderá mostrar para o aluno quais são as alterações gráficas decorrentes de alterações dos parâmetros $a, b, c$ e $d$. Quando um parâmetro for alterado, os demais serão mantidos e serão observadas as alterações no gráfico da função.

\subsubsection{Passo a passo da construção}

- Passo 1: Construir controles deslizantes. Na barra de ferramentas de acesso rápido, escolha "Controle Deslizante" e clique com o botão esquerdo do mouse 4 vezes na janela de visualização. Dessa forma, serão criados os controles deslizantes $a, b, c$ e $d$. (Controle deslizante é um parâmetro numérico ajustável que pode ser utilizado nas construções);

- Passo 2: Criar uma função com a utilização dos parâmetros $a, b, c$ e $d$ criados. Para isso, vá à caixa de entrada e digite: $f(x)=a * \sin (b * x+c)+d$;

- Passo 3: Alterar os controles deslizantes. Note que todos os controles deslizantes 
que foram criados têm valor 1 . Altere os controles deslizantes para $a=1, b=1$, $c=0$ e $d=0$. Note que dessa forma temos $f(x)=a \cdot \operatorname{sen}(b \cdot x+c)+d=\operatorname{sen}(x)$, cujo gráfico pode ser visto na Figura 6.4;

- Passo 4: Alterar cor e estilo. Altere a cor e o estilo da função para melhorar a visualização;

- Passo 5: Alterar os incrementos do eixo das abscissas. Para isso, na parte branca da janela de visualização, clique com o botão direito do mouse. Na guia eixo x, vá em distância e escolha $\pi / 2$.

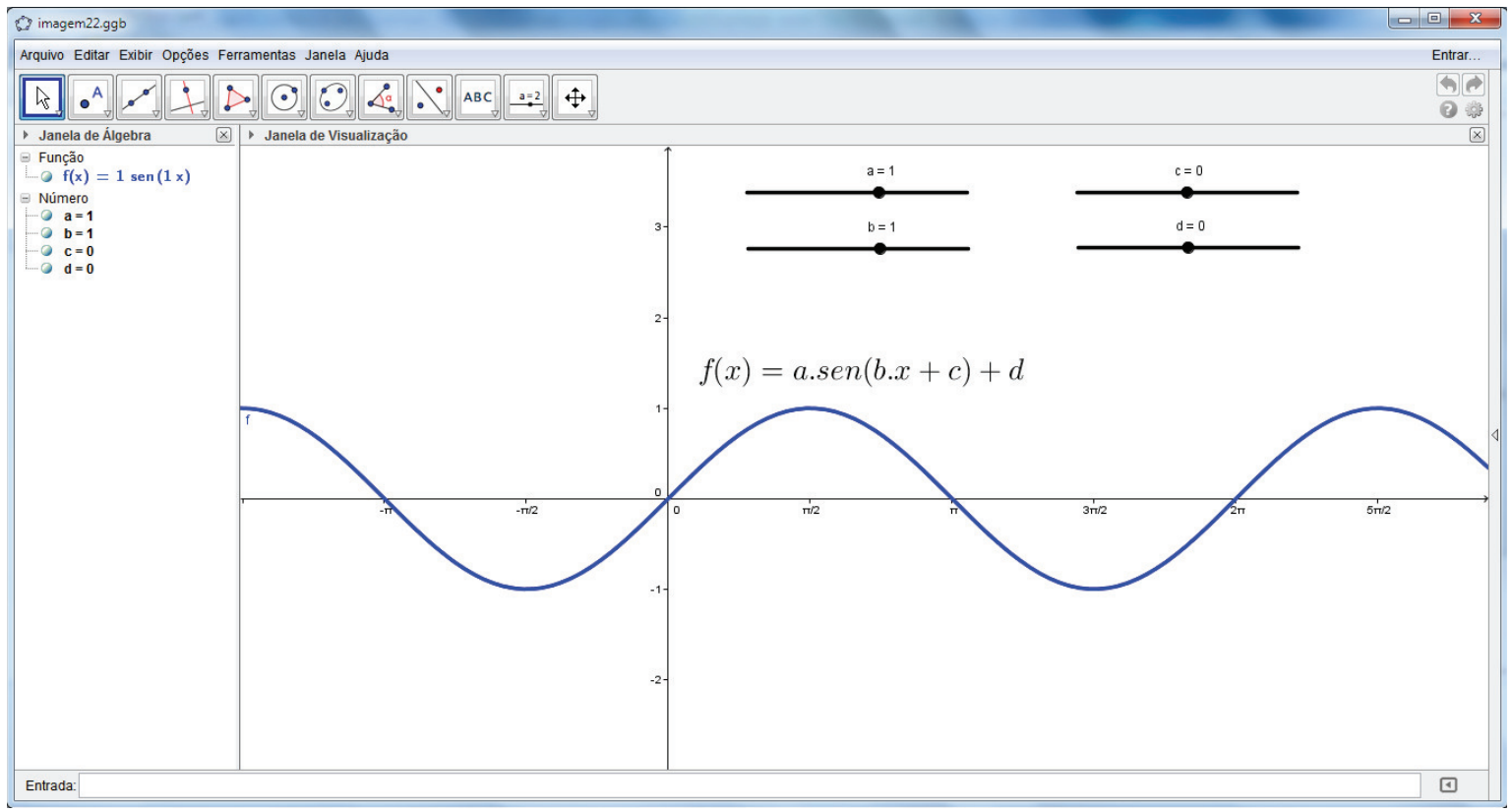

Figura 6.4: Gráfico da função $f(x)=a \cdot \operatorname{sen}(b \cdot x+c)+d$ para $a=1, b=1, c=0$ e $d=0$, resultante da execução dos passos 1-5 da Atividade 1

Com a configuração $a=1, b=1, c=0$ e $d=0$ a função $f(x)=a \cdot \operatorname{sen} .(b \cdot x+$ $c)+d=\operatorname{sen}(x)$ e todas as alterações gráficas geradas por alterações nos parâmetros $a$, $b, c$ e $d$ serão observadas em comparação com a função $h(x)=\operatorname{sen}(x)$.

Alterando o parâmetro $a$ de 1 para 5 e mantendo os parâmetros $b, c$ e $d$, obtém-se o gráfico apresentado na Figura 6.5.

É possível observar que houve manutenção das intersecções entre o gráfico e o eixo das abscissas, ou seja, os zeros das funções $h(x)$ e $f(x)$ são os mesmos, ou ainda, as raízes da equação $a \cdot \operatorname{sen}(b \cdot x+c)+d=0$ para $a=5, b=1, c=0$ e $d=0$ coincidem com as raízes da equação $\operatorname{sen}(x)=0$. Isso mostra que não houve alteração no período da função. Não houve também alteração do domínio, continua sendo $\mathbb{R}$. Por outro lado, percebe-se uma alteração da amplitude do gráfico, ou seja, a imagem da função que estava no intervalo $[-1,1]$ agora está no intervalo $[-5,5]$. É possível concluir que 


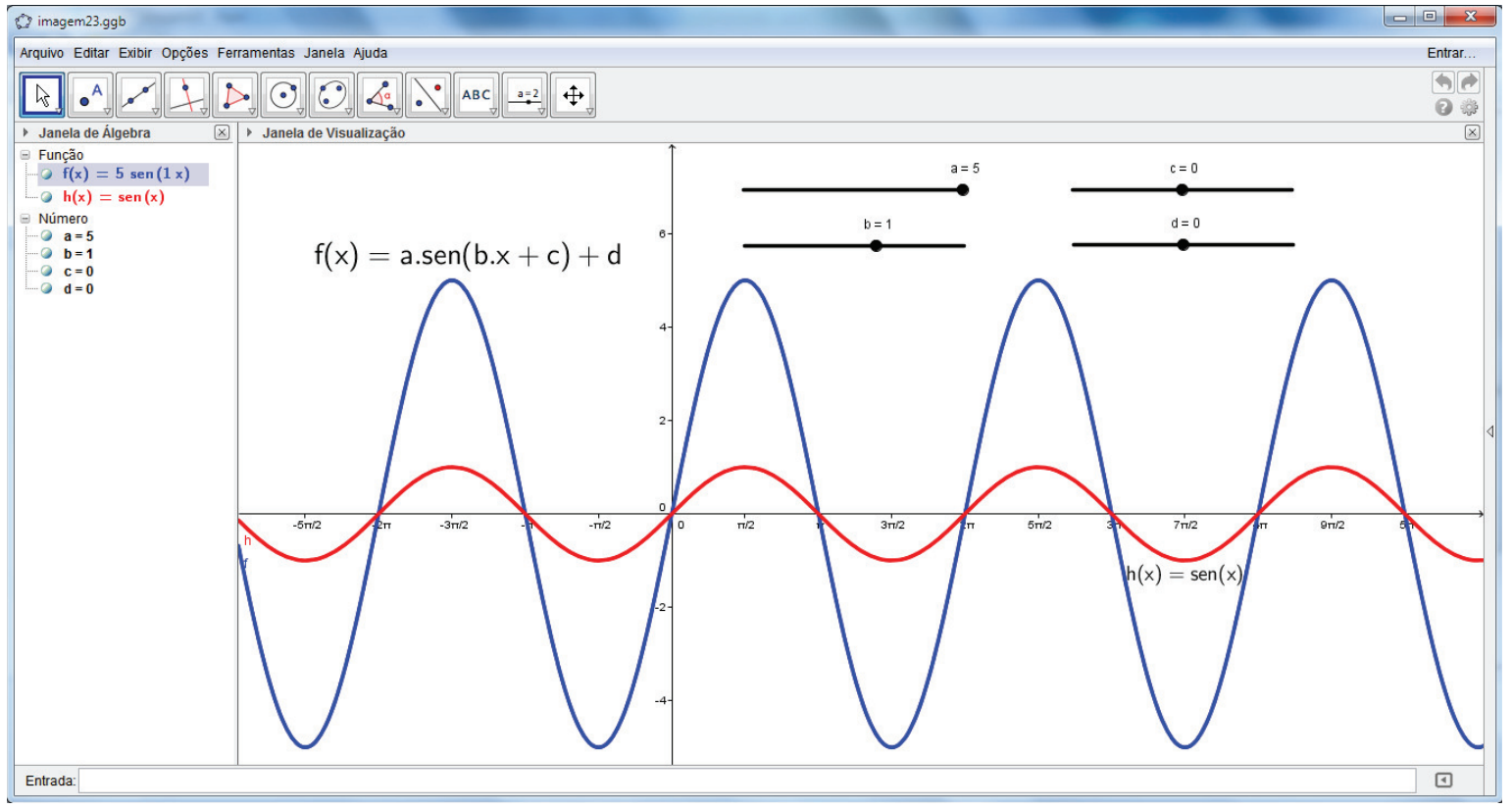

Figura 6.5: Gráfico da função $f(x)=a \cdot \operatorname{sen}(b \cdot x+c)+d$ para $a=5, b=1, c=0$ e $d=0$

uma alteração no parâmetro $a$ implica necessariamente uma alteração na imagem da função. Essa alteração pode ser uma ampliação ou redução da amplitude da imagem da função. Neste trabalho, não consideraremos o caso $a=0$, no qual teríamos uma função constante e igual a zero.

Mas, o que aconteceria se o parâmetro $a$ fosse alterado de 1 para -4 ? A Figura 6.6 ilustra essa alteração.

Notemos que não houve alteração das interseções do gráfico com o eixo das abscissas, mas houve uma alteração na amplitude da imagem do gráfico. Porém, aconteceram duas alterações importantes, um aumento da amplitude da imagem, seguido de uma reflexão do gráfico da função em relação ao eixo das abscissas. A reflexão está relacionada com o sinal negativo do parâmetro $a$.

As Figuras 6.7-6.9 ilustram alterações gráficas geradas por alterações no parâmetro b. A Figura 6.7 mostra o gráfico para $b=-5$, a Figura 6.8 mostra o gráfico para $b=0,2$, e a Figura 6.9 mostra o gráfico para $b=5$, mantendo-se inalterados nos três casos os parâmetros $a, c$ e $d$.

Observando as Figuras 6.7-6.9, percebem-se que alterações no parâmetro $b$ não alteram a imagem da função. Excetua-se o caso de $b=0$, em que $f$ se torna uma função constante e igual a zero. Porém, existe um aumento do período da função quando $b$ é alterado para algum valor no intervalo ] - 1, 1[ e uma diminuição desse período quando $b$ é alterado para algum valor real que não esteja no intervalo $[-1,1]$. Da mesma forma que observado nas alterações do parâmetro $a$, quando o parâmetro $b$ 


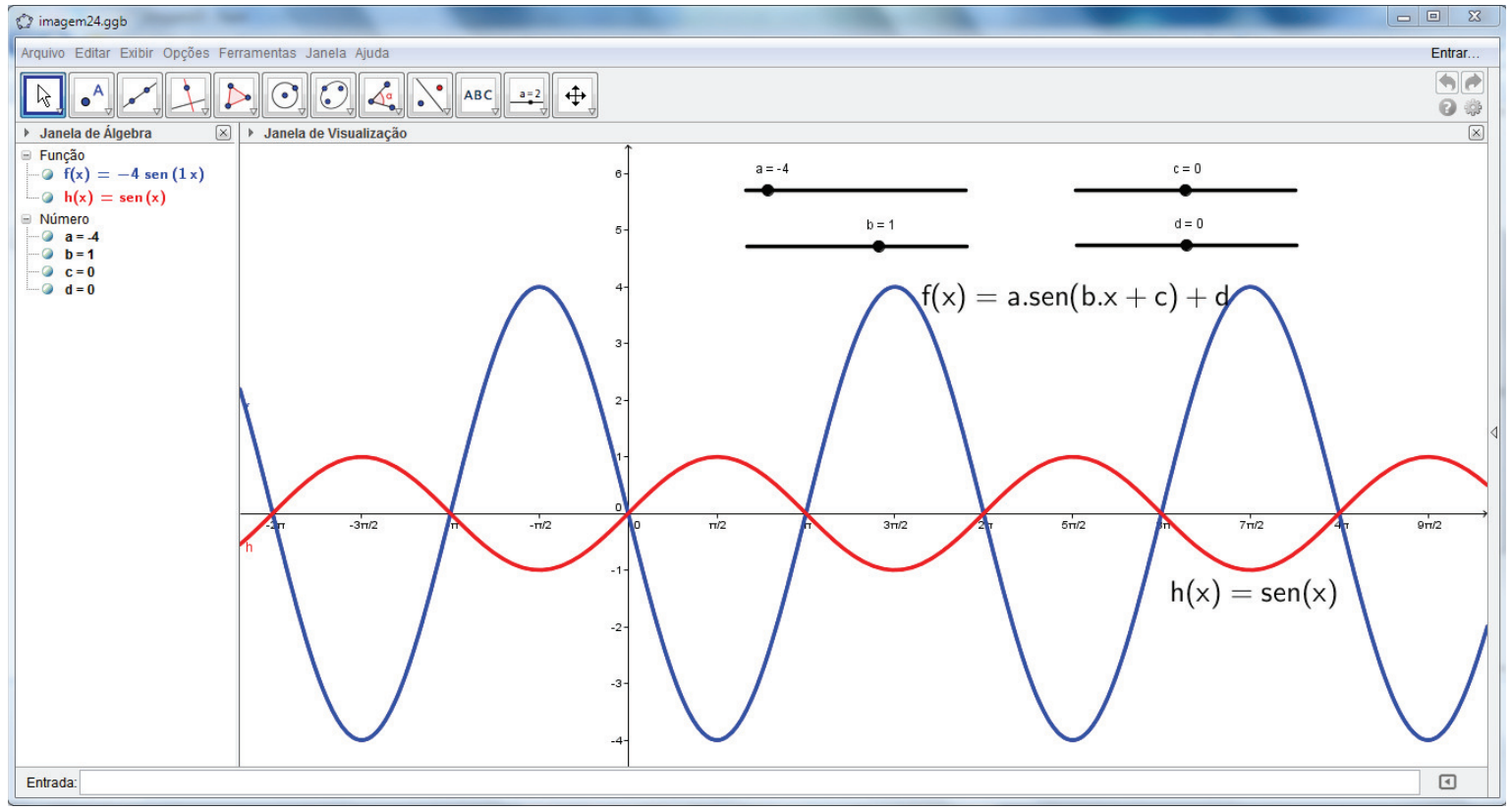

Figura 6.6: Gráfico da função $f(x)=a \cdot \operatorname{sen}(b \cdot x+c)+d$ para $a=-4, b=1, c=0$ e $d=0$

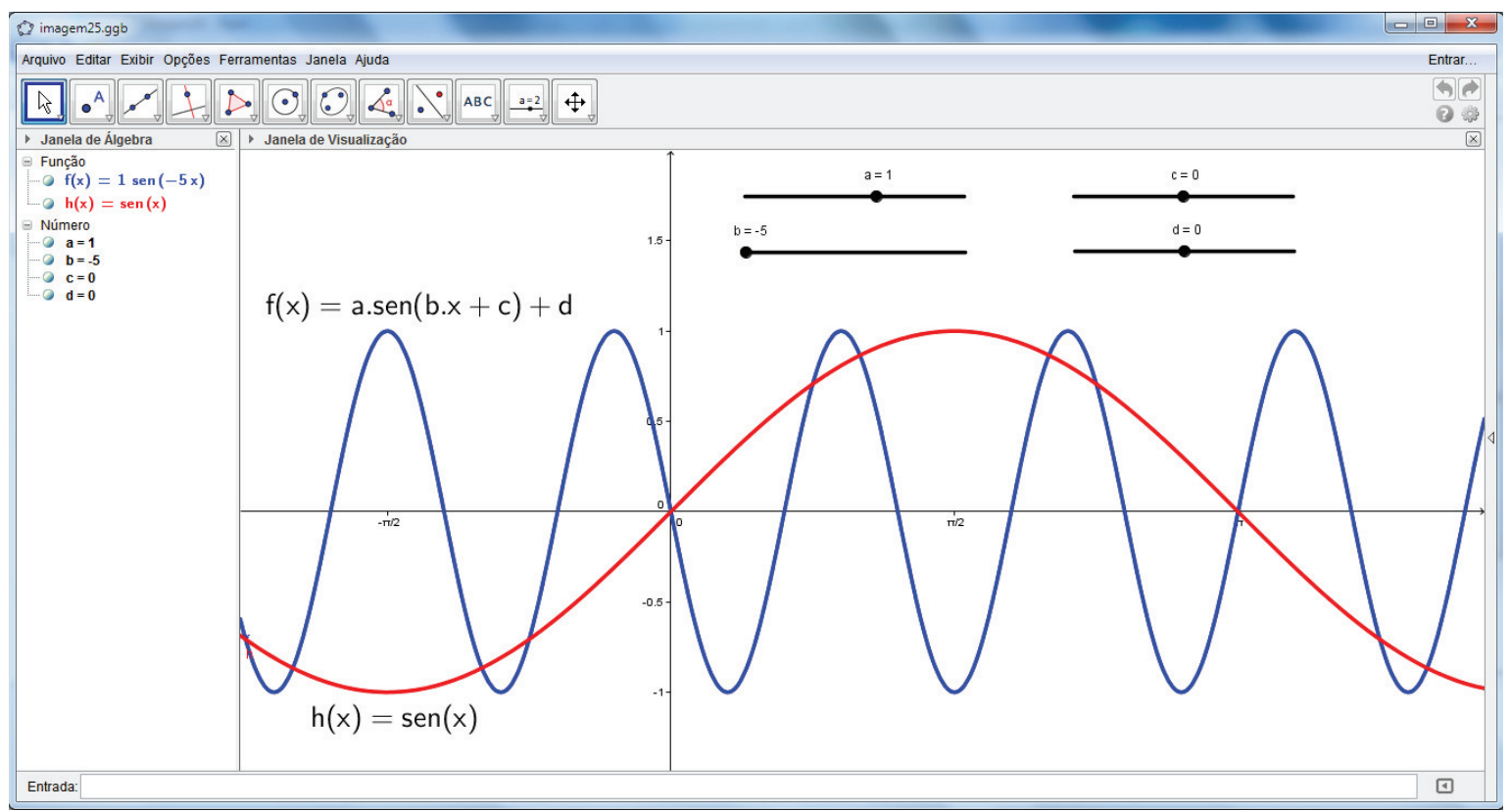

Figura 6.7: Gráfico da função $f(x)=a \cdot \operatorname{sen}(b \cdot x+c)+d$ para $a=1, b=-5, c=0$ e $d=0$

assume valores negativos, observa-se uma reflexão em relação ao eixo das abscissas.

A Figura 6.10 mostra o gráfico que é gerado quando altera-se o parâmetro $c$ de 0 para 2, mantendo-se os parâmetros $a, b$ e $d$ inalterados.

Na Figura 6.10, é possível observar que uma alteração no parâmetro $c$ não implica em alteração de domínio e imagem. O parâmetro $c$ mantém o gráfico com o mesmo formato, mas com um deslocamento horizontal. O deslocamento do gráfico será para 


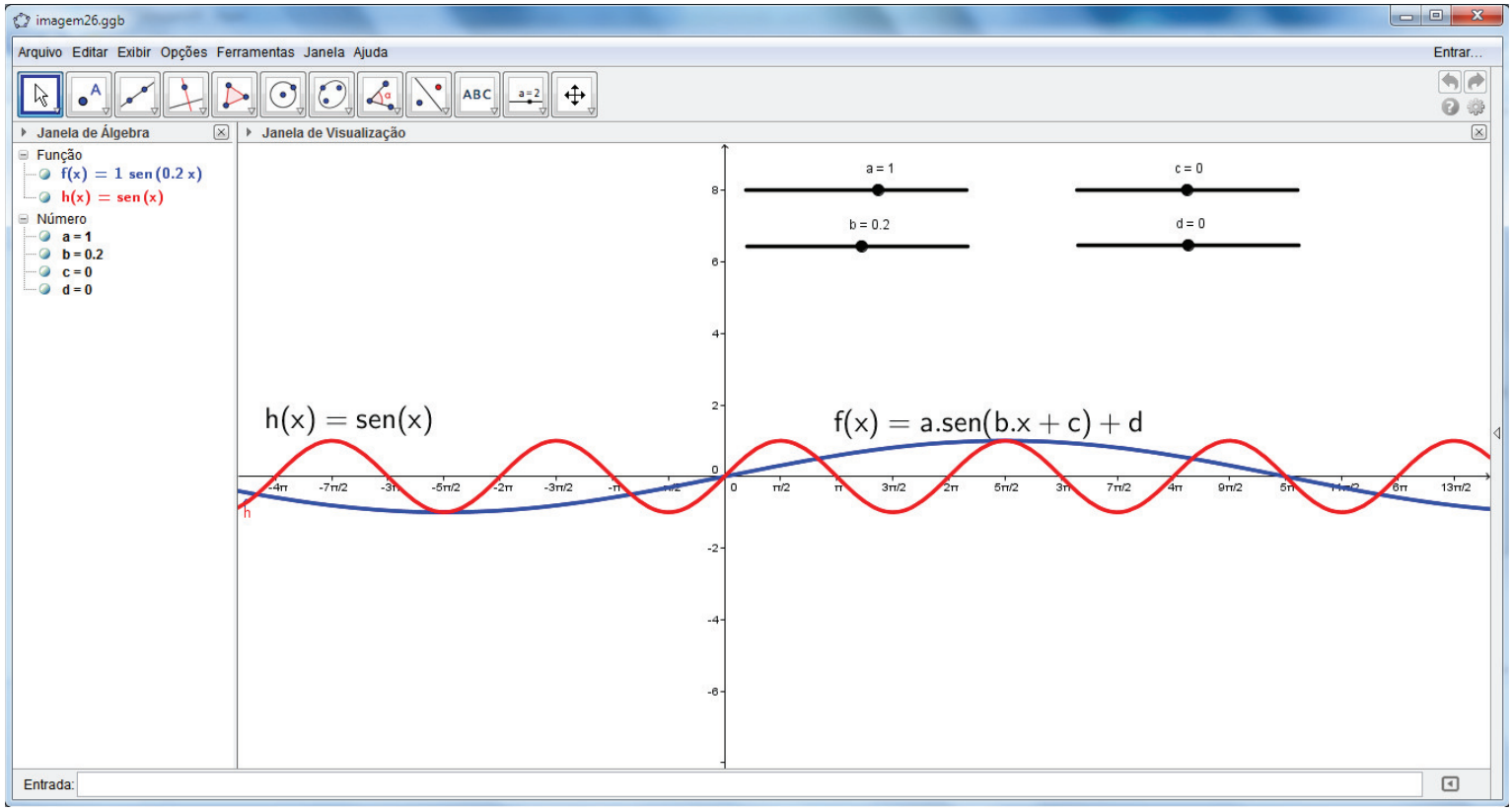

Figura 6.8: Gráfico da função $f(x)=a \cdot \operatorname{sen}(b \cdot x+c)+d$ para $a=1, b=0,2, c=0$ e $d=0$

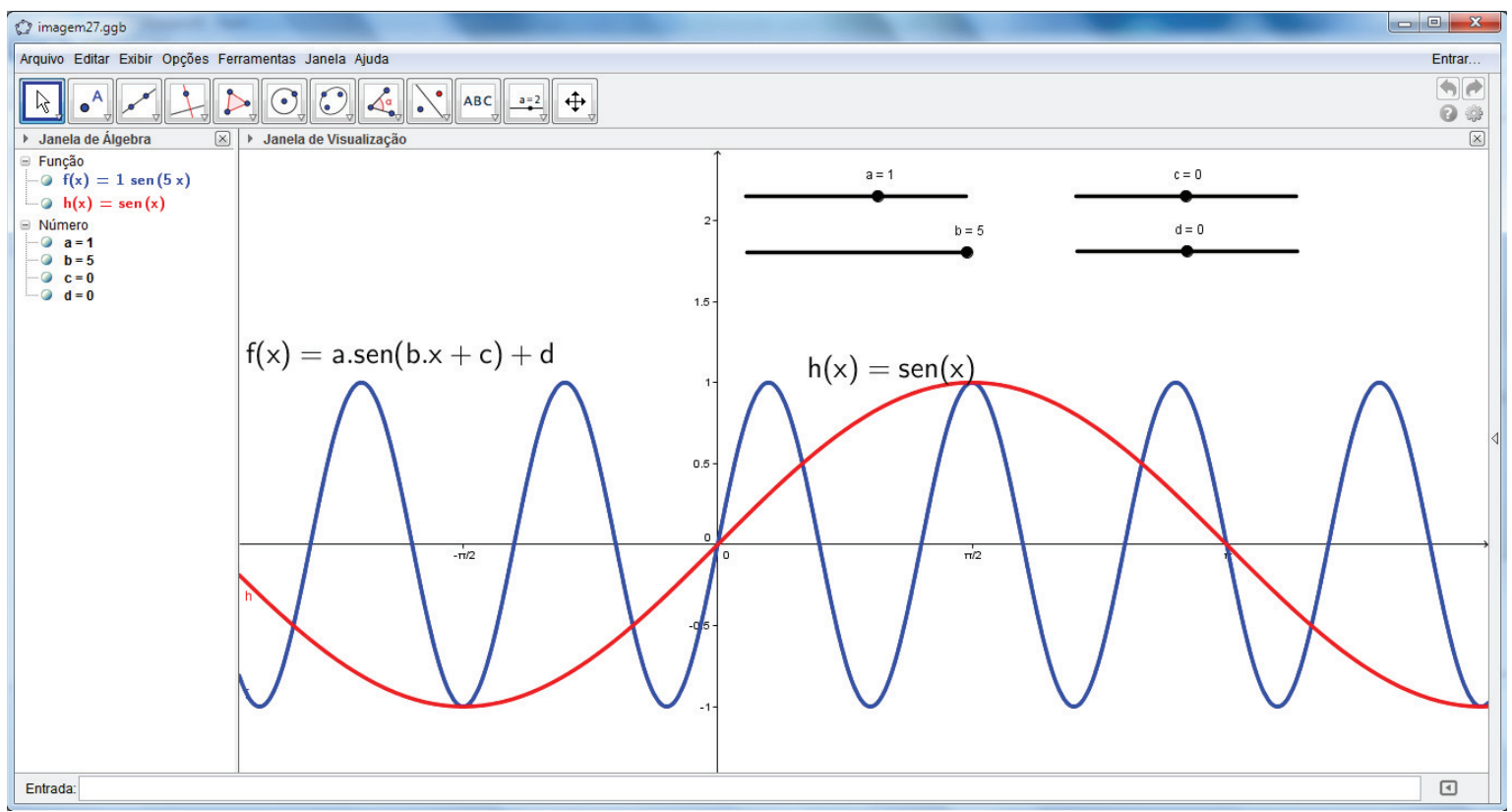

Figura 6.9: Gráfico da função $f(x)=a \cdot \operatorname{sen}(b \cdot x+c)+d$ para $a=1, b=5, c=0$ e $d=0$

a direita quando $c$ assumir valores menores que 0 (zero), e para a esquerda quando $c$ assumir valores maiores que 0 (zero). O módulo do deslocamento horizontal do gráfico é igual ao módulo do novo valor de $c$.

A Figura 6.11 mostra o gráfico gerado quando se altera o parâmetro $d$ de 0 (zero) para 4. Observa-se que uma alteração no parâmetro d gera uma alteração no gráfico similar a uma alteração no parâmetro $c$. As alterações no parâmetro $d$ não alteram o 


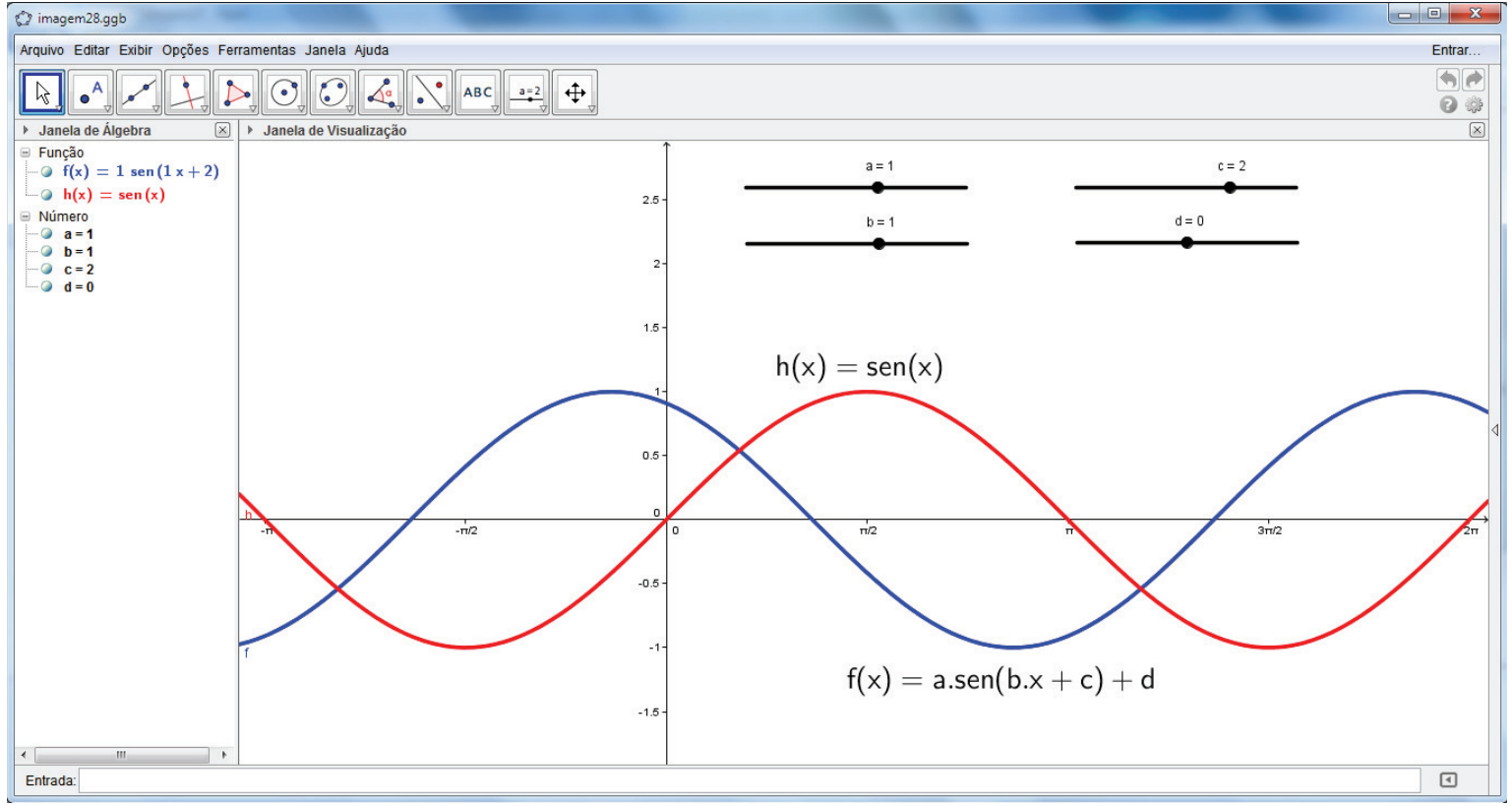

Figura 6.10: Gráfico da função $f(x)=a \cdot \operatorname{sen}(b \cdot x+c)+d$ para $a=1, b=1, c=2$ e $d=0$

domínio e a periodicidade da função, mas alteram a imagem, mantendo-se o formato do gráfico, ou seja, ocorrem deslocamentos verticais. O gráfico sofre deslocamento para cima quando $d$ assume valores maiores que 0 (zero), e deslocamento para baixo quando $d$ assume valores menores que 0 (zero). O módulo do deslocamento vertical é igual ao módulo do novo valor de $d$.

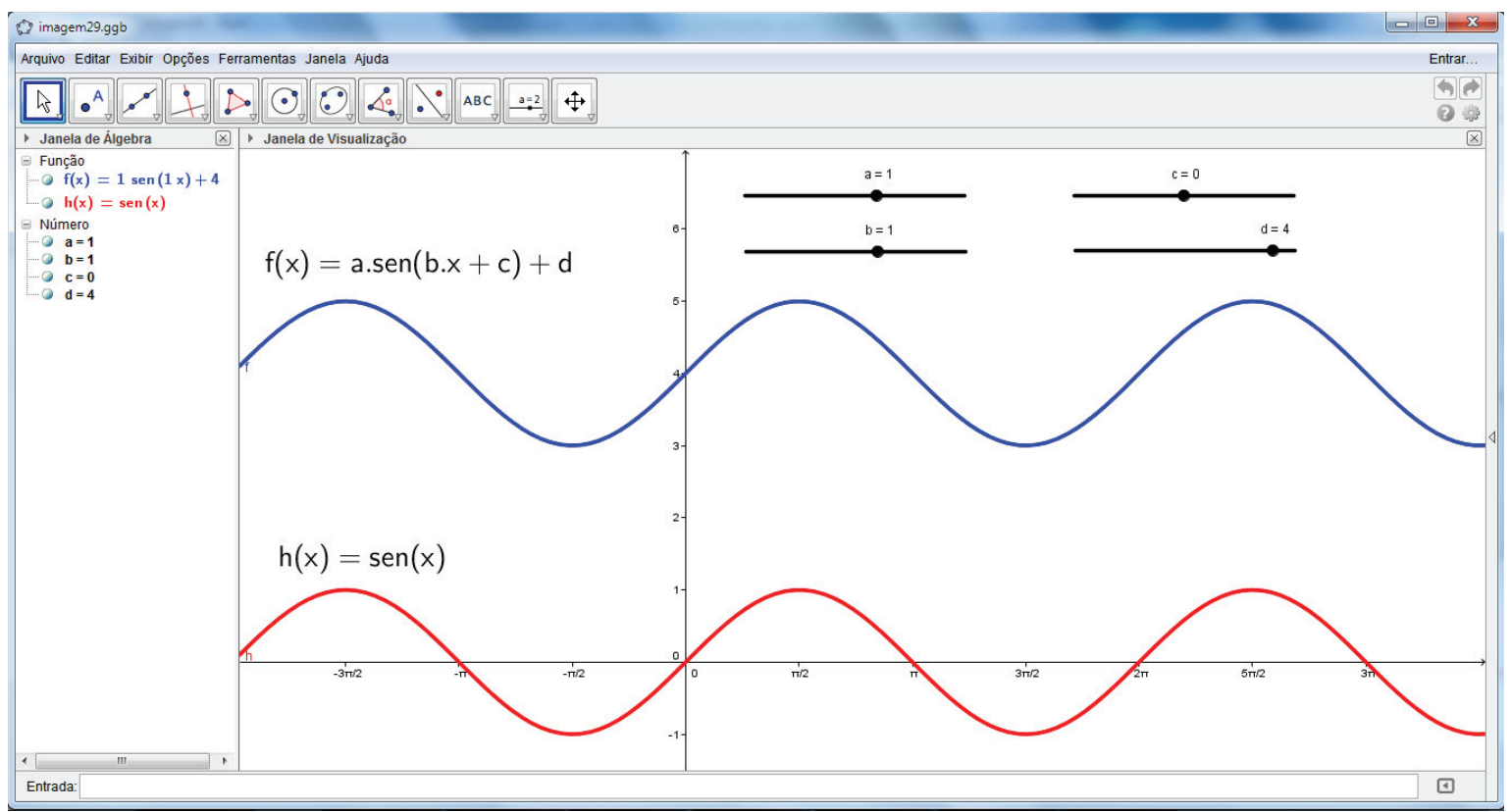

Figura 6.11: Gráfico da função $f(x)=a \cdot \operatorname{sen}(b \cdot x+c)+d$ para $a=1, b=1, c=0$ e $d=4$ 


\subsection{Atividade 3: Comparando as funções $f(x)=$}

$$
\operatorname{sen}(x) \text { e } g(x)=\cos (x+\pi / 2)
$$

Esta atividade tem como objetivo mostrar que é possível estabelecer relação de simetria entre os gráficos das funções $f(x)=\operatorname{sen}(x)$ e $g(x)=\cos (x+\pi / 2)$ e que o gráfico da função $g(x)=\cos (x+\pi / 2)$ pode ser obtido através de um deslocamento horizontal do gráfico da função $f(x)=\operatorname{sen}(x)$ e vice-versa. Para mostrar a relação de simetria, será utilizada a soma de funções e, para mostrar que os gráficos das duas funções têm o mesmo formato, será acrescido um incremento no argumento trigonométrico de uma das funções.

\subsubsection{Passo a passo da construção - $1^{\mathrm{a}}$ Parte}

- Passo 1: Construir o gráfico da função $f(x)=\operatorname{sen}(x)$. Para isso, vá à caixa de entrada e digite: $f(x)=\sin (x)$;

- Passo 2: Construir o gráfico da função $g(x)=\cos (x+\pi / 2)$. Para isso, vá na caixa de entrada e digite: $g(x)=\cos (x+p i / 2)$;

- Passo 3: Construir o gráfico da função que represente a soma das funções $f(x)=$ $\operatorname{sen}(x)$ e $g(x)=\cos (x+\pi / 2)$. Para isso, vá à caixa de entrada e digite: $\mathrm{h}(\mathrm{x})=$ $\sin (\mathrm{x})+\cos (\mathrm{x}+\mathrm{pi} / 2)$. Neste caso, como as funções $f(x)=\operatorname{sen}(x)$ e $g(x)=$ $\cos (x+\pi / 2)$ foram nomeadas de $f(x)$ e $g(x)$, outra opção de digitação na caixa de entrada é: $h(x)=f(x)+g(x)$;

- Passo 4: Alterar os incrementos do eixo das abscissas. Para isso, na parte branca da janela de visualização, clique com o botão direito do mouse e na guia eixo x, vá em distância e escolha " $\pi / 2$ ";

- Passo 5: Alterar a cor e o estilo dos gráficos das funções.

A Figura 6.12 mostra os gráficos obtidos através da execução dos passos 1-5 da Atividade 3.

Esta é uma atividade que traz um aspecto visual muito interessante, uma vez que é possível perceber nitidamente a simetria entre as duas funções em relação ao eixo das abscissas. A função $h(x)$, resultante da adição de $f(x)$ com $g(x)$, ajuda a compreender essa simetria. É importante salientar também que as duas funções, $f(x)$ e $g(x)$ têm suas imagens no intervalo [-1,1], e mesmo assim a função $h(x)$, sendo resultante de um somatório, tem sua imagem unitária e igual a 0 (zero). Vale observar que só é possível encontrar uma função igual a zero no somatório de duas funções, se as duas funções adicionadas tiverem valores opostos, ponto a ponto. 


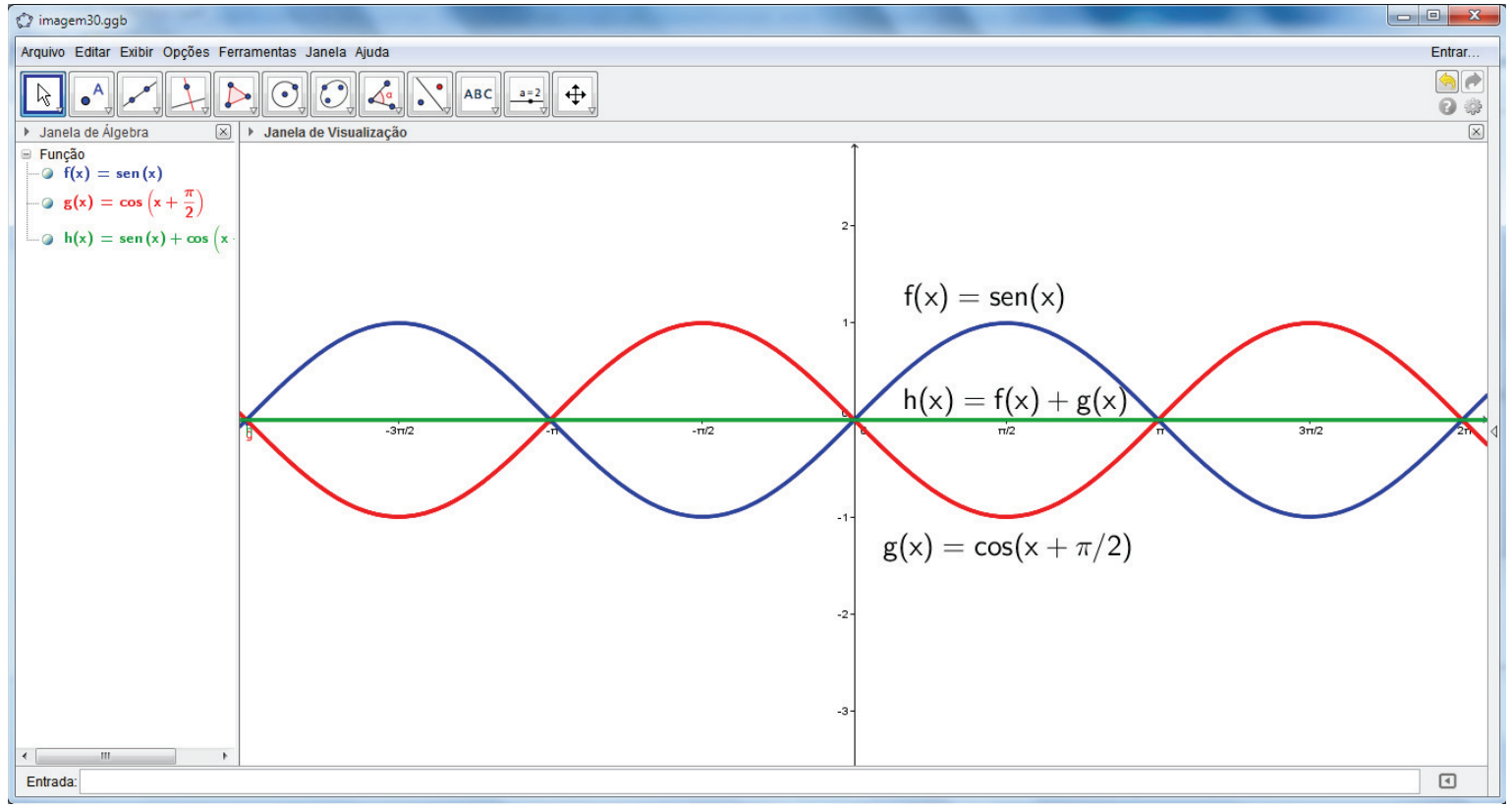

Figura 6.12: Gráfico das funções $f(x)=\operatorname{sen}(x), g(x)=\cos (x+\pi / 2)$ e $h(x)=\operatorname{sen}(x)+$ $\cos (x+\pi / 2)$ da $1^{\text {a }}$ Parte da Atividade 3

$\mathrm{Na}$ atividade 2, em que foi feita uma análise da função $f(x)=a \cdot \operatorname{sen}(b \cdot x+c)+$ $d$, através dos parâmetros $a, b, c$ e $d$, foi possível observar que o parâmetro $c$ foi o responsável por um deslocamento horizontal do gráfico. Esse parâmetro $c$ é um incremento do argumento trigonométrico da função. Na Figura 6.12, observa-se que os gráficos das funções $f(x)=\operatorname{sen}(x), g(x)=\cos (x+\pi / 2)$ aparentemente têm o mesmo formato. Percebe-se também que esses dois gráficos têm o mesmo período. Ainda se observa que para $x=\pi / 2$ tem-se um ponto de mínimo local da função $g(x)=\cos (x+\pi / 2)$, e para $x=3 \pi / 2$ tem-se um ponto de mínimo local da função $f(x)=\operatorname{sen}(x)$. A função $f(x)=\operatorname{sen}(x)$ também apresenta um ponto de mínimo local para $x=-\pi / 2$. Pelo exposto, supõe-se que as funções $g(x)=\cos (x+\pi / 2) \mathrm{e}$ $p(x)=\operatorname{sen}(x+\pi)$ têm o mesmo gráfico. Para isto ser verdade, as duas funções devem ser iguais ponto a ponto. Sendo iguais, a diferença entre as duas funções deve ser igual a 0 (zero). Para confirmar essa suposição observemos a $2^{\text {a }}$ parte do passo a passo da Atividade 3.

\subsubsection{Passo a passo da construção - $2^{\mathrm{a}}$ Parte}

- Passo 1: Construir o gráfico da função $p(x)=\operatorname{sen}(x+\pi)$. Para isso, vá à caixa de entrada e digite: $f(x)=\sin (x+p i)$;

- Passo 2: Construir o gráfico da função $g(x)=\cos (x+\pi / 2)$. Para isso, vá à caixa de entrada e digite: $g(x)=\cos (x+p i / 2)$; 
- Passo 3: Construir o gráfico da função que represente a diferença das funções $p(x)=\operatorname{sen}(x+\pi)$ e $g(x)=\cos (x+\pi / 2)$. Para isso, vá à caixa de entrada $\mathrm{e}$ digite: $\mathrm{d}(\mathrm{x})=\sin (\mathrm{x}+\mathrm{pi})-\cos (\mathrm{x}+\mathrm{pi} / 2)$. Neste caso, como as funções $p(x)=$ $\operatorname{sen}(x+\pi)$ e $g(x)=\cos (x+\pi / 2)$ foram nomeadas de $p(x)$ e $g(x)$, outra opção de digitação na caixa de entrada é: $d(x)=p(x)-g(x)$;

- Passo 4: Alterar os incrementos do eixo das abscissas. Para isso, na parte branca da janela de visualização, clique com o botão direito do mouse, e na guia eixo x, vá em distância e escolha " $\pi / 2$ ";

- Passo 5: Alterar a cor e o estilo dos gráficos das funções.

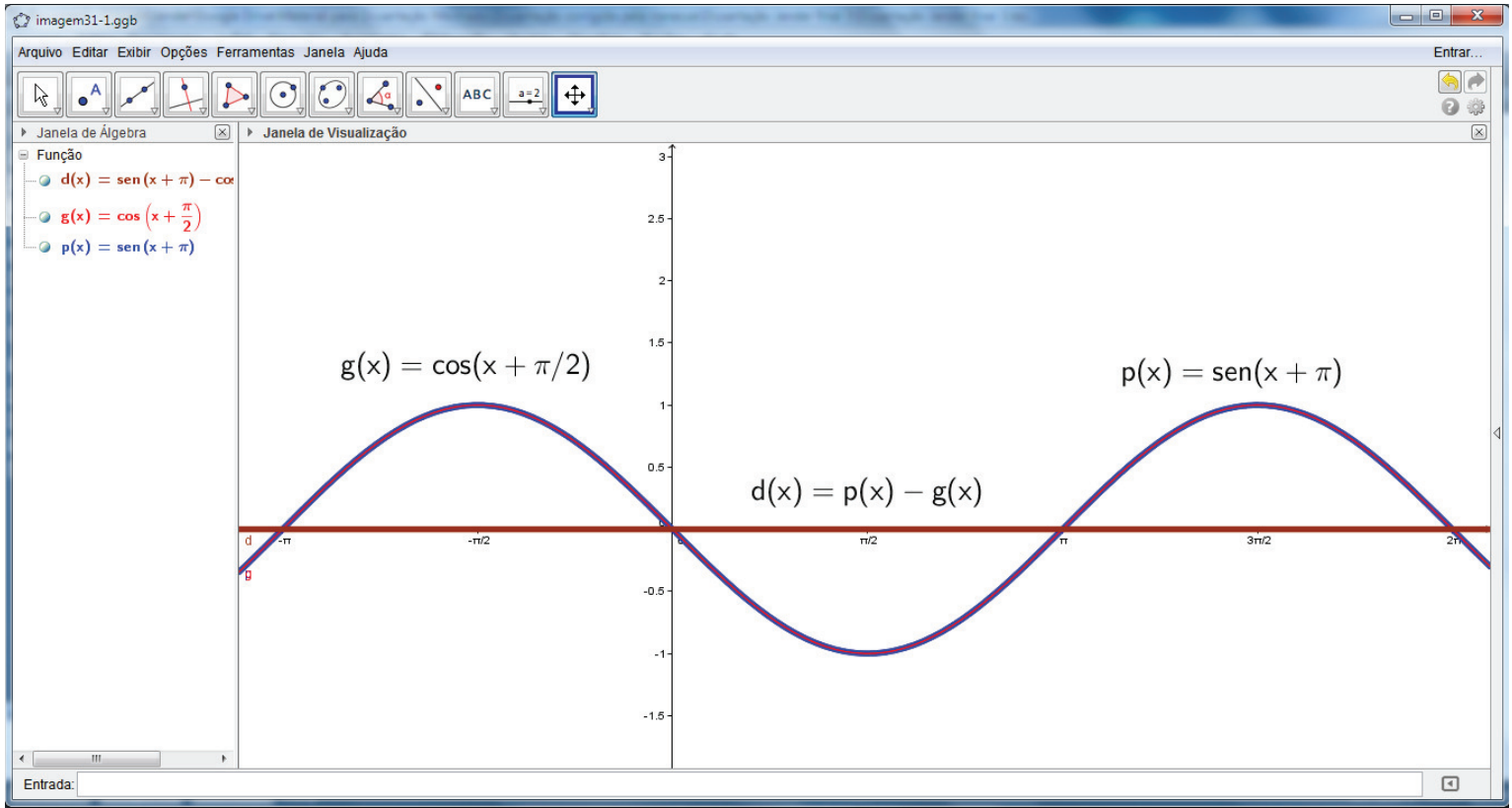

Figura 6.13: Gráfico das funções $p(x)=\operatorname{sen}(x+\pi), g(x)=\cos (x+\pi / 2)$ e $d(x)=$ $\operatorname{sen}(x+\pi)-\cos (x+\pi / 2)$

Na Figura 6.13, os gráficos das funções $p(x)=\operatorname{sen}(x+\pi)$ e $g(x)=\cos (x+\pi / 2)$ aparentemente ficaram sobrepostos, e o gráfico da função $d(x)=\operatorname{sen}(x+\pi)-\cos (x+$ $\pi / 2)$ é uma reta horizontal que passa pela origem. Além disso, os gráficos das funções $p(x)=\operatorname{sen}(x+\pi)$ e $g(x)=\cos (x+\pi / 2)$ são gráficos de funções ímpares, cuja imagem é o intervalo $[-1,1]$. Como o gráfico da função $d(x)$ é uma reta horizontal que passa pela origem, as funções $p(x)$ e $g(x)$ são iguais ponto a ponto. 


\section{Capítulo 7}

\section{Equações trigonométricas com o auxílio do GeoGebra}

Série de aplicação das atividades: De acordo com São Paulo(2012), as atividades propostas neste capítulo são indicadas para a $2^{\mathrm{a}}$ série do ensino médio para o estudo de equações trigonométricas.

Neste capítulo, são apresentadas três atividades:

- Atividade 1: - Verificando a relação fundamental da trigonometria: $\operatorname{sen}^{2}(x)+$ $\cos ^{2}(x)=1$

- Atividade 2: - Resolvendo a equação $\operatorname{sen}(\mathrm{x})=\mathrm{a}$, para todo $a$ real;

- Atividade 3: - Descobrindo a soma das raízes da equação $\operatorname{sen}^{2}(x)-\cos (x)=0$.

Uma das grandes dificuldades dos alunos em equações trigonométricas é a interpretação do resultado, visto que geralmente a parte algébrica não é amplamente associada à parte gráfica. No estudo de equações trigonométricas, é possível a associação com funções trigonométricas. Esse aspecto é facilitador de aprendizagens, uma vez que gráficos são representações visuais de comportamentos algébricos, e o GeoGebra traz a possibilidade de ver antes de resolver.

Na Atividade 1, serão feitas duas verificações da relação fundamental da trigonometria: $\operatorname{sen}^{2}(x)+\cos ^{2}(x)=1$. A primeira verificação levará em conta aspectos geométricos e a segunda, aspectos gráficos.

Na Atividade 2, será feita a resolução gráfica da equação $\operatorname{sen}(x)=a$. Nela, será possível observar uma dificuldade do GeoGebra para representar graficamente e algebricamente infinitas soluções para a equação.

Na atividade 3, será possível perceber com clareza a importância da resolução de equações trigonométricas pelo método gráfico. Visualizar o comportamento do gráfico 
de uma função associado a uma equação norteia significativamente a compreensão das soluções da equação.

\subsection{Atividade 1 - Verificando a relação fundamental da trigonometria: $\operatorname{sen}^{2}(x)+\cos ^{2}(x)=1$}

Nesta atividade, será mostrado, de dois modos diferentes, que a relação fundamental da trigonometria: $\operatorname{sen}^{2}(x)+\cos ^{2}(x)=1$ é válida para qualquer $x$ real. No $1^{\circ}$ modo, será utilizada a circunferência trigonométrica com o auxílio de retas perpendiculares, e no $2^{\circ}$ modo será utilizada a soma das funções $f(x)=\operatorname{sen}^{2}(x)$ e $g(x)=\cos ^{2}(x)$.

\subsubsection{Passo a passo da construção - $1^{\circ}$ Modo}

- Passo 1: Repetir os passos 1 a 15 da Atividade 2 do capítulo 5 referentes à construção da circunferência trigonométrica, mantendo o ponto A no primeiro quadrante;

- Passo 2: Construir retas perpendiculares. Para isso, utilize o botão "Reta Perpendicular" e construa uma reta perpendicular ao segmento OD passando pelo ponto A, clicando no segmento OD e depois no ponto A, renomeie essa reta para $j$. Na sequência, construa também uma reta perpendicular ao segmento OC passando pelo ponto A, renomeie essa reta para $k$.

- Passo 3: Medir os comprimentos dos segmentos AC e AD. Para isto, utilize o botão "Distância, Comprimento ou Perímetro";

- Passo 4: Medir o ângulo AĈO. Para isso, utilize o botão "Ângulo";

- Passo 5: Criar os números $p$ e $q$. O número $p$ deverá representar o quadrado da medida do segmento(cateto) AC. Para isso, vá à caixa de entrada e digite: $\mathrm{p}=\mathrm{AC} * \mathrm{AC}$. $\mathrm{O}$ número $q$ deverá representar o quadrado da medida do segmento(cateto) OC. Para isso, vá à caixa de entrada e digite: $q=0 C * 0 C$. Os resultados numéricos estarão visíveis na janela de álgebra;

- Passo 6: Criar o número $r$. O número $r$ deverá ser o resultado do somatório de $p$ e $q$. Para isso, vá à caixa de entrada e digite: $r=p+q$;

- Passo 7: Animar o ponto A.

Após a execução do passo 3 da Atividade 1 - $1^{\circ}$ Modo, o aluno poderá observar que o quadrilátero ADOC é um retângulo, pois tem lados opostos com a mesma medida. 


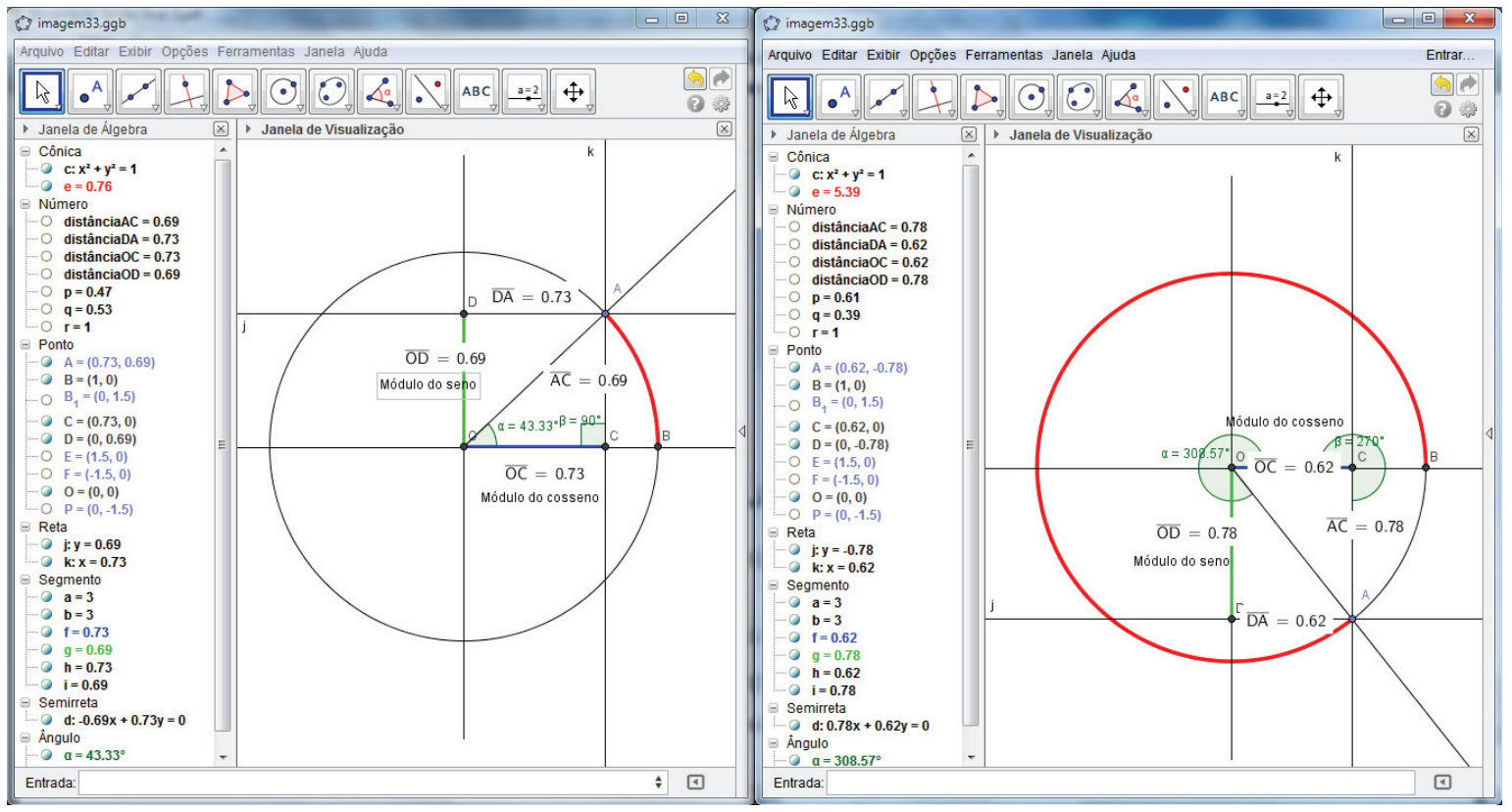

Figura 7.1: Resultado dos passos 1-7 do $1^{\circ}$ modo da atividade 3

Poderia também chegar a essa conclusão, observando que os segmentos OD e OC formam um ângulo reto e, supostamente, a reta $j$ contém o segmento AD e, portanto, os segmentos AD e OD seriam perpendiculares. Supondo que o aluno ainda não tenha chegado a essa conclusão, após a execução do passo 5 espera-se que não tenha mais dúvida. Neste ponto, o aluno perceberá que o triângulo ACO é retângulo em $\mathrm{C}$ e as medidas de seus catetos são $\operatorname{sen}(x)$ e $\cos (x)$, e a hipotenusa é o raio da circunferência trigonométrica que vale 1. Basta, neste momento, aplicar o Teorema de Pitágoras para verificar que $\operatorname{sen}^{2}(x)+\cos ^{2}(x)=1$. O Teorema de Pitágoras ficará mais evidente ao passo que se visualizar as oscilações nos valores de $p$ e $q$ com simultânea manutenção do valor de $r$. A Figura 7.1 mostra dois momentos da animação do ponto A. Do lado esquerdo, o ponto A está no $1^{\circ}$ quadrante, e do lado direito está no $4^{\circ}$ quadrante.

A relação $\operatorname{sen}^{2}(x)+\cos ^{2}(x)=1$ também pode ser verificada no GeoGebra por meio de gráficos de funções. O passo a passo da construção - $2^{\circ}$ Modo ilustra esta verificação.

\subsubsection{Passo a passo da construção - $2^{\circ}$ Modo}

- Passo 1: Construa o gráfico da função $f(x)=\operatorname{sen}^{2}(x)$. Para isso, vá à caixa de entrada e digite: $f(x)=\sin (x) * \sin (x)$;

- Passo 2: Construa o gráfico da função $g(x)=\cos ^{2}(x)$. Para isso, vá à caixa de entrada e digite: $\mathrm{g}(\mathrm{x})=\cos (\mathrm{x}) * \cos (\mathrm{x})$;

- Passo 3: Construa o gráfico da funçao $h(x)=f(x)+g(x)$. Para isso, vá à caixa 
de entrada e digite: $h(x)=f(x)+g(x)$;

- Passo 4: Altere a cor e o estilo das três funções.

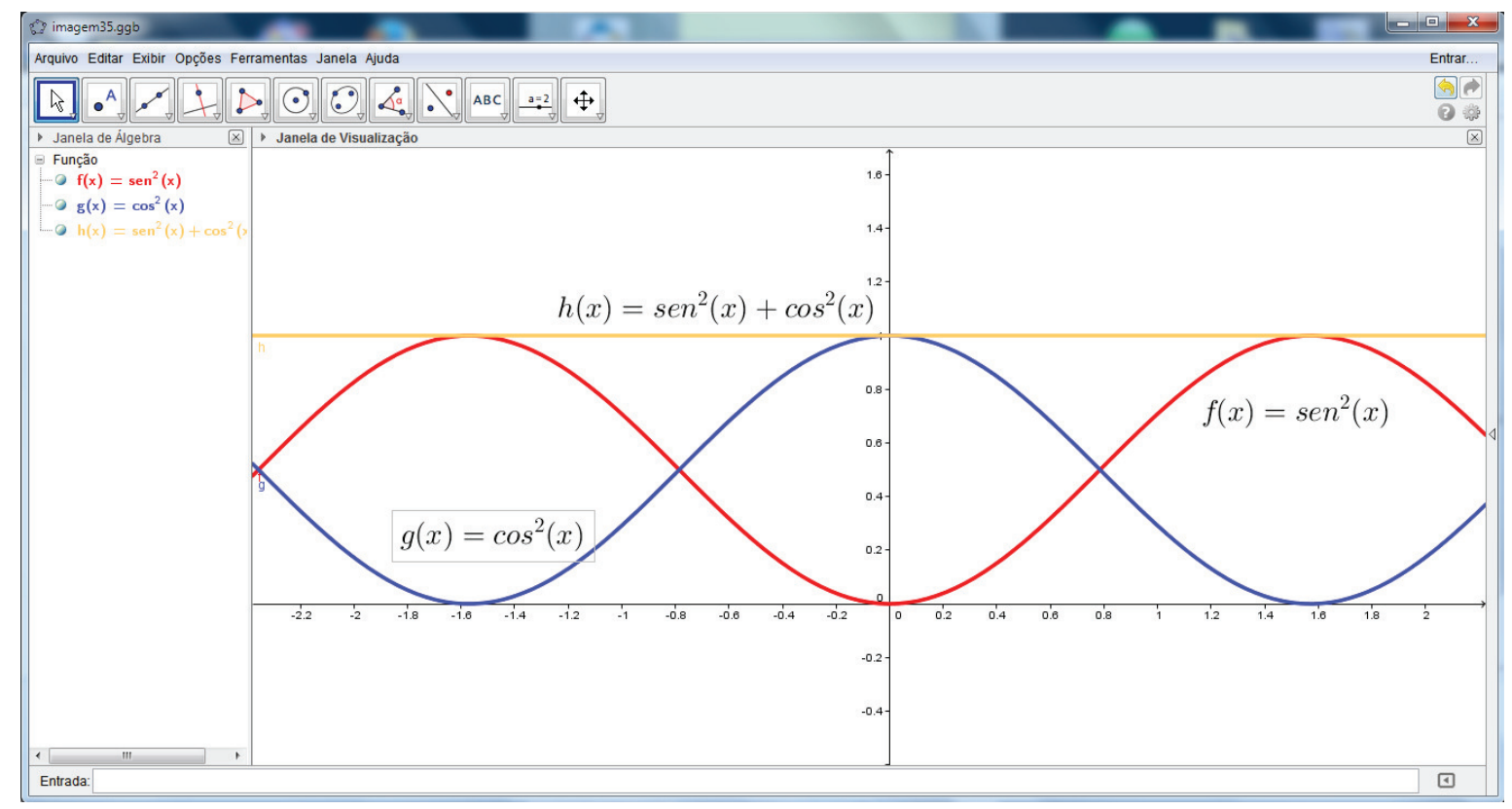

Figura 7.2: Gráfico da função $h(x)=f(x)+g(x)$, sendo $f(x)=\operatorname{sen}^{2}(x)$ e $g(x)=\cos ^{2}(x)$ resultante da execução dos passos 1-4 da Atividade 1 - $2^{\circ}$ Modo

A Figura 7.2 mostra os gráficos das funções $f(x)=\operatorname{sen}^{2}(x), g(x)=\cos ^{2}(x)$ e $h(x)$ como resultante do somatório ponto a ponto de $f(x)$ com $g(x)$. O interessante desses gráficos é que somando duas funções periódicas, obtém-se uma função constante. Como o domínio das três funções é real, observa-se que para qualquer x temos $f(x)+g(x)=1$. Isso mostra que para qualquer $\mathrm{x}$ real vale a relação fundamental da trigonometria, $\operatorname{sen}^{2}(x)+\cos ^{2}(x)=1$.

\subsection{Atividade 2 - Resolvendo a equação $\operatorname{sen}(x)=a$, para todo a real}

Esta é uma atividade muito interessante para ser trabalhada com o GeoGebra. Por um motivo muito simples. O gráfico da função constante do tipo $g(x)=a$ é uma reta horizontal que corta o eixo das ordenadas no ponto $a$ e a função $f(x)=\operatorname{sen}(x)$ tem imagem em [-1,1], e é periódica. Considerando a no intervalo [-1,1], tem-se infinitos pontos de interseção entre os gráficos dessas duas funções. O GeoGebra representa os pontos de interseção graficamente e algebricamente. Porém, esse é um caso em que é impossível registrar todos estes pontos algebricamente e graficamente, por se tratar de infinitos pontos. Dessa forma, em caso de infinitas interseções, por uma questão 
de racionalidade, supõe-se que o GeoGebra, ao receber o comando "Interseção de Dois Objetos" utiliza algum método de aproximação para encontrar o ponto de interseção mais próximo em relação a pontos dos dois gráficos selecionados. No caso de infinitas interseções, o GeoGebra as encontra ponto por ponto. Essa Atividade 2 ilustrará esta situação.

\subsubsection{Passo a passo da construção}

- Passo 1: Construa o gráfico da função $f(x)=\operatorname{sen}(x)$. Para isso, vá à caixa de entrada e digite $f(x)=\sin (x)$;

- Passo 2: Construa um controle deslizante. Para isso utilize o botão "Controle Deslizante". Será automaticamente criado o controle deslizante $a$;

- Passo 3: Construa o gráfico da função $g(x)=a$. Para isso, vá à caixa de entrada e digite $\mathrm{g}(\mathrm{x})=\mathrm{a}$ (o valor de $a$ é o mesmo do controle deslizante criado no passo $2)$;

- Passo 4: Costrua os pontos de interseção entre os gráficos das funções f(x) e g(x). Para isso utilize o botão "Interseção de Dois Objetos" e clique respectivamente nos gráficos das funções $f(x)$ e $g(x)$. Como já mencionado anteriormente, apesar de existirem infinitos pontos de interseção, foi criado apenas o ponto A. Repita este passo mais vezes, clicando nos gráficos em local próximo de outros pontos de interseção;

- Passo 5: Altere a unidade do eixo das abscissas para $\pi$. Para isso, clique com o botão direito do mouse sobre eixo x, e escolha "Janela de Visualização". Na guia eixo x escolha "Distância";

- Passo 6: Altere a cor e o estilo dos gráficos;

- Passo 7: Animar o controle deslizante a. Para isso, clique com o botão direito do mouse sobre o controle deslizante $a$ e escolha "Animar".

Como as propriedades do controle deslizante $a$ não foram alteradas, com a animação seus valores oscilarão no intervalo $[-5,5]$. Porém, só existirão interseções entre o gráficos das funções $f(x)=\operatorname{sen}(x)$ e $g(x)=a$ quando o valor do controle deslizante $a$ pertencer ao intervalo $[-1,1]$. Portanto, a equação $\operatorname{sen}(x)=a$ só terá solução para $a$ pertencente ao intervalo [-1,1]. A Figura 7.3 mostra a resolução gráfica da equação $\operatorname{sen}(x)=a$ em um momento em que o valor do controle deslizante $a$ é igual a 0.5. 


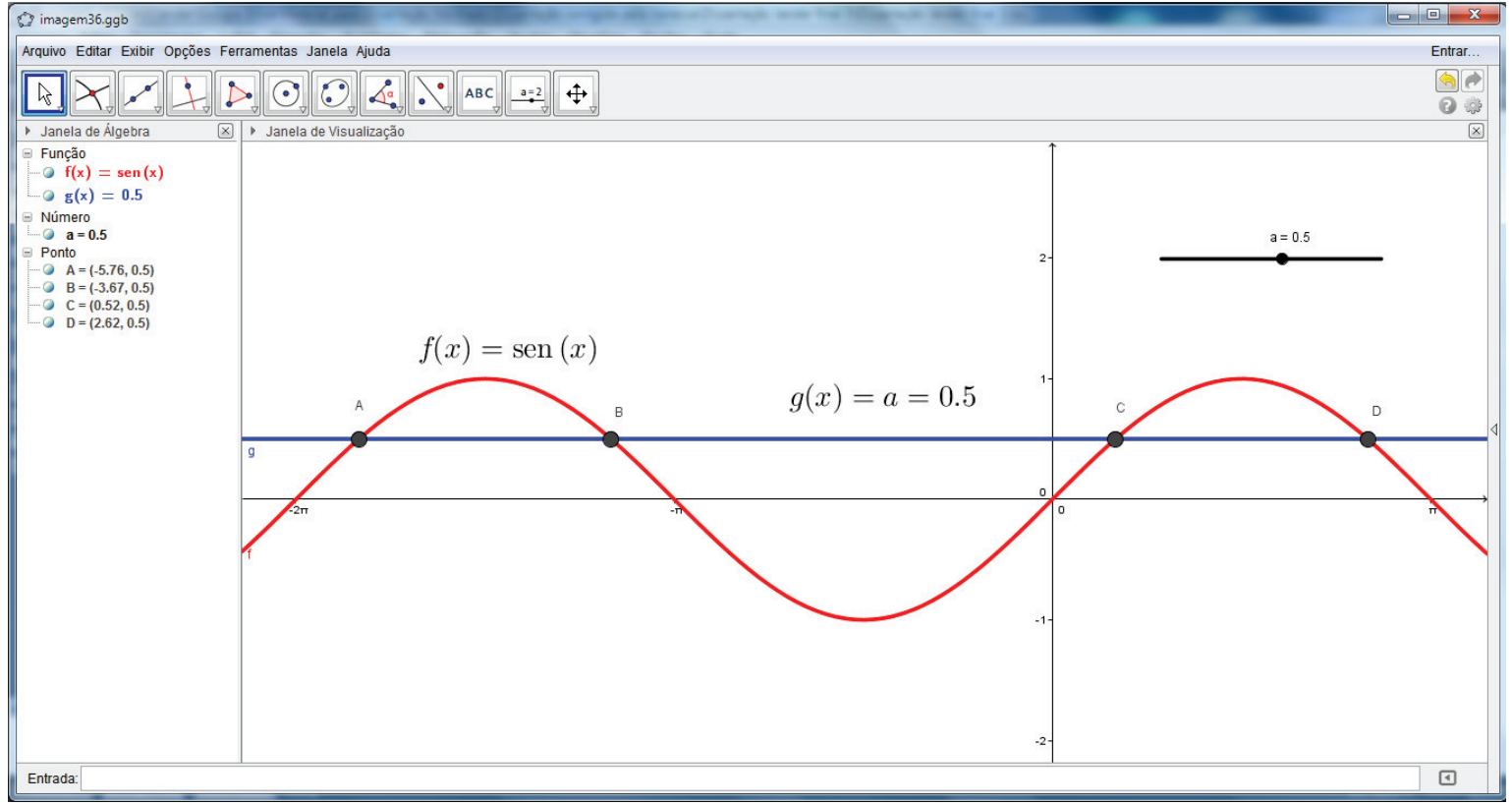

Figura 7.3: Resolução gráfica da equação sen $(x)=0,5$

\subsection{Atividade 3 - Descobrindo a simetria das raízes da equação $\operatorname{sen}^{2}(x)-\cos (x)=0$ no intervalo [- $2 \pi, 2 \pi]$}

Sejam $q_{1}+q_{2}+q_{3}+\ldots . .+q_{n}$ as raízes da equação $\operatorname{sen}^{2}(x)-\cos (x)=0$. Utilize o GeoGebra para mostrar graficamente que as raízes da equação $\operatorname{sen}^{2}(x)-\cos (x)=0$ no intervalo $[-2 \pi, 2 \pi]$ são simétricas.

\subsubsection{Passo a passo da construção}

- Passo 1: Contruir o gráfico da função $f(x)=\operatorname{sen}^{2}(x)$. Para isso, vá à caixa de entrada e digite: $\mathrm{f}(\mathrm{x})=\sin (\mathrm{x}) * \sin (\mathrm{x})$;

- Passo 2: Construir o gráfico da função $g(x)=\cos (x)$, para isso, vá à caixa de entrada e digite: $\mathrm{g}(\mathrm{x})=\cos (\mathrm{x})$;

- Passo 3: Alterar o estilo e a cor dos gráficos;

- Passo 4: Construir o gráfico da função $h(x)=f(x)-g(x)$. Para isso, vá à caixa de entrada e digite: $\mathrm{h}(\mathrm{x})=\mathrm{f}(\mathrm{x})-\mathrm{g}(\mathrm{x})$. Altere a cor e o estilo do gráfico;

- Passo 5: Ocultar os gráficos das funções $f(x)$ e $g(x)$. Para isso, clique com o botão direito do mouse sobre o gráfico e escolha "Exibir Objeto"; 
- Passo 6: Encontrar ponto de interseção do gráfico com o eixo das abscissas. Utilize o botão "Interseção de Dois Objetos" para encontrar as interseções mais próximas do ponto $(0,0)$. Observe que foram criados os ponts A e B. Crie o ponto $\mathrm{O}(0,0)$;

- Passo 7: Encontrar as distâncias do ponto $\mathrm{O}(0,0)$ ao ponto A e ao ponto B;

- Passo 8: Alterar a quantidade de casas decimais. Na barra de menus, clique em "Opções", em seguida em "Arredondamento" e depois em "5 casas decimais";

- Passo 9: Construir duas circunferências. Uma com centro em O e raio OA e outra com centro em $\mathrm{O}$ e raio $\mathrm{OB}$;

- Passo 10: Encontrar os pontos C e D de interseção do eixo x com o gráfico. Escolha os pontos de interseção mais próximos do ponto $\mathrm{O}(0,0)$;

- Passo 11: Encontrar as distâncias do ponto $\mathrm{O}(0,0)$ ao ponto $\mathrm{C}$ e ao ponto D;

- Passo 12: Construir duas circunferências. Uma com centro em O e raio OC e outra com centro em $\mathrm{O}$ e raio OD;

- Passo 13: Criar o número p. Para isso, vá à caixa de entrada e digite: p=0A-0B;

- Passo 14: Criar o número q. Para isso, vá à caixa de entrada e digite: q=OC-OD;

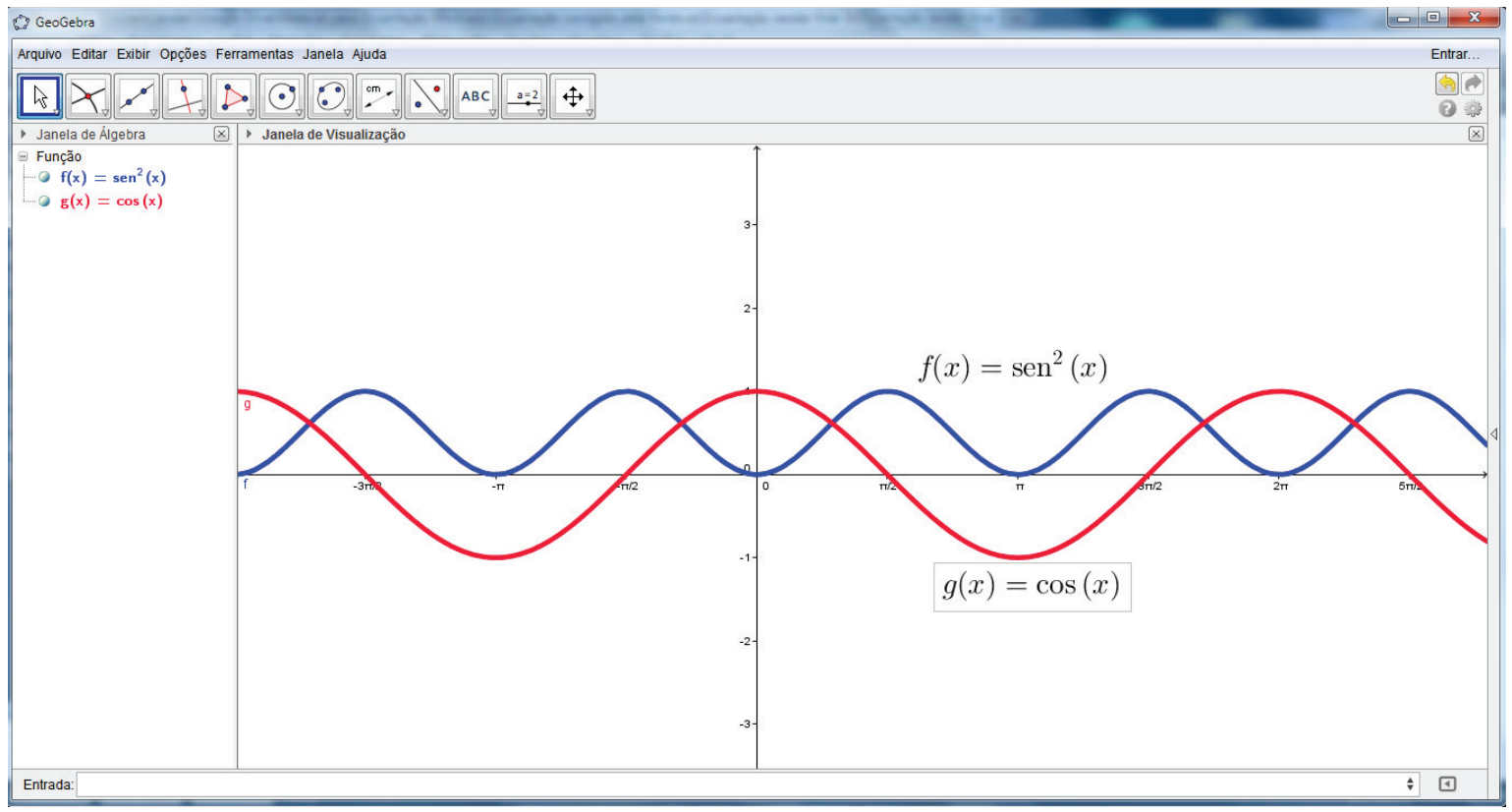

Figura 7.4: Gráficos das funções $f(x)=\operatorname{sen}^{2}(x)$ e $g(x)=\cos (x)$ 


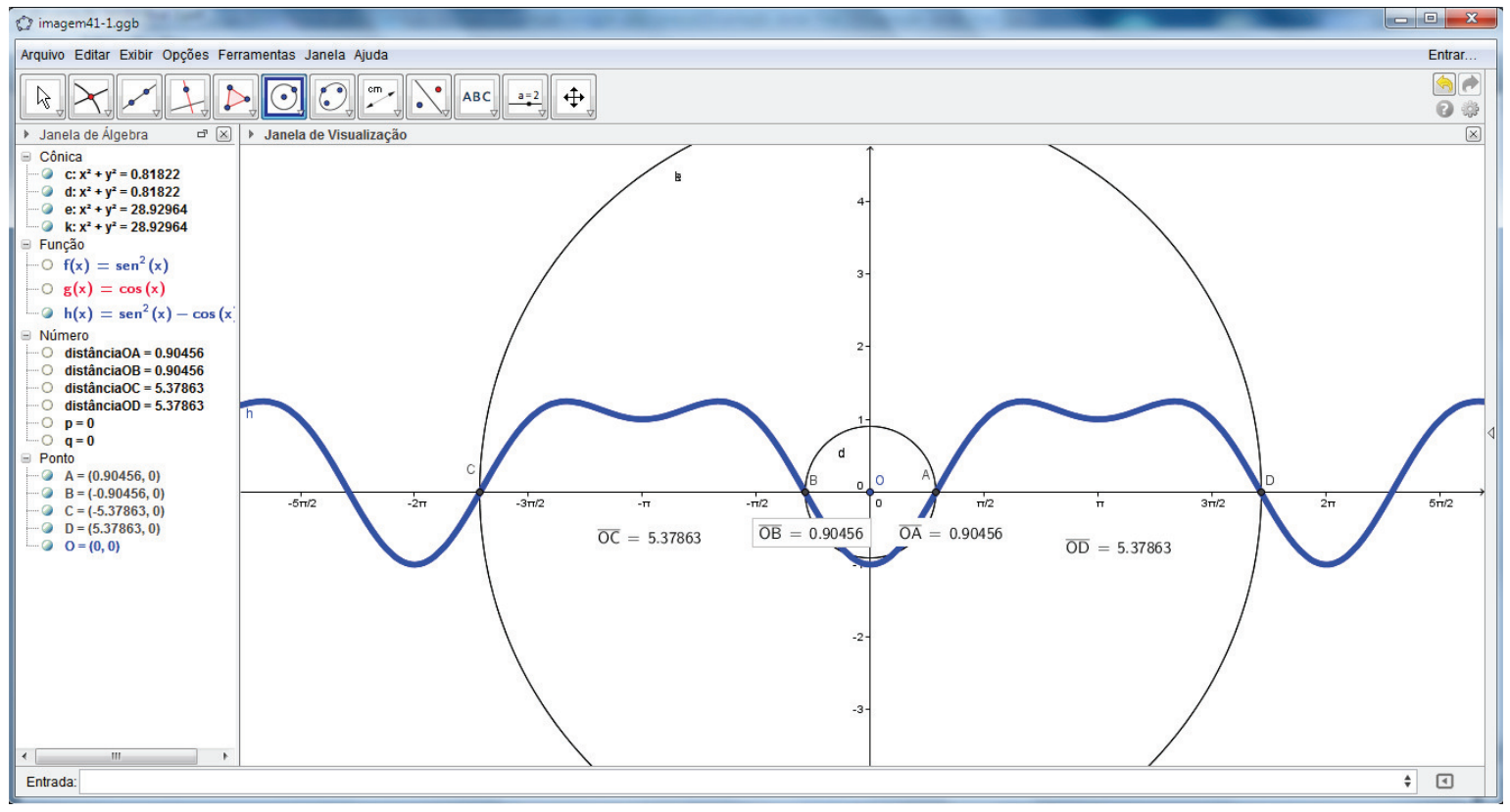

Figura 7.5: Gráfico da função $h(x)=f(x)-g(x)$ resultante da execução dos passos $4-14$

Se a equação $\operatorname{sen}^{2}(x)-\cos (x)=0$ fosse resolvida algebricamente, poderia se perguntar: existem as raízes $q_{1}, q_{2}, q_{3}, \ldots . ., q_{n}$ ? Como a equação $\operatorname{sen}^{2}(x)-\cos (x)=0$ é equivalente a $\operatorname{sen}^{2}(x)=\cos (x)$ e, como o gráfico da equação $\operatorname{sen}^{2}(x)=0$ oscila no intervalo $[0,1]$, o gráfico da equação $\cos (x)=0$ oscila no intervalo $[-1,1]$ e a interseção entre estes dois gráficos não é vazia, a resposta é sim, existem as raízes $q_{1}, q_{2}, q_{3}, \ldots . ., q_{n}$. Esse procedimento é trabalhoso e não favorece a visualização.

Já a resolução gráfica dá mais sentido para raiz de uma equação. Notemos que após a execução do passo 2 , já é possível concluir que as raízes da equação $\operatorname{sen}^{2}(x)-\cos (x)$ existem, pois existem interseções entre os gráficos das funções $f(x)=\operatorname{sen}^{2}(x)$ e $g(x)=$ $\cos (x)$. A Figura 7.4 ilustra a execução dos passos 1-2, e mostra as interseções entre os dois gráficos.

A Figura 7.5 mostra o gráfico da função $h(x)=\operatorname{sen}^{2}(x)-\cos (x)$. Observemos que as circunferências $c$ e $d$ criadas tiveram a mesma equação até a $5^{\text {a }}$ casa decimal. O mesmo aconteceu com as circunferências e e $k$. Notemos também que os pares de segmentos OA e OB tiveram a mesma medida até $5^{\text {a }}$ casa decimal. O mesmo aconteceu com os segmentos OC e OD. Isso sugere que os pontos A e B são simétricos em relação ao ponto O. O mesmo pode ser observado com os pontos $\mathrm{C}$ e D. Tais fatos sugerem que as raízes da equação $\operatorname{sen}^{2}(x)-\cos (x)=0$ tenham duas a duas, mesmo módulo e sinais opostos. Isso mostra que as raízes da equação são simétricas em relação à origem. Porém, essa conclusão fica limitada à quinta casa decimal. Mas, o número $p$ que representa a diferença das medidas dos comprimentos dos segmentos OA e OB é igual a zero. O mesmo acontece com o número q que representa a diferença dos comprimentos dos 
segmentos OC e OD. Vale ressaltar também que as funções $\operatorname{sen}^{2}(x)$ e $\cos (x)$ são funções pares. Como nesta atividade foi analisado apenas o intervalo $[-2 \pi, 2 \pi]$, espera-se que o aluno questione a existência de infinitas raízes para a equação. 


\section{Capítulo 8}

\section{Considerações finais}

Este trabalho buscou apresentar atividades relacionadas ao tema trigonometria, norteadas pela aplicação do software de geometria dinâmica GeoGebra. Acredita-se que a maior contribuição venha do detalhamento das atividades apresentadas que oferecem flexibilidade, para que tanto professores quanto alunos utilizem o GeoGebra como gerador de imagens dinâmicas. As imagens devem enriquecer as aulas auxiliando na compreensão visual de comportamentos gráficos de funções e equações trigonométricas, entre tantos outros assuntos de Matemática. Além disso, os comentários apresentados nas atividades fomentam alunos e professores para uma compreensão mais profunda das próprias atividades, bem como na criação de outras.

Como trabalhos futuros, sugere-se a aplicação do GeoGebra para resoluções gráficas de inequações trigonométricas, estimulando o aluno a observar as regiões nas quais as soluções podem estar contidas. 


\section{Referências Bibliográficas}

ALVES, G. S.; SOARES, A. B. Geometria Dinâmica: um estudo de seus recursos,potencialidades e limitações através do software Tabulae. Disponível em: $<$ http://www.GeoGebra.imuff.mat.br/biblioteca/ WIE George Adriana.pdf>. Acesso em: 15 maio 2014.

BACELAR JÚNIOR, J.S. Uso do geogebra no ensino da trigonometria. 2013.112 f. Dissertação (Mestrado) - Curso de Profmat, Universidade Federal do Ceará, Fortaleza, 2013.

BRANDÃO, P. C. R. "Resolvendo problemas em geometria plana usando o Cabri-Geometre II." (2004).

BRASIL. Lei de Diretrizes e Bases da Educação Nacional. Lei número 9394, 20 de dezembro de 1996.

BRASIL, Comitê Gestor da Internet no (Org.). TIC Educação 2012: Pesquisa sobre o uso das tecnologias de informação e comunicação nas escolas brasileiras. São Paulo: Cgi, 2013.

FREIRE, P. Pedagogia da Autonomia: saberes necessários à prática educativa. São Paulo: Ega, 1996. 92 p.

FORTIS, A.; Bînzar, A.; Laiu, C. GeoGebra: another way of looking at Mathematics, Annals. Computer Science Series, n. 2, 2011.

GIRALDO, V.; Caetano, P.; Mattos, F. Recursos computacionais no ensino de Matematica. Rio de Janeiro: SBM, 2012.

GONÇALVES, A. O. O software Régua e Compasso numa perspectiva construcionista: possibilidades e desafios. IX Congresso Nacional de Educação, EDUCERE, Curitiba. 2009.

IEZZI, G. Fundamentos de matemática elementar, 3: trigonometria 7. ed.São Paulo: Atual, 1993.

IDOETA, P. A. (Ed.). Jovens precisam criar, não só interagir com tecnologia, diz especialista. 2014. Disponível em: <http://www.bbc.co.uk/portuguese/noticias/ 
2014/05/140429 entrevista resnick educacao pai>. Acesso em: 16 ago. 2014.

JACYNTHO, L. A. Uso de Episódios Históricos e de Geometria Dinâmica para Desenvolvimento de Conceitos de Integral de Riemann e do Teorema Fundamental do Cálculo para Funções Reais de Variável Real. 2008. Dissertação (Mestrado Profissional). Instituto de Matemática, Estatística e Computação Científica. Universidade Estadual de Campinas. Campinas, 2008.

KAMPFF, A. J. C.; Cavedini, P. Ambientes informatizados de aprendizagem matemática: $\mathrm{O}$ estudo da geometria no ensino fundamental . In: CONGRESSO IBEROAMERICANO DE INFORMÁTICA EDUCATIVA, 7., 2004, Monterrey, México, 2004. p. 1102 - 1111.

KENSKI, V. M. Educação e Tecnologias: O novo ritmo da informação. 2. ed. Campinas: Papirus, 2007. 62 p.

KENSKI, V. M. Tecnologias e Ensino Presencial e a distância. 6. ed. Campinas: Papirus, 2003. 163 p.

KOCH, B. C.; Ghiggi, I. M. F. Uma prova comtemporânea para um teorema milenar. Revista Técnico Científica do IFSC, v. 1, n. 5, p. 597, 2013.

LIMA, C. E. O. A Utilização do software GeoGebra como ferramenta para o ensino de funções. 2013. 61 f. Dissertação (Mestrado) - Curso de Matemática, Universidade Federal do Ceará, Fortaleza, 2013.

LOPES, M. M. Sequência didática para o ensino de trigonometria usando o software GeoGebra, Bolema, Rio Claro-SP v. 27. n. 46, pp. 631-644, 2013.

LOPES JUNIOR, G. Geometria Dinâmica com o GeoGebra no Ensino de Algumas Funções, 2013. Dissertação (Mestrado Profissional). Universidade Federal de Viçosa. Viçosa-MG, 2013.

MACHADO, S. D. A. Educação matemática: uma introdução. São Paulo: EDUC, 1999.

MISKULIN, R. G. S. Concepções teórico-metodológicas sobre a introdução e a utilização de computadores no processo ensino/aprendizagem da geometria. 1999. 577 f. Tese (Doutorado) - Curso de Pós Graduação em Educação, Universidade Estadual de Campinas, Campinas, 1999, p.33 e 47.

OLIVEIRA, T. Trigonometria: a mudança da prática docente mediante novos conhecimentos. Dissertação de Mestrado em Ensino de Ciência Exatas. São Carlos. UFSCAR, 2010.

PERRENOUD, P. Dez novas competências para ensinar., trad. Patrícia Chittoni Ramos. Porto Alegre: Artmed, 2000. 
REIS, Z. A. Computer supported with GeoGebra. Procedia Social and Behavioral Sciences, v. 9, pp. 1449-1455, 2010.

ROCHA, M. V. ; Miranda, G. M. H. . Uma sequência didática para o estudo da geometria hiperbólica. In: Graphica 2011 - XX Simpósio Nacional de Geometria Descritia e Desenho Técnico e IX International Conference on Graphics Engineering for Arts and Design, Rio de Janeiro, 2011.

SÂO PAUlO, (Estado) Secretaria da Educaçao. Currículo do Estado de São Paulo: Matemática e suas tecnologias / Secretaria da Educação; coordenação geral, Maria Inês Fini; coordenação de área, Nilson José Machado. - $1^{\mathrm{a}}$ ed. atual. São Paulo; SE, 2012.72p.

SILVA, J.C.S. Utilizando o Excel ${ }^{\circledR}$ para mediar a construção de competências e habilidades no ensino de matemática: utilização do Excel ${ }^{\circledR}$ na mediação da construção de competências e habilidades no ensino de matemática. 2012. 1 v. Monografia (Especialização) - Curso de Novas Tecnologias no Ensino da Matemática, Universidade Federal Fluminense, Franca, 2012.

THAMBI, N.; Eu, L. K. Effect of students achievement in fractions using GeoGebra. SAINSAB, v. 16, pp. 97-106, 2013.

VALENTE, J. A. O computador na sociedade do conhecimento. Campinas: UNICAMP- Núcleo de Informática Aplicada à Educação-NIED, 1999.

YOUSSEF, A. N.; Soares, E.; Fernandez, V. P. Matemática: Ensino médio Volume único São Paulo: Scipione, 2008.

ZENGIN, Y.; Furkan, H.; Kutluca, T. The effect of dynamic mathematics software geogebra on student achievement in teaching of trigonometry, Procedia - Social and Behavioral Sciences, WCLTA, 2011

ZENGIN, Y.; Tatar, E. The teaching of polar coordinates with dynamic mathematics software, International Journal of Mathematical Education in Science and Technology, pp. 1-13, 2014. 